$$
\text { UNIVERSIDADE DE SÃO PAULO }
$$

FACULDADE DE FILOSOFIA, LETRAS E CIÊNCIAS HUMANAS DEPARTAMENTO DE LETRAS MODERNAS PROGRAMA DE LÍNGUA E LITERATURA FRANCESA

\title{
CULTURA E REPRESENTAÇÕES NA DIDÁTICA DO FRANCÊS LÍNGUA ESTRANGEIRA
}

Tânia Regina Gomes Soares Hirata 
UNIVERSIDADE DE SÃO PAULO

FACULDADE DE FILOSOFIA, LETRAS E CIÊNCIAS HUMANAS

DEPARTAMENTO DE LETRAS MODERNAS

PROGRAMA DE PÓS-GRADUAÇÃO EM LÍNGUA E LITERATURA FRANCESA

\section{CULTURA E REPRESENTAÇÕES NA DIDÁTICA DO FRANCÊS LÍNGUA ESTRANGEIRA}

Tânia Regina Gomes Soares Hirata

Dissertação apresentada ao Programa de Pós-Graduação em Língua e Literatura Francesa, do Departamento de Letras Modernas da Faculdade de Filosofia, Letras e Ciências Humanas da Universidade de São Paulo, para obtenção do título de Mestre em Letras.

Orientadora: Profa. Dra. Cristina Moerbeck Casadei Pietraróia

São Paulo

2006 


\section{AGRADECIMENTOS}

Toda estrada esconde em si os segredos do caminho, segredos estes que só se revelam àqueles que ousaram percorrê-la. E neste percurso, nunca estamos sós, embora tenhamos a sensação da solidão. A passos largos ou a passos lentos, somos acompanhados constantemente por aqueles que nos amam, eternos e silenciosos companheiros de caminhada. Uma vez iniciado o caminho, buscamos incessantemente o ponto de chegada, e no cansaço, procuramos o aconchego e a compreensão destes discretos companheiros que nos amparam. Ao medir hoje a distância percorrida desde o ponto de partida, percebo que a estrada longa tornouse menos árdua graças ao seu incomensurável apoio, Enzo, você que, na discreção dos gestos, soube entender as dificuldades do percurso. Agradeço com a mesma intensidade a minha mãe Tereza, aos meus irmãos e aos meus amigos a solidariedade, a paciência e os préstimos que me foram concedidos nesta jornada.

Agradeço, igualmente, à Profa Dra Cristina Moerbeck Casadei Pietraróia pela valiosa orientação neste trabalho de pesquisa, ao Professor Dr. Jean-Claude Beacco da Universidade Paris III - Sorbonne Nouvelle pelos conselhos e orientações de leitura, aos membros das bancas de defesa Profa Dra. Maria Eugênia Poulet da Universidade Lumière Lyon 2, à Profa Dra. Neide Gonzáles, e de qualificação Profa Dra Lígia Ferreira. Agradeço, também, aos funcionários da Association Française d'Action Artistique (AFAA) pela gentileza em me permitir pesquisar em seus arquivos os artigos publicados sobre o Ano do Brasil na França (2005). 


\section{RESUMO}

O processo de abertura a outros universos culturais decorrente do estreitamento das relações entre as sociedades fez emergir mais fortemente a necessidade de reflexão sobre as noções de cultura e de representação. Tais noções tornam-se, no campo da Didática das Línguas Estrangeiras, de fundamental importância uma vez que o conhecimento das línguas representa o vínculo de aproximação entre as diferentes comunidades culturais, e favorece a compreensão das diversas formas de ver e de viver o mundo.

O processo de ensino-aprendizagem de uma língua estrangeira deve, deste modo, buscar favorecer a reflexão sobre o diverso com vistas ao despertar do aprendiz a essa diversidade, evitando, sempre que possível, a folclorização das culturas.

Através da análise do corpus extraído da imprensa francesa e cujo objeto do discurso é o Brasil, buscamos demonstrar objetivamente uma das vias de reflexão sobre o diverso, uma vez que nos vemos representados no e pelo discurso dos artigos selecionados. Isto nos parece enriquecedor, pois nos coloca, enquanto brasileiros, frente às representações do Outro sobre a nossa sociedade, e nos faz perceber e refletir sobre a existência de um processo inverso de construção de representações de uma outra cultura, onde nos encontramos como agentes.

O objetivo é favorecer, através da objetivação dos fatos apresentados, a reflexão sobre a diversidade cultural, sobre a importância da relativização e sobre os perigos da generalização.

\section{PALAVRAS-CHAVE / KEY WORDS}

cultura, representações, discurso, construção de representações, ensino de língua estrangeira. 


\section{ABSTRACT}

The opening process to other cultural universes generated through more closeness between societies as created needs for a new thinking approach on culture and representation. These concepts are now put in the field of Foreign Language Didactic at a very important place because the understanding of languages is an essential element in the relationship between various cultural communities and therefore help the understanding of the diverse forms to see and living the world.

The teaching-learning of a foreign language must also stimulate the reflection on the diversity of cultural facts therefore stimulating the awareness of the learning person that excessive folklorisation could damage badly the reality of theses cultures.

Through the analysis of the French Press elements about Brazil, we have been looking for an objective approach on how to demonstrate possible diversities, after having acknowledged the manner we have been seen through the selected articles. That has been very interesting because, as Brazilian, we have been in front of how the Other sees our society and therefore how we should conduct our representation analysis of the Other.

The final aim is to support, through a better objectivity of the given facts, a thinking process on cultural diversity, on the importance of relativism and on the danger of excessive generalisation. 


\section{ÍNDICE}

Introdução

1

1. Cultura : a evolução de seus estudos e conceitos.....................................4

1.1. A evolução do conceito de cultura: de suas origens latinas ao início do século $\mathrm{XX}$

1.2. O nascimento do conceito científico de cultura.................................................17

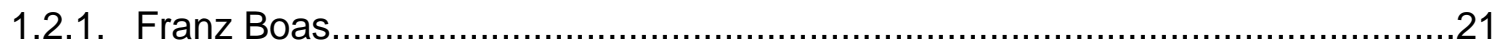

1.3. Breve percurso sobre a concepção de cultura no século XX ............................26

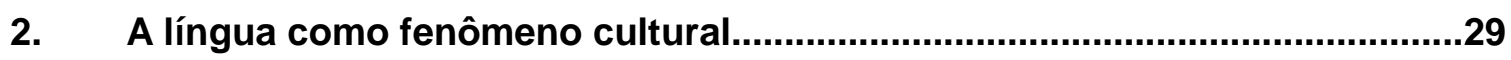

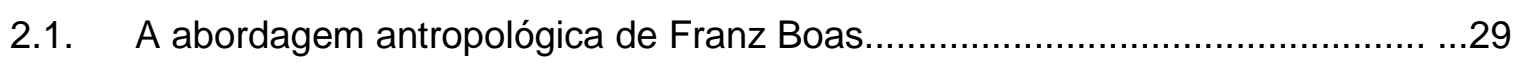

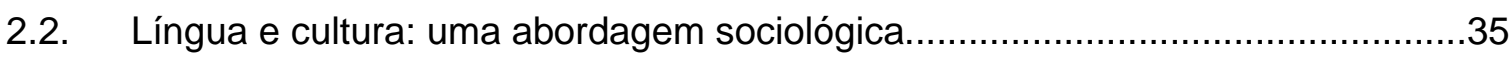

3. A construção das representações do Outro pelo discurso: o Brasil na imprensa

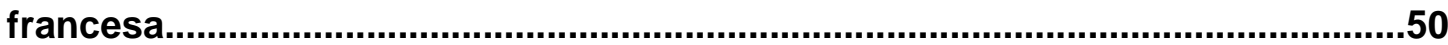

3.1. A noção de representação dentro das Ciências Humanas..................................50

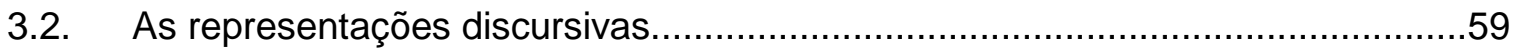

3.3. A construção das representações interculturais pelo discurso: o Brasil na

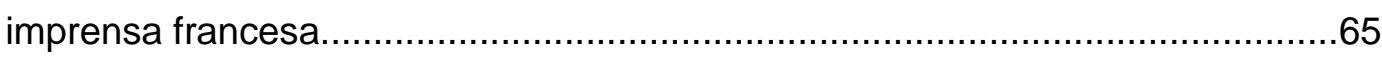

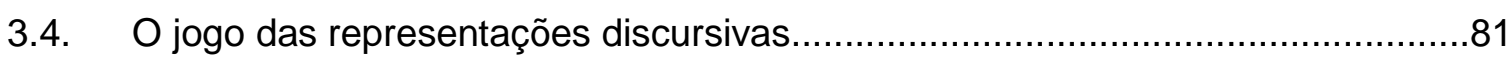

3.4.1. Rio de Janeiro: pólo de concentração das representações do Brasil.

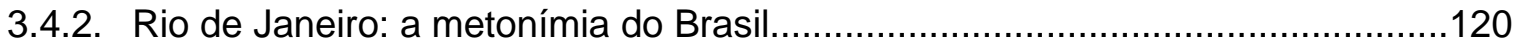

3.4.3. Brasil e França: outras Vibrations................................................................147

4. Língua, cultura e representações na didática do francês língua estrangeira 156

5. Conclusão

6. Bibliografia. 


\section{Introdução}

O crescente estreitamento das relações entre as sociedades ocorrido a partir da segunda metade do século XX solidificou-se ainda mais com o desenvolvimento das comunicações que possibilitou o estabelecimento de contatos entre membros de comunidades culturais distantes e distintas numa velocidade até então não imaginada. Este processo de abertura a outros universos culturais do qual somos testemunhas e, ao mesmo tempo, agentes não se resume unicamente num movimento financeiro e comercial na medida em que ele mobiliza e desloca $o$ material humano em direção a outros horizontes culturais.

As línguas representam deste modo, o vínculo de aproximação entre universos diferentes, entre novas formas de ver e de viver o mundo, um meio que nos coloca em contato com valores e códigos sócio-culturais distintos. Sendo assim, o seu ensino e o seu aprendizado constituem a porta de acesso a um mundo repleto de representações que nos coloca face a esse Outro desconhecido ou pouco conhecido, e através do qual passamos a nos conhecer melhor.

Concomitantemente ao estudo de uma língua estrangeira, este processo dinâmico de construção e reconstrução de nossas representações se vê submetido igualmente ao número de informações e/ou de contatos travados com outras comunidades culturais, seja por via indireta através da mídia; seja por contatos pessoais diretos (relações de parentesco, de amizade, entre outras), levando-se em consideração o tempo e o tipo de relação vivenciados e estabelecidos.

O ensino-aprendizado de uma língua em contexto exolingüe se revela um importante meio condutor e veiculador de representações uma vez que nos vemos confrontados à ideologia da instituição de ensino, às representações individuais de seu corpo docente acerca da cultura apresentada, e também de suas ferramentas de ensino, o livro didático e o material complementar utilizado pelos professores.

Em meu percurso como professora de francês e de português línguas estrangeiras em empresas multinacionais instaladas em São Paulo, fui testemunha de situações conflituosas, por vezes constrangedoras ou até mesmo cômicas vividas pelos aprendizes brasileiros e estrangeiros. Esse contexto empresarial me mostrou que representações culturais estereotipadas são fator relevante no processo de ensino-aprendizagem de uma língua estrangeira e que deveriam ser objeto de reflexão aprofundada para todos aqueles que trabalham com o ensino de línguas, 
visto que elas interferem, em grande parte de forma negativa, na relação entre os membros dessas sociedades.

Ao considerar este contexto empresarial como um dos meios em que o contato direto entre membros de sociedades culturais diversas se estabelece, pude perceber que, em um primeiro momento, ocorre a instalação de um processo de estranhamento decorrente tanto de estruturas sócio-políticas e empresariais que não se assemelham quanto de comportamentos que escapam às referências das quais todos nos servimos em nossas interações com outros indivíduos. Por outro lado, esta convivência e esta interação podem propiciar o desencadeamento de um processo de reflexão onde o Outro nos faz enxergar, pela diferença, como somos, como pensamos, como vivemos e como nos comportamos.

Esta experiência me fez questionar a respeito de como o meio escolar propicia e vivencia estes processos tendo em vista que, no Brasil, ele é composto, geralmente, por aprendizes e docentes brasileiros que, na maioria das vezes, mantêm pouco contato direto com os membros da sociedade que ensinam/estudam. Tudo isto suscitou em mim o interesse pela questão das representações culturais e pelo seu processo de construção, levando-me a buscar e a refletir sobre as possibilidades e maneiras de despertar tanto professores quanto aprendizes à diversidade cultural, visando à redução dos estereótipos para o melhor entendimento entre as culturas.

Dentro de todo este contexto, o questionamento a respeito das noções de cultura e de representação emerge e apresenta-se, ao nosso ver, de extrema importância para que possamos, enquanto educadores, abordar e apresentar uma cultura estrangeira.

A nossa proposta neste trabalho consiste, deste modo, em compreender estas noções e qual o papel da língua e do discurso como construtores ou reconstrutores de representações culturais.

O primeiro capítulo propõe, portanto, um percurso evolutivo das concepções de cultura, de sua origem latina até a sua definição científica, onde buscamos retraçar os principais períodos e as concepções dos principais estudiosos até o início do século $X X$. 
O segundo capítulo busca estabelecer a relação existente entre língua e cultura através dos trabalhos do antropólogo Franz Boas, dos estudos de Mikhaïl Bakhtine e de L. S. Vygotsky.

O terceiro capítulo propõe, num primeiro momento, o estudo da noção de representação dentro da Sociologia e da Análise do Discurso, a fim de abordar, em seguida, a construção das representações culturais pelo discurso através das operações de designação e caracterização do objeto. Para isto, nos apoiamos na noção de esquematização proposta por Jean-Blaise Grize. 


\section{Cultura: a evolução de seus estudos e conceitos}

\subsection{A evolução do conceito de cultura: de suas origens latinas ao início do século $\mathrm{XX}$.}

Nosso questionamento a respeito do contexto de surgimento do conceito científico de cultura nos levou a buscar o que se tinha dito sobre cultura desde a sua concepção latina onde designava simplesmente o cultivo da terra até chegar a embarcar os valores culturais de um povo, suas tradições, sua língua, seus costumes, suas crenças, e muito mais. Procuramos nos centrar, sobretudo, na questão da língua como um dos aspectos da cultura: a partir de quando ela foi inserida na concepção de cultura, quem teria sido o responsável por essa inclusão, e por quais razões?

Partimos então do primeiro verbete de alguns dicionários que, dentre outros sentidos atribuídos posteriormente, definiam "cultura" como o ato, efeito ou modo de cultivar a terra (Novo Dicionário Aurélio da Língua Portuguesa ${ }^{1}$ ), action de cultiver la terre; ensemble des opérations propres à tirer du sol les végétaux utiles à l'homme et aux animaux domestiques (Le Petit Robert ${ }^{2}$ ), ou action de cultiver (une terre, une plante) (Le Petit Larousse en Couleurs ${ }^{3}$ ).

Originária do latim cultura, essa expressão designava, na Antiguidade, o cultivo dos alimentos através do trabalho de fertilização da terra a fim de lhe oferecer as condições necessárias para o nascimento e desenvolvimento das plantas.

Enquanto ato de ou ação de, percebemos que a cultura se define, nas acepções acima relacionadas, pela ação do homem sobre a terra. Sendo assim, ele age sobre ela a fim de obter $\mathrm{o}$ seu sustento. $\mathrm{O}$ ato de cultivar exige, portanto, uma dinâmica e um comportamento ativo daquele que o pratica, e nos leva a inferir que tais ações não serão idênticas em todas as sociedades, visto que o tipo de solo, a variação climática, os meios e utensílios necessários a essa ação se desenvolverão de acordo com um quadro contextual peculiar. Isto não significa dizer que não existirão semelhanças entre as formas de se cultivar a terra de uma sociedade a

\footnotetext{
${ }_{1}^{1}$ Novo Dicionário Aurélio da Língua Portuguesa, 1986, $2^{a}$. ed., Editora Nova Fronteira

${ }^{2}$ Le Nouveau Petit Robert. Paris : Dictionnaires Le Robert, 1993.

${ }^{3}$ Le Petit Larousse en Couleurs. Paris : Larousse, 1991.
} 
outra, significa aventar que diferenças existirão de acordo com cada contexto geográfico.

Sendo assim, sugerimos que mesmo nessas acepções primeiras do termo cultura, existe um embrião, um germe de algo que é dinâmico e não homogêneo, pois dependente de cada contexto. Como declara Cuche (2001):

"Si toutes les «populations » humaines possèdent le même stock génétique, elles se différencient par leurs choix culturels, chacune inventant des solutions originales aux problèmes qui se posent à elle.» (Cuche, 2001:3)

Já na Idade Média, no momento em que o homem começa a voltar os olhos para si mesmo e para a sua condição efêmera, poderíamos supor que o contexto sócio-político e cultural tenha influenciado a evolução de uma concepção puramente agrícola, de cultivo da terra, a uma concepção do cultivo do espírito através do conhecimento. Segundo Cuche (2001:8), o termo cultura na língua francesa começa a se tornar polissêmico já no século XIII, ao designar não somente o ato ou efeito de cultivar a terra, mas também a parcela de terra cultivada. Em meados do século XVI, a acepção de cultura como uma faculdade aparece, mas não encontra reconhecimento acadêmico até o século das Luzes ou lluminismo, que tentará explicar tudo através da razão.

A partir do século XVIII na França, a cultura começou a ser concebida e propagada como o ato de cultivar o espírito através do conhecimento, exigindo, a partir de então, um complemento de especificação - a cultura das artes, a cultura das ciências, a cultura das letras - a fim de se precisar o objeto cultivado.

O lluminismo representa um marco de desenvolvimento tanto para as ciências naturais quanto para as posteriores ciências humanas, um período de efervescência cultural, científica e filosófica que influenciou o mundo ocidental da época, pois tinha como princípio a confiança no progresso da razão e da ciência a fim de dissipar as sombras da ignorância e da superstição, pregando a liberdade de pensamento e o 
desejo de reformas ${ }^{4}$, opondo-se totalmente à hegemonia dos princípios religiosos da Igreja Católica que regiam toda a sociedade até então.

No que se refere à concepção de cultura, tal movimento encontrou grande repercussão, mas também objeções e resistências, sobretudo devido ao seu caráter universalista. Os filósofos iluministas concebiam a cultura universal e não as culturas particulares, de forma a englobar o progresso ou a evolução total da humanidade como sendo decorrentes de um mesmo processo civilizacional respeitando a regras ou leis universais. Segundo tais princípios, toda a evolução cultural era regida por um mesmo conjunto de leis uniformes aplicado a toda a humanidade, como podemos verificar na concepção iluminista de cultura descrita por Cuche (2001):

"...] les penseurs des Lumières conçoivent la culture
comme un caractère distinctif de l'espèce humaine. La culture, pour eux, est la somme des savoirs accumulés et transmis par l'humanité, considérée comme totalité, au cours de son histoire[...] toujours employée au singulier, ce qui reflète l'universalisme et l'humanisme des philosophes: la culture est le propre de l'Homme (avec majuscule), au-delà de toute distinction de peuples ou de classes. "Culture " s'inscrit donc pleinement dans l'idéologie des Lumières: le mot est associé aux idées de progrès, d'évolution, d'éducation, de raison qui sont au cœur de la pensée l'époque. » (Cuche, 2001:9)

Dentro desta premissa, não havia, portanto, espaço para as diferenças, e o desenvolvimento cultural se caracterizava por um movimento ascendente que homogeneizava e aniquilava as particularidades e riquezas que a pluralidade das culturas poderia fornecer em termos de conhecimento e de compreensão dos seres humanos e das diversas sociedades existentes.

De acordo com Geertz (1978), a perspectiva iluminista do homem era a de que ele constituía uma só peça com a natureza e partilhava da uniformidade geral de composição que a ciência natural havia descoberto. Assim, as diferenças

\footnotetext{
${ }^{4}$ Dictionnaire des Noms Propres. Paris : Éditions Le Petit Robert. (tradução nossa), 1994:331.
} 
existentes, como podemos verificar na seguinte explanação crítica de Geertz, consistiam em meros acréscimos que em nada mudavam o constante, o universal, o geral no homem:

"A enorme e a ampla variedade de diferenças entre os homens, em crenças e valores, em costumes e instituições, como de tempo quanto de lugar para lugar, é essencialmente sem significado ao definir a sua natureza. Consiste em meros acréscimos, até mesmo distorções, sobrepondo e obscurecendo o que é verdadeiramente humano: o constante, 0 geral, o universal no homem”. (Geertz,1978:46)

A racionalidade instaurada exigia um "modelo de homem" que desse conta de toda a sua complexidade. Na verdade, o que houve foi uma tentativa de simplificação da complexidade humana, de imobilização do dinâmico, de explicação científica do que não é tão facilmente cientificamente explicável. Para Geertz (1978), as abordagens iluminista e antropológica clássica possuíam em comum a tentativa de definição da natureza humana a partir de um tipo humano universal:

"Elas tentam construir uma imagem do homem como um modelo, um arquétipo, uma idéia platônica ou uma forma aristotélica, em relação à qual os homens reais - você, eu, Churchill, Hitler [...]não são mais que reflexos, distorções, aproximações. No caso do iluminismo os elementos desse tipo essencial deviam ser descobertos desvendando as exterioridades da cultura dos homens verdadeiros para ver o que sobrava - o homem natural. Na antropologia clássica, seriam descobertos pela decomposição das banalidades da cultura, verificando então o que aparecia - o homem consensual. Em qualquer dos casos o resultado é o mesmo que tende a emergir em todas as 
abordagens tipológicas de problemas científicos: as diferenças entre os indivíduos e entre os grupos de indivíduos tornam-se secundárias. A individualidade passa a ser vista como excentricidade, a diferença como desvio acidental do único objeto de estudo legítimo para o verdadeiro cientista, o tipo normativo subjacente, imutável. Em tal abordagem [...] os detalhes vivos são submersos em estereótipos mortos [...]".(Geertz, 1978:63)

Um dos mais fervorosos combatentes das idéias iluministas sobre as leis universais e a onipotência dos métodos científicos foi o escritor e filósofo alemão Johann Gottfried Herder (1744-1803). Enquanto os filósofos iluministas acreditavam que a realidade era ordenada por leis universais, eternas, objetivas e inalteráveis, que poderiam ser descobertas através da pesquisa racional, Herder acreditava que qualquer atividade, situação, período histórico ou civilização estava dotado de um caráter exclusivamente próprio, de forma que a tentativa de reduzir estes fenômenos a combinações de elementos uniformes e descrevê-los e analisá-los em termos de regras universais tendia a obliterar as diferenças cruciais que constituíam a qualidade específica da matéria em estudo, tanto no âmbito da natureza quanto no da história ${ }^{5}$. E é dentro deste contexto de idéias e ideologias divergentes que nascerá a diferença entre as concepções alemã de Kultur e Zivilisation, e a francesa de Culture e Civilisation.

Na Alemanha do século XVIII, encontramos uma classe burguesa intelectual que se opõe enormemente aos valores da Corte alemã, valores esses tomados por empréstimo da Corte francesa. Acusada de superficialidade, a Corte dos príncipes alemães dedicava-se, sobretudo, ao cultivo, pela imitação, do cerimonial da corte francesa que disseminava o gosto pelo refinamento representado por um rei galante e uma corte magnífica (De Carlo:1998) . A esse apreço pela superficialidade, os intelectuais alemães opunham valores espirituais mais profundos, fundamentados na ciência, na arte, na filosofia e na religião, e designados por eles como Kultur, como podemos verificar na seguinte definição de De Carlo (1998):

\footnotetext{
${ }^{5}$ BERLIN, I. Vico e Herder. Brasília: 1976, Editora Universidade de Brasília, p. 133.
} 
“ Le terme Kultur, élaboré par la classe moyenne [alemã], contient une vision du monde qui s'oppose à l'idéal courtois (de la Cour): cet idéal d'homme raffiné et cultivé, qui a pour modèle un roi galant et une cour magnifique, est rejeté comme faux et hypocrite par les intellectuels bourgeois. Ceux-ci exaltent en revanche les qualités du cœur et n'acceptent pas comme naturelle la distinction entre les hommes." (De Carlo, 1998:14)

A fim de marcar claramente uma ruptura não somente de idéias, mas também de ideologias, a burguesia intelectual alemã adota, portanto, o termo Zivilisation para expressar os valores superficiais da aristocracia que havia relegado, ao segundo plano, as artes e a literatura. A Kultur opõe-se, portanto, à Zivilisation, como a profundidade se opõe à superficialidade, como bem descreve Cuche (2001):

"Pour l'intelligentsia bourgeoise allemande, la noblesse de cour, si elle est civilisée, manque singulièrement de culture. Comme le petit peuple en est également dépourvu, cette intelligentsia se considère en quelque sorte investie d'une mission, celle de développer et de faire rayonner la culture allemande." (Cuche, 2001:11):

Neste contexto de ideologias opostas, a classe burguesa avança e denuncia, como forma de alienação, os estreitos laços entre as cortes alemã e francesa. Rejeita igualmente o uso do francês falado pela elite aristocrática e intenciona restabelecer ao alemão o seu lugar como língua nacional. É neste afã de resgatar a dignidade e a identidade nacional que a antítese Kulture Zivilisation se acentua.

Uma das maneiras, portanto, encontradas pela burguesia intelectual alemã, separada até então do poder político dos príncipes, é a de formar, num país que contava trezentos principados, uma unidade que lhe desse força e identidade. Essa necessidade e esse desejo de se formar uma nação alemã se intensifica quando da 
derrota das tropas alemãs para o exército de Napoleão, na batalha de léna, em 1806. Segundo Cuche (2001), a Alemanha desmoralizada necessitava resgatar seus brios e sua dignidade. Ressaltar os valores do espírito seria, portanto, a maneira de forjar uma personalidade, um caráter, que mais tarde se estenderia a toda a nação alemã. A concepção de Kultur liga-se cada vez mais fortemente à idéia de unidade e identidade nacional constituindo, desta forma, o conjunto da produção artística, intelectual e moral de um povo, expressão maior de uma cultura. Como declaram Ladmiral e Lipianski (1989:113), a burguesia culta alemã encontrará uma justificativa de sua razão de ser justamente no valor de suas realizações intelectuais, adotando gostos e modelos opostos aos da aristocracia.

Esta concepção da cultura como relevando da alma de um povo, do cultivo de valores mais profundos representados nas artes, na literatura e no enriquecimento do espírito através do conhecimento, fez e ainda faz parte da idéia expressa por esse termo, como podemos verificar nas seguintes definições de alguns dicionários:

\section{Culture:}

Développement de certaines facultés de l'esprit par des exercices intellectuels appropriés [...]; ensemble des connaissances acquises qui permettent de développer le sens critique, le goût, le jugement [...]; ensemble des aspects intellectuels d'une civilisation » (Le Nouveau Petit Robert, 1993:525, Dictionnaires Le Robert)

\section{Cultura :}

"Atividade e desenvolvimento intelectuais; saber, ilustração, instrução". (Novo Dicionário da Língua Portuguesa Aurélio, 1986:508, Editora Nova Fronteira)

E é nisso, igualmente, que se centra boa parte da obra de Herder, tido como o precursor do relativismo. Para ele, as sociedades, por serem particulares, só poderiam ser compreendidas e apreendidas de acordo com o seu próprio sistema de 
valores e suas próprias normas de pensamento e ação. Em sua luta contra os princípios universalistas do lluminismo, Herder estabelece uma vertente pluralista que acredita tanto na multiplicidade quanto na incomensurabilidade dos valores das diferentes culturas e sociedades. Para ele, não existem verdades nem valores absolutos imutáveis aplicáveis a toda a espécie humana. Ao contrário, prefere a variedade à uniformidade, e como declara Berlin (1976), a variedade para Herder não implicava conflito.

Somando-se a essa vertente pluralista das idéias "herdianas", temos uma vertente populista que acredita na importância, para os membros de uma sociedade, em se identificar ao grupo ao qual pertencem com vistas a um desenvolvimento pessoal pleno. Sua defesa da língua alemã contra a hegemonia do latim e do francês caracterizava justamente o papel da língua como um dos elementos de identificação entre os membros de uma mesma sociedade, juntamente com as artes e a literatura.

No que diz respeito à França, a sociedade francesa iluminista, por sua vez, ainda não apresentava fissuras em sua estrutura social tal qual verificamos entre a burguesia intelectual e a aristocracia alemã. Sendo assim, o termo Civilisation que inicialmente designava o requinte dos modos e dos costumes da corte francesa, ganha, dentro dos princípios iluministas, o sentido daquilo que é capaz de dissipar as sombras da ignorância e da superstição, através da razão e do conhecimento. Com o intuito de transpor este conceito do plano filosófico ao plano político e, sobretudo, de enveredar toda a nação no caminho da razão e não mais da religião, o termo Civilisation passa a ser definido, portanto, pelos pensadores iluministas, como um processo de desenvolvimento progressivo e contínuo que passa obrigatoriamente por uma mudança e melhoria das instituições, da legislação e da educação. Enquanto processo de desenvolvimento progressivo e contínuo, exige, das sociedades tidas como mais evoluídas dentro deste processo, um posicionamento de intervenção sobre aquelas tidas como menos evoluídas ou primitivas a fim de que estas possam atingir um grau mais alto de civilidade segundo os parâmetros das sociedades que se julgam já "civilizadas".

Desta concepção, podemos extrair a idéia da hierarquização cultural, de um pensamento colonialista que desconsidera e menospreza todos os fatos culturais de outros povos, pois não correspondem e não se encaixam dentro dos valores e do grau de civilização do colonizador. Este preceito de caráter supostamente altruísta - 
de guiar os povos menos evoluídos no caminho do progresso e do desenvolvimento - pode ser constatado ao longo dos tempos na história da humanidade.

Segundo Ladmiral et Lipianski (1989), a concepção universalista apregoada pela França teria uma dupla origem, histórica e sociológica. A primeira seria proveniente da perpetuação da tradição aristocrática oriunda do modelo de vida da Corte Francesa, baseado no refinamento dos modos, dos costumes, das boas maneiras, da arte da conversação e das regras de politesse, da linguagem elaborada, da manifestação mais completa de uma sociedade que segue normas gerais que acredita que devam ser aplicadas a todas as sociedades, pois se constituem num ideal do homem civilizado. A segunda origem dessa concepção universalista decorreria da assimilação da ideologia aristocrática pela classe burguesa francesa que encontrou, nesses ideais, uma maneira de esconder suas origens sociais não nobres :

"L’idéologie de la bourgeoisie qui a trouvé dans la notion de civilisation l'une de ses expressions, s'efforce de masquer son origine de classe; elle présente cet idéal non comme celui d'un groupe particulier, mais comme celui de la raison et l'identifie par là-même à un idéal d'humanité; la civilisation n'est pas la culture et le mode de vie de la classe dominante; c'est la manifestation la plus parfaite d'une nature humaine par essence universelle". (Ladmiral e Lipianski,1989:112)

O modelo de civilização francesa passa a ser identificado como o modelo de civilização universal, visto que a França imputa a si mesma o papel de civilizadora, como podemos constatar na seguinte afirmação de De Carlo (1998):

"La conviction que la civilisation française est en mesure de représenter un optimum à atteindre de la part de tous les hommes remonte aux dernières décennies du XVIIle. siècle [...] Les encyclopédistes, les philosophes et les penseurs du siècle des 
Lumières se croyaient chargés de répandre parmi tous les peuples (De Carlo, $1998: 18$ ) "les vérités utiles à leur bonheur, de les éclairer sur leurs intérêts comme sur leurs droits». (Condorcet apud De Carlo, $1998: 18)$

De acordo com essa tarefa "altruísta" junto aos menos evoluídos, constatamos a convicção da "vocação" civilizadora de alguns povos nos séculos XVIII e XIX, como nos relata Cuche (2001) ao descrever a concepção de civilização dessa época:
"[...] la civilisation peut et doit s'étendre à tous les peuples composant l'humanité. Si certains peuples sont plus avancés que d'autres dans ce mouvement, si certains (la France particulièrement) sont même si avancés qu'on peut les considérer d'ores et déjà comme "civilisés ", tous les peuples, même les plus "sauvages", ont vocation à entrer dans le même mouvement de civilisation, les plus avancés ayant le devoir d'aider les plus attardés à combler leur retard. » (Cuche, 2001:10)

A concepção francesa de civilização traduz-se, portanto, em um ideal do homem civilizado, que pode e deve ser atingido por toda a humanidade. A civilização é entendida como o meio pelo qual a humanidade atingirá um grau máximo de civilidade através da amenização dos modos rudes, ligados à barbárie, de um controle da natureza bruta e da humanização dos indivíduos (Ladmiral e Lipianski, $1989: 105)$.

Em contrapartida, ao voltar os olhos para aqueles que sofreram a influência civilizadora de outros povos, constatamos igualmente quase que $o$ aniquilamento de seus elementos culturais em detrimento da assimilação dos novos valores impostos, tal qual a catequização dos índios brasileiros obrigados a aceitar a existência de um único Deus. 
Essa concepção hierárquica das culturas é ressentida por Herder, em seu ensaio Uma Outra Filosofia da História, publicado em 1774, como algo muito mais destrutivo do ponto de vista cultural do que construtivo:

"Os povos estrangeiros eram julgados (por Roma) em termos de costumes para eles desconhecidos; impostos pela violência, eles distorciam o caráter dos conquistados, até que a águia romana... tirava seus olhos, devorava suas entranhas e cobria seus corpos miseráveis com suas asas enfraquecidas. $O$ dia em que a sangrenta tirania de Roma se uniu à cristandade não foi um dia feliz... Roma arruinou a Grécia e os reis teutônicos, enquanto os poloneses recentemente convertidos exterminavam os prussianos e escravizavam os pobres bálticos e os pacíficos eslavos [...] Pode alguém mencionar uma nação onde os europeus tenham entrado sem desonrar-se a si mesmos ante uma humanidade indefesa e confiante, mediante a palavra injusta, o fraude ganancioso, a opressão esmagadora e as doenças que levaram consigo? Nossa parte da terra não deveria ser chamada a mais sábia, senão a mais arrogante, agressiva e cobiçosa; o que ela tem dado a esses povos não é civilização, mas a destruição dos rudimentos de suas próprias culturas, sempre que teve ocasião de destruí-las". (Herder apud Berlin, 1976:145)

A fim de ressaltar este ponto de vista em relação ao que se concebia como civilização, Berlin (1976) relata uma conversa entre um asiático (um hindu) e um europeu, imaginada por Herder em seu periódico Adrastea, datado de 1802:

“_ Diga-me, vocês ainda não perderam o hábito de procurar converter a sua fé as pessoas que vocês 
roubam, saqueiam, escravizam, assassinam e privam de suas terras e propriedades, e aos quais vossos costumes parecem revoltantes? Supondo que uma dessas pessoas fosse a vossa terra e, insolentemente, proclamasse ser absurdo tudo quanto vocês acham mais sagrado - suas leis, sua religião, seu saber, suas instituições, e assim por diante - o que vocês fariam com ela?

- Oh, mas isso é um assunto completamente diferente, replicou o europeu, nós temos força, navios, canhões, cultura." (Herder apud Berlin, 1976:146)

Mais adiante, ele continua com um outro exemplo:

"Porque você está derramando água sobre a minha cabeça? _ perguntou um escravo moribundo a um missionário cristão.

_ Para que você possa ir ao Paraíso.

_ Eu não quero ir a um paraíso onde há homens brancos, respondeu o escravo e, virando-se de lado, morreu." (Herder apud Berlin, 1976:146)

Essas conversas imaginadas por Herder para expressar o seu desacordo com a concepção de civilização vigente em sua época nos mostram a que ponto ele acreditava no pluralismo cultural e na necessidade em se relativizar os valores culturais de cada povo. É através do ponto de vista do Outro - do colonizado - que ele nos faz enxergar as atrocidades cometidas em prol de uma ideologia falsamente altruísta.

Esses questionamentos nos levam a entender que, para se poder compreender os comportamentos, as crenças, as leis e outros fatos culturais referentes a um determinado povo e época, é indispensável que nos remetamos ao seu contexto histórico. Essa perspectiva histórica das culturas será um dos novos 
elementos acrescidos à maneira de se conceber a cultura no final do século XIX e início do século XX.

\subsection{O nascimento do conceito científico de cultura}

Até meados do século XIX, os estudos sociológicos e antropológicos não faziam parte de uma ciência específica, pois a Sociologia e a Antropologia só adquiriram estatuto científico no final do mesmo século, e se desenvolveram a partir do início do século XX. Tais estudos baseavam-se nas reflexões de filósofos e nas pesquisas realizadas na área da biologia acerca do desenvolvimento do homem e da sociedade em geral.

A necessidade de se entender melhor as relações humanas, suas semelhanças e diferenças se fez cada vez mais forte a partir do momento em que começaram a ser questionados os postulados dessas reflexões e pesquisas. Deste modo, a dificuldade em se encontrar uma unidade na grande diversidade das culturas humanas favorece o aparecimento, no final do século XIX e início do século $X X$, de duas vertentes de pesquisa. A primeira privilegiará a unidade sobre a diversidade, minimizando as diferenças, e baseando-se no pensamento evolucionista. Tal pensamento estabelecia uma homonimia entre raça e cultura, onde as duas noções se misturavam, e propunha o estudo da evolução dos povos através de uma concepção estratigráfica do homem, do ponto de vista biológico, psicológico, sociológico e antropológico. Essa concepção evolucionista se propagou entre as massas e acrescentou, ao mais recente conceito de nacionalidade da época, um novo significado: o de identificação entre nacionalidade e unidade racial. Tal premissa assumia que as características nacionais estavam estreitamente relacionadas à descendência racial.

Neste turbilhão de novas idéias, encontramos o germe do movimento antisemita alemão, iniciado em 1880. Este programa baseava-se inteiramente na diferença racial e supunha que cada indivíduo possuía uma personalidade definitiva, inalterável, de acordo com a sua raça e descendência, determinando desta forma o seu status político e social. Constatamos, desta vez, uma hierarquização não somente cultural, mas racial, caracterizada pelo determinismo biológico.

Geertz (1978:50) define a concepção do homem neste período como a de um ser hierarquicamente estratificado, uma espécie de depósito evolutivo em cuja 
definição cada nível, orgânico, psicológico, social e cultural, tinha um lugar designado e incontestável. Segundo ele, esta estratificação permitia que as várias ciências implicadas nos estudos do homem existissem independentemente umas das outras.

Tendo, portanto, como ponto de partida a insatisfação de uma classe intelectual que necessitava de explicações mais aprofundadas e coerentes do que as oferecidas pelas teorias raciais, do determinismo biológico e geográfico em voga na época, um conceito vai emergir, segundo as palavras de Cuche (2001:15), como uma ferramenta de grande valia para se pensar a questão das diferenças e para explorar mais cuidadosamente a diversidade humana: o conceito de cultura. É somente nesse momento que a "cultura", em sua totalidade, adquire status científico e passa a ser estudada como um elemento inerente ao homem.

Segundo Geertz (1978), as razões que levaram ao surgimento do conceito científico de cultura devem-se, sobretudo, ao momento em que os estudiosos evocaram a possibilidade da não existência de comportamentos constantes no decorrer do tempo, mas da existência de uma relação entre o homem e o seu meio, o homem consigo próprio, e o homem e suas crenças:

"A imagem de uma natureza humana constante, independente de tempo, lugar e circunstância, de estudos e profissões, modas passageiras e opiniões temporárias, pode ser uma ilusão, que o que o homem é pode estar envolvido com onde ele está, quem ele é e no que ele acredita, que é inseparável deles. É precisamente o levar em conta tal possibilidade que deu margem ao surgimento do conceito de cultura e ao declínio da perspectiva uniforme do homem". (Geertz,1978:46)

Os debates acerca do que vem a ser "cultura" se aprofundam e cada uma das novas disciplinas científicas, tais como a Etnologia e a Antropologia - por vezes ainda impregnadas de uma tradição universalista herdada do lluminismo ou então pelas premissas das pesquisas biológicas sobre raça - buscarão uma definição do termo a fim de se poder estudar a diversidade humana. 
A concepção estratigráfica do homem virá ao encontro da concepção enumerativa da cultura estabelecida por Edward Burnett Tylor ${ }^{6}$ (1832-1917), em 1871:

"Culture ou civilisation, pris dans son sens ethnologique le plus étendu, est ce tout complexe comprenant à la fois les sciences, les croyances, les arts, la morale, les lois, les coutumes et les autres facultés et habitudes acquises par l'homme dans l'état social". (Tylor, 1920:1)

De acordo com Cuche (2001:16), Tylor foi o primeiro etnólogo e um dos fundadores da Antropologia Inglesa a tentar uma definição científica do termo cultura, de acordo com a etnologia. Embora de cunho universalista, Tylor enriqueceu essa concepção ao considerar a cultura como um elemento que se adquire e, portanto, não inata e não dependente de uma suposta hereditariedade biológica. Considerando a cultura ou civilização como esse todo complexo que compreende tanto as ciências e crenças quanto às artes, a moral, as leis, os costumes e as outras faculdades e hábitos adquiridos pelo homem enquanto membro de uma sociedade, ele abrange a coletividade representada em todas as suas formas de expressão social.

Aliada a sua concepção universalista, Tylor concebia igualmente a cultura como sendo evolutiva, considerando estágios que iam do primitivo ao civilizado onde a civilização era concebida da seguinte maneira:

"Considérée d'un point de vue idéal, la civilisation peut être regardée comme étant le perfectionnement général de l'humanité due à une organisation meilleure de l'individu et de la société et ayant pour fin d'augmenter la bonté, le pouvoir et le bonheur de l'homme [...] La transition de l'état sauvage au nôtre (civilisé) serait donc en réalité ce progrès des arts et

\footnotetext{
${ }^{6}$ TYLOR, E.B. La Civilisation Primitive. Paris:Ancienne Librairie Schleider, Alfred Costes (Editeur), 1920, p.01. Traduction de l'anglais sur la deuxième édition par Mme Pauline Brunet.
} 
des sciences qui est un des éléments ordinaires $d u$

développement de la culture». (Tylor, 1871:30-31)

Como pudemos verificar na sua definição, ele se serve dos termos cultura e civilização quase que indistintamente. Cuche (2001:16) nos esclarece que, inicialmente, Tylor hesitou entre os dois termos, mas que, posteriormente, optou unicamente pelo termo cultura pela sua neutralidade, visto que o termo civilização remetia, por um lado, à formação das cidades, e por outro lado, designava, dentro das ciências históricas, principalmente as realizações materiais que, quando aplicadas às sociedades primitivas às quais consagrou seus estudos, se viam desprovidas de tais progressos.

Mas a definição de cultura oferecida por Tylor passa a ser questionada posteriormente por um outro antropólogo de renome, o alemão Franz Boas (18581942), tido como o fundador da Antropologia Cultural Americana e a quem devemos a inclusão da língua como um dos elementos constitutivos das culturas. Boas concebe, além da pluralidade das culturas, a necessidade de relativização ao estudá-las. Ele rompe, portanto, com a questão do determinismo racial, biológico e geográfico, e, sobretudo, com o princípio de primitivismo cultural. Ao relativizar as culturas, Boas as particulariza sendo esse um dos pontos cruciais de divergência com Tylor, de tradição universalista ${ }^{7}$.

Essa segunda vertente de pesquisa existente no século XIX e identificada nos trabalhos de Boas acentuará a importância em se estudar as diferenças culturais que em nada prejudicam a unidade humana. Pela grande importância que teve, reservaremos o próximo tópico a Franz Boas.

\subsubsection{Franz Boas}

Nascido na Westphalia, Alemanha, em 1858, Boas era filho de judeus e conheceu desde cedo as conseqüências do anti-semitismo que, anos mais tarde, se apresentou como uma das causas da Segunda Guerra Mundial. Em decorrência disso, trabalhou fervorosamente, durante seus estudos universitários, pelas causas

\footnotetext{
${ }^{7}$ As divergências epistemológicas entre Edward Tylor e Boas serão expostas com maior profundidade no nosso próximo capítulo, onde buscamos oferecer um panorama histórico e cronológico da evolução do conceito de cultura. Gostaríamos de salientar igualmente que a maioria dos desdobramentos sobre a questão da definição de cultura baseia-se nas obras desses dois antropólogos.
} 
civis e políticas, o que o levou igualmente a estudar a Filosofia e a Geografia, embora tenha se doutorado em Física, fato que demonstra a sua preocupação em estabelecer um diálogo entre as ciências.

A ruptura com os ideais de uma Alemanha que não mais reconhecia se concretizou através de sua viagem à Terra de Baffin, no Canadá, onde passaria um ano de sua vida em companhia dos esquimós. Anteriormente a Boas, os dados para a pesquisa etnográfica vinham através de viajantes e de funcionários de governo que serviam de intermediários entre a sociedade estudada e o pesquisador. Os questionamentos de Boas acerca da validade de tais informações obtidas o levam a concluir que aquele que deseja realmente conhecer e estudar a cultura de dada sociedade deve, em primeiro lugar, saber falar a língua desse povo para que ele possa sozinho aceder aos significados inerentes a essa cultura. Boas introduz, deste modo, a prática do trabalho de campo ou fieldwork na Antropologia.

As observações feitas no período em que conviveu com os esquimós o levam a crer que o homem, ou os homens, diferem-se culturalmente pelos seus costumes, sua língua, seus hábitos, mas que mantêm entre si a mesma essência que é a da espécie humana.

A introdução de uma idéia que relativiza o que vem a ser um indivíduo "culturado" nos faz entrever a semente da concepção boasiana de cultura e, por conseguinte, da Antropologia Cultural: a não existência de culturas superiores e inferiores, a relativização cultural, o reconhecimento do Outro e a redescoberta de si através do Outro, ambos abertos cultural e afetivamente a este processo.

Suas idéias sobre os povos e suas diferenças, baseadas na não hierarquização cultural, foram sendo tecidas e construídas ao longo do tempo, resultando num legado científico e histórico que serviria de base a muitas outras pesquisas realizadas posteriormente.

Em 1886, Boas parte para os Estados Unidos, país onde passaria todo o resto de sua vida e onde desenvolveria suas idéias e sua obra. Unido à América por laços familiares (Boas tinha um tio que aí residia) e pelo ideal de democracia, ministra aulas inicialmente na Clark University e depois na Universidade de Columbia, mantendo contato com Tylor do qual diverge acerca dos pressupostos evolucionistas. 
Em seu trabalho etnográfico sobre a sociedade Kwakiutl, no Canadá, Boas inicia igualmente um estudo das variedades lingüísticas, estabelecendo desta forma mais uma relação com uma outra ciência, a Lingüística, que nesta época ainda não era tida como tal. Da mesma forma, introduz o estudo de dados com bases na História, definida como a História Particular dos povos.

Boas acreditava na influência do meio como condicionante da cultura, das particularidades culturais, do fenômeno cultural, mas não como fator determinante de uma cultura. Em uma de suas cartas a Tylor, relata a introdução destes estudos históricos sobre a sociedade Kwakiutl através da análise dos mitos que o ajudaria a reconstruir tanto a gênese do mito de cada povo quanto o traçado da migração dos mesmos, defendendo através disso que uma idéia possa se desenvolver em diferentes comunidades de indivíduos, e que o material estrangeiro é incorporado por um povo e modificado pelas idéias e pelos costumes pré-existentes ${ }^{8}$.

Outra inovação boasiana diz respeito à concepção de organização das peças etnográficas, concepção posta em prática no American Museum of Natural History, onde trabalhava como curador desde 1896. Sugere a mudança das organizações, de caráter evolucionista, vigentes na época para uma organização por totalidades culturais significativas. Com esta proposta, inicia uma expedição, em fevereiro de 1898, com o intuito de investigar as condições pré-colombianas da América do Norte. Neste mesmo ano, será publicada na França a primeira série da revista L'Année Sociologique, representada, sobretudo, pelos trabalhos de Emile Durkheim e de Marcel Mauss.

Boas lança-se igualmente ao combate da discriminação racial, principalmente no que diz respeito à raça negra, alvo de fortes preconceitos na sociedade americana de então. Por outro lado, acompanha a história mexicana, e juntamente com seu orientando mexicano Manuel Gamio, funda a Escuela Internacional de Arqueologia y Antropologia. Desta forma, contamos com três áreas de grande interesse para Boas: a lingüística, com os trabalhos de Kwakuitl, as relações raciais, e a arqueologia.

Em 1911, com o lançamento de The mind of Primitive Man, Boas supera a noção tyloriana de cultura, meramente descritiva, com uma noção interpretativa.

\footnotetext{
${ }^{8}$ Trecho de carta extraído da tese de Livre Docência Celebração de Boas - O nascimento da Antropologia Cultural na obra de Franz Boas, Professora Doutora Margarida Maria Moura, FFLCH-USP, 2000: 25,26.
} 
Com esta obra, ele reitera a definição estrutural de Cultura, onde os fatos culturais são interdependentes e separa a noção de raça da noção de cultura. O surgimento desses novos conceitos representa uma reviravolta no campo intelectual e favorece o aparecimento de um período de novas idéias para a Antropologia.

A noção de cultura em Boas é uma noção que o leitor de seus artigos reconstrói no decorrer de sua leitura a partir dos questionamentos levantados por ele e de suas inúmeras exemplificações e reflexões.

Trata-se, portanto, de um processo de desconstrução das concepções vigentes em sua época e de reconstrução de uma nova maneira de se conceber não mais a cultura, mas as culturas, a partir da relativização e da contextualização dos dados coletados, da investigação histórica, do exaustivo trabalho de campo que favorece o contato direto com a sociedade estudada, do processo indutivo de análise, do aprendizado da língua do povo em questão, e, sobretudo, da importância da particularização das culturas estudadas. Para Boas, as culturas eram interessantes não pelo que podiam oferecer em termos de semelhanças, mas pelo que as diferenciava entre si.

Através da leitura de seus artigos publicados em The Mind of Primitive Man (1911), buscamos percorrer e reconstruir o caminho das concepções de cultura traçado por este autor a fim de chegarmos a uma noção que contemple tudo o que, para ele, se constituía em cultura.

Em Early Cultural Traits, um de seus trabalhos compilado em The Mind of Primitive Man (1911), Boas expressa definitivamente o seu ponto de vista sobre as questões dos estágios culturais preconizados pela teoria evolucionista, e denuncia a inadequação e os equívocos de interpretação ocorridos até então. Ao definir a cultura como a totalidade das reações e atividades físicas e mentais que caracterizam o comportamento dos indivíduos que compõem um grupo social coletiva e individualmente em relação ao seu meio natural, a outros grupos, aos membros do seu próprio grupo e de cada indivíduo ${ }^{9}$, incluindo os produtos dessas atividades e o seu papel na vida dos grupos, Boas estabelece a necessidade em se considerar as culturas de forma particular e de contextualizar os fenômenos culturais dentro do quadro que thes deu origem. Sendo assim, descarta a possibilidade de se compreender uma cultura com base nos códigos de outras culturas, e des-constrói,

\footnotetext{
${ }^{9}$ Boas, F. "The Early Cultural Traits" in The Mind of Primitive Man. 1911:159.
} 
desta forma, alguns princípios regentes das várias teorias que vigoravam até então e que dirigiam toda a sua atenção às similaridades dos fenômenos étnicos.

Entrevemos aí, através da desconstrução de um desenvolvimento unilinear cultural, além da construção de uma concepção estrutural da cultura, onde os elementos são interdependentes, a construção de uma concepção particularista que renega a cultura generalizante. Deste modo, ele restabelece a cada cultura em particular o direito de existir independentemente de outras e lhes restitui o lugar que ocupam entre todas as culturas existentes.

De acordo com esta concepção particularista da cultura, Boas nos oferece a riqueza da variedade tanto de comportamentos quanto de contextos existentes e se atêm às diferenças muito mais do que às semelhanças entre as culturas. Com isso, faz, por um lado, cair por terra a teoria evolucionista que prevê estágios de desenvolvimento cultural, e por outro lado, calca as diferenças em termos culturais e não biológicos. Ao calcar, pois, as diferenças em termos culturais e não raciais, Boas combate a idéia implícita na noção de raça da existência de uma relação entre traços físicos e traços mentais, e abandona o conceito de raça na explicação dos comportamentos humanos nos oferecendo a concepção de que a cultura é adquirida e transmitida e não inata, e que, portanto, o comportamento do homem deve se caracterizar por uma grande variabilidade de acordo com suas relações com a natureza e com os seus semelhantes.

Como afirma em seu artigo The interpretations of culture (Boas), a cultura é mais propriamente o resultado de fatores inter-actantes (que agem entre si) internos e externos a um dado grupo, o que faz com que as diferenças entre tipos humanos não tornem em nada evidente a influência da raça no curso do desenvolvimento cultural nem na definição da personalidade dos seus indivíduos.

Boas demonstra igualmente a crucial importância em se relativizar o mundo e aqueles que dele fazem parte, lembrando-nos da necessidade em se considerar a diversidade humana, visto que tanto as pessoas implicadas no fenômeno cultural quanto o local onde se encontram são distintos.

Das leituras que fizemos, percebemos que o relativismo cultural é, em Boas, tanto um princípio metodológico quanto uma concepção da cultura, pois, ao relativizar, ele volta a sua atenção ao que cada cultura tem de original, único, específico e particular, representando uma totalidade singular. Desta maneira, a comparação entre as culturas só seria válida se procedêssemos a uma análise 
minuciosa da configuração em que o dado cultural aparece, de sua contextualização histórica. Identificamos aí um princípio metodológico que requer cautela na comparação e que se insere no estudo da dinâmica histórica dos povos, de suas características de singularidades e particularidades, e de seu contexto, considerando a dinamicidade das sociedades e das formas culturais.

O que se extrai de seus trabalhos é uma grande preocupação com os perigos da generalização, da descontextualização histórica, da radicalização das várias correntes que procuram moldar a cultura a fim de explicá-la segundo seus princípios.

A noção de cultura em Boas pode ser vista, então, como sendo de cunho interpretativo historicista, contrariando os determinismos raciais, geográficos e econômicos assim como o evolucionismo. Ao considerar que as partes constitutivas da cultura não são independentes, Boas declara que a cultura é, portanto, estrutural, ou seja, possui partes que constituem uma estrutura, e que não estão soltas. Ao ver o fenômeno cultural como historicamente condicionados e transmitidos pelo processo de aprendizagem, temos que a cultura, para Boas, é adquirida e transmitida, e não inata.

Finalmente para ele, existe uma relação muito mais notável entre língua e cultura do que entre cultura e raça. A linguagem ${ }^{10}$ é, como declara Boas, uma das evidências mais importantes da história do desenvolvimento humano, visto que ela é um traço comum a toda a humanidade, além de nos diferenciar dos animais, juntamente com outras características como o raciocínio, a avaliação das ações segundo pontos de vista éticos e estéticos. A língua torna-se para o antropólogo, condição sine qua non de acesso à cultura do povo estudado.

\subsection{Breve percurso sobre a concepção de cultura no século $X X$}

A concepção do termo cultura será enriquecida no decorrer de todo o século XX, apresentando variantes e acréscimos decorrentes de correntes científicas e de princípios diversos, além do desejo de delimitação do campo de pesquisa. A própria didática se servirá de tais concepções no que se refere ao ensino de línguas estrangeiras, como dito anteriormente.

\footnotetext{
${ }^{10}$ Franz Boas usa, em inglês, o termo langage, que podemos traduzir tanto como língua quanto como linguagem. No entanto, essa possibilidade de tradução não é imparcial ou equivalente, como veremos no próximo capítulo.
} 
Dessa forma, tanto dentro da Sociologia quanto da Antropologia, encontramos não definições fechadas, mas concepções variadas sobre o termo, que se diferenciam conforme a abordagem de cada pesquisador. $O$ que na verdade se tenta é uma delimitação do objeto de estudo.

A antropóloga americana Ruth Benedict, discípula de Boas, evidenciou o conceito de padrão cultural a partir de seus estudos sobre as diferentes características das sociedades tribais, trabalho que resultou na publicação de seu livro Patterns of Culture (1934). Neste trabalho, Benedict ressalta a importância em se analisar o todo a fim de se explicar a experiência total. Sendo assim, uma sociedade só se caracterizaria na sua unidade pelos padrões aplicados ao conjunto de seus membros e não a partes separadas, padrões esses que se referem à soma total das atividades de um grupo, ao ajustamento dos diversos traços e complexos de uma sociedade.

Clifford Geertz, em seu livro A Interpretação das Culturas (1978), concebe a cultura do ponto de vista semiótico, afirmando que sendo o homem um animal amarrado a teias de significados que ele mesmo teceu, ele assume a cultura como sendo essas teias e a sua análise, portanto, não como uma ciência experimental em busca de leis, mas como uma ciência interpretativa à procura de significados (1978:15). O que se percebe, portanto, nesta concepção de Geertz, é que a cultura é um produto do homem, dotada de significados por ele articulados, e na qual ele se apóia. A cultura é, desta forma, simbólica, e como ele mesmo afirma, pública e que, embora uma ideação, não existe na cabeça de alguém e que, embora não física, não é uma identidade oculta (1978: 20). Geertz (1978:24) acrescenta que a cultura não é um poder, algo ao qual podem ser atribuídos casualmente acontecimentos sociais, os comportamentos, as instituições ou os processos; ela é um contexto, algo dentro do qual eles podem ser descritos de forma inteligível.

A proposta de uma abordagem semiótica da cultura, baseada nos significados articulados como teias dentro de um contexto, evidencia em Geertz o ponto global de sua abordagem que é o de nos auxiliar a ganhar acesso ao mundo conceitual no qual vivem os nossos sujeitos, de forma a podermos, num sentido um tanto mais amplo, conversar com eles (1978:35). É necessário, desta forma, analisar o discurso social cujos significantes são atos ou conjunto de atos simbólicos (1978: 36), o que nos leva a concluir que a interpretação no trabalho antropológico é inevitável, e 
enquanto interpretação, caracteriza-se por uma reconstrução do que já foi construído pelos membros de determinada sociedade. Sendo uma reconstrução sobre a construção, a análise cultural é, segundo Geertz (1978:31), uma adivinhação dos significados, uma avaliação das conjeturas, um traçar de conclusões explanatórias a partir das melhores conjeturas e não a descoberta do Continente dos Significados. Teríamos então os olhos do observador, e não os do ator.

Tais questionamentos, como se pode observar, expandiram as variáveis de estudo para o conceito de cultura e inauguraram novas perspectivas que merecerão um estudo mais aprofundado, constituindo, deste modo, um complemento em trabalho posterior.

\section{A língua como fenômeno cultural}

\subsection{A abordagem antropológica de Franz Boas}

Os fatos culturais que poderiam emergir a partir do estudo da língua de um povo levou Franz Boas a dedicar grande parte de sua vida a analisar os fenômenos linguísticos da língua dos esquimós. Esta importância dada às informações culturais de ordem lingüística tinha sido negligenciada até então por seus antecessores, os chamados antropólogos de gabinete, que obtinham os dados de suas pesquisas por intermédio de diplomatas ou de nativos falantes de outras línguas. Para Boas, a obtenção terceirizada de informação, que compreenderia o corpus científico a ser estudado, se mostrava perigosa uma vez que o acesso a tais informações já teria passado pelo crivo de outros olhos culturais, de outras reconstruções de representações e chegaria, portanto, ao pesquisador, certamente impregnado de elementos já deformados por uma segunda visão dos dados coletados.

Para Geertz (1978:24), os dados antropológicos coletados já se encontram, de uma certa maneira, impregnados de uma primeira interpretação, aquela feita pelos próprios nativos. Desta forma, sendo os textos antropológicos interpretativos, tais interpretações já seriam de segunda ou terceira mãos quando transformadas em 
trabalhos publicáveis, pois somente um nativo faz a interpretação em primeira mão, pois se trata de sua própria cultura.

Essa noção de acesso em segunda ou terceira mãos aos fatos culturais de uma determinada sociedade nos remete de certa maneira às reflexões de Giambattista Vico ${ }^{11}$ presentes em sua obra La Nuova Scienza (1725), e comentadas por Isaiah Berlin em seu livro Vico e Herder (1976), dedicado ao estudo das premissas desses dois filósofos. Em uma época marcada pela valorização das ciências matemáticas em detrimento das ciências naturais, Vico acreditava que somente aquele que contribuiu à construção de sua própria cultura poderia compreendê-la por completo. Tal concepção se confrontava com as premissas da escola cartesiana, que tentava explicar todos os acontecimentos através da razão e da lógica. Além disso, Vico pregava que o verdadeiro conhecimento só se daria pela experiência, atividade e participação humanas, a partir de uma visão interna e não externa decorrente da mera observação.

Ao conceber a língua como a ferramenta semiológica do antropólogo (Moura, 2001:150 $)^{12}$, Boas acredita que ela possa revelar e esclarecer aspectos da cultura até então não muito claros devido justamente à maneira de se obter os dados para a pesquisa antropológica. Ele realiza, deste modo, um estudo publicado na introdução ao Handbook of North American Languages (1911) que descreve minuciosamente o funcionamento da língua. Um dos primeiros problemas evocados nesta descrição, assemelha-se ao que ele mesmo dissertou em seu artigo On alternating sounds ${ }^{13}$, onde tratou dos problemas de compreensão e recepção de alguns sons, decorrentes da dificuldade de reconhecimento e percepção dos mesmos por parte de um nãofalante de determinada língua. Este fenômeno, que Boas denominou soundblindness ou cegueira do som (faz analogia ao termo color-blindness, já empregado na língua americana ${ }^{14}$ ), se caracterizaria por uma alternância na percepção dos sons fonéticos recebidos por um estrangeiro que não domina nem está familiarizado com os novos sons que ouve. Isto ocorreria por duas razões: em primeiro lugar, o estrangeiro não compartilha o mesmo sistema fonético do falante nativo; em segundo lugar, as diversas formas de articulação da fala que mobilizam, em cada

\footnotetext{
${ }_{11}^{11}$ Giambattista Vico, escritor, historiador e filósofo italiano, nascido em 1668, em Nápoles.

${ }_{12}$ MOURA, M.M. Tese de doutoramento, 2001: 150.

${ }_{13}^{13}$ Artigo publicado em The Shaping of American Anthropology, 1883-191, pp. 72 à 77.

${ }^{14} \mathrm{~A}$ esse respeito, Margarida Maria Moura prefere o emprego de sound-deftness, ou surdez do som, pois acredita que o sentido da expressão se torna mais claro.
} 
língua, áreas distintas do aparelho fonológico, evidenciam um lapso entre a língua do falante e a língua do ouvinte, de acordo com o trabalho diferenciado dos órgãos da fala.

É interessante fazermos aqui um pequeno paralelo com a nossa prática em sala de aula como professores de Francês Língua Estrangeira, onde podemos verificar as dificuldades e, por vezes, a incapacidade dos aprendizes tanto na produção de sons do sistema fonético francês não existentes na língua portuguesa, quanto na percepção desse mesmo som como sendo um som diferente.

Para exemplificarmos, poderíamos citar a dificuldade do aprendiz iniciante de FLE em diferenciar o som $[y]$, correspondente à grafia " $u$ ", e o som [u] correspondente à grafia "ou", como nas palavras rue / roue (ambas substantivos feminino); but / bout (ambas substantivo masculino); bu (particípio passado do verbo boire) / boue (substantivo); pu (particípio passado do verbo pouvoir) / pou (substantivo); $v u$ (particípio passado do verbo voir ) / vous (pronome sujeito); nu / nous; du (artigo contraído) / doux (adjetivo). De acordo com os estudos de Boas, o fato de não perceber facilmente essa diferença sonora leva o aprendiz (para Boas, o estrangeiro) a tentar encontrar, no seu sistema fonético, o som que mais se assemelha ao som de [y], que no caso da língua portuguesa é o [i]. Muitas vezes ele é incapaz tanto de perceber ou de sentir essa diferença quanto de reproduzi-la, embora reconheça que se trata de duas palavras graficamente, semanticamente e gramaticalmente diferentes.

$\mathrm{Na}$ introdução ao Handbook of North American Languages ${ }^{15}$, Boas aborda igualmente a questão do aspecto inconsciente dos elementos fonéticos. Para ele, um som, na sua unicidade, não existe independentemente de outros sons, pois este só passa a ter existência num complexo sistema de sons que lhe darão significado definido. A palavra forma, portanto, uma unidade que adquire significado no todo. Desta maneira, as formas gramaticais exercem grande influência em determinadas línguas, pois são passíveis de modificar a idéia expressa através de um único fonema, tal é o caso do " $s$ " como marca de plural. Sendo assim, um elemento fonético só se torna consciente quando analisado gramaticalmente.

Boas (1911:24) foi ainda mais longe ao afirmar que as línguas não diferem somente no caráter de seus elementos fonéticos, mas também no grupo de idéias 
que encontra expressão nos grupos de fonemas fixos. Ao considerar que a possibilidade combinatória desses elementos é ilimitada, ressalta que somente um número limitado desses elementos é usado para expressar idéias. De acordo com sua explicação, esta limitação consiste na expressão de um acontecimento psicológico onde diferentes experiências individuais nos aparecem como representativas de uma mesma categoria de pensamento. Esta categoria pode se mostrar, portanto, descritiva em uma língua e sintética em outra. Como exemplo disso, ele nos oferece a polissemia encontrada nas palavras "neve" e "foca" que, na língua esquimó, apresentam diversos termos que expressarão, de acordo com a situação ou as diferentes condições, idéias diferentes. Tal fenômeno é denominado pela Lingüística como holofrase, ou seja, a possibilidade de se expressar uma idéia complexa por meio de um único termo. Essas diferenças entre as línguas denotam a arbitrariedade do signo lingüístico, preconizado posteriormente por Saussure.

Boas (1911:72) levanta igualmente a questão da classificação dos conceitos existentes em todas as línguas. Toda língua classifica, segundo seus próprios critérios, seus elementos gramaticais constituintes. No que diz respeito aos substantivos, por exemplo, determinadas línguas os classificam como animados e inanimados, abstratos e concretos, e assim por diante. Entretanto, embora procedam a classificações distintas, sua ocorrência deve ser considerada como prova da unidade de processos psicológicos fundamentais :

"Todos os traços do pensamento humano, conhecidos por influenciar a história das ciências e que representam um papel mais ou menos importante na história geral das civilizações, ocorrem com igual freqüência no pensamento do homem primitivo". (Boas, 1911:72)

O interesse de Boas é o de demonstrar que a noção de aquisição da língua consiste, na sua origem, em processos cognitivos inerentes a todo ser humano. Com essa teoria, ele faz desaparecer a noção de primitivismo lingüístico que cede lugar ao particularismo e à complexidade. Desta maneira, assim como a sua noção de cultura, a sua concepção de língua também é particularista. Logo, as funções 
relacionais da gramática, seus aspectos e seus processos podem variar de língua para língua sem que isso fade uma ou outra a ser mais primitiva e simples ou mais complexa e elaborada. Na verdade, é a maneira de se ordenar o pensamento que é distinta.

Além de particularizar as línguas, oferecendo a cada uma o seu devido valor, Boas afirma que traços lingüísticos, quando similares entre duas ou mais línguas, podem ter se originado de forma independente de acordo com os interesses culturais de cada povo, tal qual a quase inexistência de idéias abstratas nas línguas de alguns povos primitivos que se interessavam, sobretudo, às ocupações do seu quotidiano. Sendo assim, a língua se comporta, pois, como a cultura.

$O$ fenômeno lingüístico passa a ser deste modo, em Boas, também um fenômeno etnológico, uma vez que a língua compõe um dos fenômenos culturais. A diferença feita entre ambos, linguístico e etnológico, é que embora possuam uma mesma origem inconsciente, o segundo aflora mais freqüentemente à consciência, pois se mostra passível de reflexão e de explanações, enquanto o primeiro permanece no nível inconsciente até o momento em que se decida estudar a sua gramática. Boas afirma que uma das vantagens dessa permanência inconsciente do fenômeno lingüístico é que os estudiosos podem seguir os processos que levaram à sua formação sem contar com fatores de desvio ou de explanações secundárias freqüentes na etnologia.

Um outro aporte dos seus estudos lingüísticos diz respeito à relação estabelecida entre linguagem e pensamento. Como dissemos acima, a maneira de se ordenar o pensamento varia de língua para língua. Sendo assim, a associação entre língua e pensamento torna-se o meio pelo qual um povo representa o seu mundo e revela a sua cultura através das palavras.

As palavras podem estar, portanto, culturalmente condicionadas. Um exemplo disso é a evolução do léxico, a criação de palavras novas que possam representar uma realidade em constante mudança. As línguas não são, deste modo, estáveis, e sofrem influências internas e externas, tais como:

a) Empréstimos de outras línguas: no português temos como empréstimo do francês palavras como soutien (de soutien-gorge), déjà-vu, entre outras;

b) Incorporação de novos significados a palavras "velhas"; 
c) Adição ou supressão de formas gramaticais, de fonemas, como nas palavras isle, fenestre, do francês, que perderam o "s" e ganharam um circunflexo île, fenêtre;

d) Incorporação de palavras estrangeiras com novo significado: em português temos palavras como rendez-vous, que está associada, na nossa cultura, a casas de tolerância possivelmente por relacionar os encontros "sur rendezvous" (termo usado em francês para designar qualquer compromisso com hora marcada, mas que foi culturalmente associado às prostitutas) entre as prostitutas francesas estabelecidas no Brasil e seus clientes; couvert que, para os brasileiros, corresponde a um antepasto ou a uma taxa cobrada por apresentação de músicos em restaurantes, neste caso couvert artístico, mas que, em francês, significa talheres; entre outras.

e) Mudanças de pronúncias para empréstimos estrangeiros: como é o caso do próprio rendez-vous, pronunciado como [redivu], forró do inglês for all;

Sendo assim, na língua, a experiência a ser comunicada é classificada de acordo com um certo número de aspectos distintos que compõem os processos gramaticais. Tais processos e conceitos gramaticais orientam a atenção da comunidade lingüística numa determinada direção e podem influenciar a poesia, as crenças, até mesmo o pensamento especulativo, sem, no entanto, diminuir a capacidade, inerente a qualquer língua, de se adaptar às necessidades suscitadas pelos progressos do conhecimento ${ }^{16}$. Deste modo, entrevemos como a língua pode influenciar a produção cultural.

Ao afirmar que a língua, em seu sentido mais amplo, engloba os significados por meio dos quais as experiências volitivas, emocionais e sensoriais de um indivíduo são expressas e transmitidas visualmente, taticamente e auditivamente a outrem através dos movimentos corporais, do toque e do som ${ }^{17}$, constatamos que as contribuições boasianas à área da Linguística foram inúmeras, indo desde a constatação do caráter inconsciente da linguagem, o estabelecimento de uma

\footnotetext{
${ }^{16}$ JAKOBSON, La notion de signification grammaticale selon Boas in Essais de Linguistique Générale, Paris : Edition de Minuit, p. 197, 1963.

${ }^{17}$ BOAS, F. Language in General Anthropology, p. 124 (tradução nossa).
} 
relação entre linguagem e pensamento e entre língua e cultura, hoje estudados pela Psicolingüística e pela Sociolingüística, a relativização e a consequente particularização das línguas que tornaram interessante o estudo de "todas" as línguas e suas descrições sem se basear em um modelo geral; a densa descrição dos processos gramaticais e categorias lingüísticas às quais atribuiu funções e significados que ajudariam na compreensão da cultura, e, sobretudo, à importância dada às línguas como parte dos fenômenos etnológicos, dotadas de uma dinâmica que segue o fluxo constante da cultura, mas que também exercem influências sobre ela.

\subsection{Língua e cultura: uma abordagem sociológica}

O debate acerca das relações intrínsecas entre língua e cultura data de muito tempo e remonta ao século XVIII. Desde então, tem se tentado estabelecer qual seria a natureza dessas relações: estrutural segundo Claude Lévi-Strauss, morfossintática, para Whorf e Sapir, entre outras.

Pelos estudos lingüísticos de Boas comentados no capítulo anterior, percebemos a importância da descrição da língua em seus trabalhos. Esta preocupação boasiana se explica, tanto do ponto de vista antropológico quanto do ponto de vista lingüístico, pela predominância, em todo o século $\mathrm{XIX}$, do método comparativo, ao qual Boas apresentava restrições e por vezes, combatia. Tal método era utilizado, sobretudo, para explicar as semelhanças entre culturas e línguas. A vertente evolucionista começa, desde então, a ser colocada em questão frente à necessidade de particularização e relativização das culturas e línguas que tinham por base o estudo das diferenças. Desta maneira, os elementos que caracterizam e singularizam uma cultura e uma língua passam a ser aqueles que as diferenciam.

Nesse contexto de ebulição de novos princípios científicos que caracterizam o fim do século XIX e o início do século XX em quase todas as áreas das ciências humanas em processo de fundação, percebemos que os estudos da linguagem começam a ganhar espaço dentro da reflexão lingüística da época calcada nos trabalhos de Ferdinand de Saussure (1857-1913) e em sua obra fundadora da Lingüística Estrutural, Curso de Lingüística Geral (1916). 
Ao estabelecer as bases da nova ciência, Saussure procura romper com os princípios da gramática comparada e historicista, e busca "estudar a estrutura geral da língua em geral"18.

"Le Cours de Linguistique Générale (CLG), publié en 1916 par Bally et Séchehaye, d'après les notes des étudiants qui avaient suivi les cours de Saussure entre 1906 et 1911, apparaît comme le texte fondateur de la linguistique moderne, reposant sur l'étude de la langue comme système. Même si nombre de thèmes abordés par Saussure circulent dans les recherches de la deuxième moitié du XIXe siècle, le CLG constitue cependant ce qu'on a pu appeler une "coupure épistémologique ", i.e. une façon radicalement différente de considérer les faits de langage. Le travail de Saussure instaure en effet une rupture avec la linguistique comparatiste de son époque, en proposant une approche non historique, descriptive et systématique (on dira plus tard “structurale ») (Paveau e Sarfati, $2003: 60 / 61$ )

Saussure determina como objeto da Lingüística o estudo da língua e o seu funcionamento interno e autônomo. A linguagem como faculdade inata do ser humano constituirá o objeto de estudo de uma lingüística externa que descreva as relações que a língua pode ter com o que está fora dela mesma:

"Ce que Saussure appelle "linguistique externe" entretient en effet des rapports avec l'ethnologie, l'histoire politique, ce qu'il appelle «les institutions de toutes sortes" comme l'Église et l'École, la géographie linguistique et la dialectologie. C'est une linguistique qui décrit les liens que la langue peut

\footnotetext{
${ }^{18}$ PAVEAU, M-A. SARFATI, G-E. Les grandes théories de la linguistique. Paris : Armand Colin, p. 62, 2003.
} 
avoir avec ce qui est en dehors d'elle-même, qui accumule des informations, mais qui ne rend pas compte de son fonctionnement interne et autonome » (Paveau e Sarfati, $2003: 60 / 61$ )

A dissociação, neste momento, entre «langue » e «parole » é crucial na determinação e delimitação da língua como objeto de estudo da lingüística interna e como sistema de signos, relegando, deste modo, a uma lingüística externa, os estudos da "parole":

"Récapitulons les caractères de la langue: 1. Elle est un objet bien défini dans l'ensemble hétéroclite des faits de langage [...]. Elle est la partie sociale du langage, extérieure à l'individu, qui à lui seul ne peut ni la créer ni la modifier; elle n'existe qu'en vertu d'une sorte de contrat entre les membres de la communauté [...]. 2. La langue, distincte de la parole, est un objet qu'on peut étudier séparément. [...] Non seulement la science de la langue peut se passer des autres éléments du langage, mais elle n'est possible que si ces autres éléments n'y sont pas mêlés. 3. Tandis que le langage est hétérogène, la langue ainsi délimité est de nature homogène : c'est un système de signes où il n'y a d'essentiel que l'union du sens et de l'image acoustique, et où les deux parties du signe sont également psychiques " (Saussure apud Paveau et Sarfati, 2003 :64)

Novos questionamentos a respeito do conceito saussuriano de língua emergem nas décadas de 10 e 20 e desencadeiam o processo embrionário dos estudos sobre o discurso, representado, em um primeiro momento, nos trabalhos dos formalistas russos, como declara Brandão (2002:15): 
"Pode-se afirmar com Maingueneau (1976) que foram os formalistas russos que abriram espaço para a entrada no campo dos estudos lingüísticos daquilo que se chamaria mais tarde discurso [...] Essa abertura em direção ao discurso não chega, entretanto, às últimas conseqüências, pois seus seguidores, os estruturalistas, propõem-se como objetivo estudar a estrutura do texto "nele mesmo e por ele mesmo" e restringem-se a uma abordagem imanente do texto, excluindo qualquer reflexão sobre sua exterioridade" (Brandão, 2002:15).

A linha de pesquisa adotada na análise do discurso neste primeiro momento baseia-se, desse modo, na estrutura interna do texto. Tal prática do tratamento do objeto de pesquisa - o texto literário - permanecerá em voga por muitas décadas, pois o estruturalismo ganha força e se difunde ocupando um espaço cada vez maior nas pesquisas realizadas nas áreas da Psicologia e da Lingüística. Em relação à Didática das Línguas Estrangeiras, novas metodologias emergem com bases nesses estudos que privilegiam a estrutura interna da língua e a criação de automatismos lingüísticos, como o método áudio-oral e o SGAV (Structuro-Global Audio Visuel).

Segundo Brandão (2002:15), é somente no início dos anos 50 que algumas mudanças ocorrerão, sobretudo, com os trabalhos de Harris, Jakobson e Benveniste:

"Os anos 50 serão decisivos para a constituição de uma análise do discurso enquanto disciplina. De um lado, surge o trabalho de Harris (Discourse Analysis, 1952) que mostra a possibilidade de ultrapassar as análises confinadas meramente à frase, ao estender procedimentos da lingüística distribucional americana aos enunciados (chamados discursos), e, de outro lado, os trabalhos de Jakobson e Benveniste sobre a enunciação" (Brandão, 2002:15). 
Constituída em disciplina, a análise do discurso estabelece novos campos teóricos, tais como as lingüísticas enunciativas e discursivas cujas bases ancoramse na comunicação viva dos falantes.

"Les linguistiques énonciatives ont pour fondement commun une critique de la linguistique de la langue, et une volonté d'étudier les faits de parole: la production des énoncés par les locuteurs dans la réalité de la communication" (Paveau e Sarfati, $2003: 166)$

Entretanto, embora os fundamentos de uma nova lingüística pós-saussuriana tenham encontrado maior repercussão a partir da década de 50 , os estudos do russo Mikhaïl Bakhtine (1895-1975) já tinham demonstrado, desde a década de 20, que tais preocupações e reflexões acerca da língua e da fala remontavam a décadas bem anteriores.

"La tradition donne couramment Émile Benveniste (années 50 et 60) comme "père " de la théorie de l'énonciation, alors que l'intérêt des linguistes pour les problèmes énonciatifs remonte aux années 1910 et 1920 en Europe et en Russie. Cette époque voit en effet émerger la problématique énonciative, mais son développement est arrêté par l'expansion rapide $d u$ modèle structuraliste ". (Paveau e Sarfati, $2003: 168)$

A expansão rápida do modelo estruturalista explica, desse modo, a razão pela qual os trabalhos de Bakhtine sobre a enunciação só se tornaram mais conhecidos e difundidos há apenas algumas décadas. Seus estudos divergem em vários pontos da abordagem saussuriana da língua: enquanto que para Saussure os estudos lingüísticos deveriam concentrar seus esforços no estudo da língua como um conjunto de normas que compõem o código, restringindo, desse modo, o seu objeto de análise a um sistema estável de formas e combinações lingüísticas, para 
Bakhtine, sua importância reside, inversamente, no estudo da língua como produto da interação social:

"La véritable substance de la langue n'est pas constituée par un système abstrait de formes linguistiques ni par l'énonciation monologue isolée, ni par l'acte psycho-physiologique de sa production, mais par le phénomène social de l'interaction verbale, réalisée à travers l'énonciation et les énonciations. L'interaction verbale constitue ainsi la réalité fondamentale de la langue" (Bakhtine, $1977: 136)$

Embora ambos considerem a língua como um fato social, seus princípios teóricos e metodológicos revelam concepções distintas do seu objeto de análise. Em seu livro Marxisme et Philosophie du Langage (1929), Bakhtine denuncia a inutilidade em se recortar e abstrair a língua do seu contexto de uso, isolando-a e tratando-a como um objeto acabado:

"La réflexion grammaticale à caractère formalosystématique a été contrainte inévitablement d'adopter à l'égard des langues vivantes une position conservatrice et académique, c'est-à-dire, de traiter la langue vivante comme si elle était achevée, ce qui implique une attitude hostile vis-à-vis de toutes les innovations linguistiques [...] Le système de formes renvoyant à une norme ne peut servir de base à la compréhension et à l'explication des faits de langue dans leur vie et leur évolution. Au contraire, il nous éloigne de la réalité évolutive et vivante de la langue et de ses fonctions sociales" (Bakhtine, $1977: 113,118)$ 
Em suas críticas à lingüística estruturalista, Bakhtine (1977:123) estabelece as bases de sua teoria da enunciação centrada na interação verbal social:

\begin{abstract}
"L'énonciation est le produit de l'interaction de deux individus socialement organisés et même s'il n'y a pas un interlocuteur réel, on peut substituer à celui-ci le représentant moyen du groupe social auquel appartient le locuteur » (Bakhtine, 1977 :123).
\end{abstract}

A teoria bakhtiniana da enunciação sublinha, dessa maneira, a importância do papel desempenhado pelo contexto na interação entre os falantes de uma mesma língua. É no e pelo contexto social que os participantes da comunicação verbal orientarão seu discurso, farão as suas escolhas discursivas:

\begin{abstract}
"[...] la situation façonne l'énonciation, lui imposant telle résonance et pas telle autre [...] la situation et les participants les plus immédiats déterminent la forme et le style occasionnels de l'énonciation. Les couches plus profondes de sa structure sont déterminées par les contraintes sociales plus substantielles et plus durables auxquelles le locuteur est soumis » (Bakhtine, $1977: 124,125)$.
\end{abstract}

Não podendo ser concebida nem analisada fora do seu contexto social, a língua assim como a cultura apresenta a sua dinamicidade e atualização na evolução das relações sociais. O contexto, os interlocutores e suas escolhas discursivas comporão as bases de análise da enunciação.

Ao percorrermos esse caminho evolutivo que tem como ponto de partida a inclusão da língua como parte do fenômeno etnológico e, por conseguinte a ruptura com os estudos lingüísticos históricos e comparatistas vigentes no século XIX, chegamos, como demonstramos, aos estudos de Saussure e de Bakhtine que representam dois recortes diferentes acerca da importância da pesquisa lingüística. Por um lado, a delimitação do objeto de estudo da lingüística interna estabelecida por Saussure dissocia a língua da cultura. Por outro, relegando à lingüística externa 
o estudo da língua e os laços que esta mantêm com o mundo externo, abre-se um novo caminho aos estudos da linguagem e do discurso que estabelecem, através de Bakhtine, a estreita relação e inviável dissociação entre língua, cultura e linguagem.

De acordo com o Dicionário de Lingüística (Dubois et alii, 1993) a língua é definida como a parte da linguagem que existe na consciência de todos os membros da comunidade lingüística; a soma das marcas depositadas pela prática social de inúmeros atos de fala concretos. Deste modo, a língua é um fenômeno da linguagem, um sistema de signos culturalmente convencionados de acordo com cada sociedade, através do qual o pensamento, organizado pela linguagem, se concretiza em palavras.

A linguagem é, por sua vez, um fenômeno psicológico através do qual o pensamento se organiza de forma a ser expresso em palavras (unidades da língua) através da fala. É, deste modo, um sistema de representações do mundo através do qual o pensamento é agenciado. Tais representações serão expressas em palavras, sendo que essas, segundo Boas (1911:43), só poderão expressar uma parte do conceito completo que temos na mente, levando-se em consideração que cada língua tem uma tendência particular a selecionar este ou aquele aspecto da imagem mental que é transmitida pela expressão do pensamento.

Ao considerarmos, então, que as palavras podem estar culturalmente condicionadas, tendo em vista que o léxico se desenvolve em conformidade com as atividades de expansão ou de mudanças (Boas, Language in General Anthropology:141), a língua passa a ser o reflexo do estado da cultura e segue seu desenvolvimento de acordo com o que a cultura demanda (op.cit. p. 142). Esta influência de uma sobre a outra pode ser exemplificada, atualmente, através dos neologismos decorrentes dos avanços tecnológicos na área da informática. Criado pela língua das Américas e representado pela sociedade Norte Americana (EUA) que detém, nesse domínio, a "patente" das inovações tecnológicas e lingüísticas, o vocabulário da informática e da internet ganhou todo o mundo ocidental e parte do oriental, acrescentando a essas línguas palavras que até então não existiam. Muitas delas foram assimiladas tal qual na língua de origem, como "login”, "enter", etc. Outras sofreram a influência da língua materna e foram incorporadas pelos seus falantes, como o verbo "deletar". A língua, assim, evolui como a cultura, 
apresentando-se em um movimento dinâmico, sofrendo influências externas e internas, como declara Bakhtine (1977:137-138):

"Les relations sociales évoluent (en fonction des infrastructures), puis la communication et l'interaction verbales évoluent dans le cadre des relations sociales, les formes des actes de parole évoluent du fait de l'interaction verbale, et le processus d'évolution est reflété, enfin, dans le changement des formes de la langue » (Bakhtine, $1977: 137-138)$

Sendo assim, poderíamos então dizer que a relação entre língua e cultura se estabelece em níveis onde a detecção da influência da segunda sobre a primeira (através da qual essa relação possa ser explicitada) pode ora se mostrar de forma mais direta, pela incorporação de palavras estrangeiras ao código lingüístico da LM, o que denota, deste modo, uma relação inter-cultural; ora de forma indireta, como é o caso do acréscimo de novos sentidos a palavras já existentes na língua que suplantam, por vezes, o significado primeiro de uma determinada palavra. Segundo Bakhtine (1977:38), a palavra carrega consigo as lentas acumulações das mudanças sociais, consistindo no indicador mais sensível de todas as transformações sociais.

Desta maneira, a relação língua-cultura somente será estabelecida ao considerarmos seu aspecto dinâmico que se traduz na interação social dos falantes (numa escala que abrange a coletividade nacional, regional ou social), e na influência e interação tanto econômica quanto política e social entre sociedades diferentes:

"Les rapports de production et la structure sociopolitique qu'ils conditionnent directement déterminent tous les contacts verbaux possibles entre individus, toutes les formes et les moyens de communication verbal: au travail, dans la vie politique, dans la création idéologique [...] La psychologie du corps social se manifeste essentiellement dans les aspects les plus divers de l'énonciation sous la forme de différents modes de discours [...] Chaque époque et 
chaque groupe social a son répertoire de formes de discours dans la communication socio-idéologique [...] une analyse plus fine révélerait l'importance incommensurable de la composante hiérarchique dans le processus d'interaction verbale, quelle influence puissante exerce l'organisation hiérarchisée des rapports sociaux sur les formes de l'énonciation. Le respect des règles de l'étiquette, du bien parler [...] ont une portée immense dans le processus de mise en évidence des principaux modes de comportement. » (Bakhtine, 1977 :38-40).

Por outro lado, sendo a língua a parte da linguagem que existe na consciência de todos os membros da comunidade lingüística, ela compõe um sistema de representações do mundo que, através de conceitos generalizados do real, será expresso em palavras. Em Vygotsky (1991), o estudo do significado das palavras passa a ser preponderante no estabelecimento da relação entre pensamento e linguagem. De acordo com ele, o significado das palavras consiste na união do pensamento conceitual e da fala, e resulta de um processo psicológico de construção de representações e verbalização do real. A gênese de todo esse processo está ligada, deste modo, diretamente à maneira de se conceber o mundo $\mathrm{e}$ à maneira de transmiti-lo por meio das palavras. Como explica Vygostsky (1991:128129):

"Na mente, o pensamento está presente em sua totalidade e num só momento, mas na fala tem que ser desenvolvido em uma seqüência. $A$ transição do pensamento para a palavra passa pelo significado. $\mathrm{Na}$ nossa fala há sempre o pensamento oculto, $\mathrm{O}$ subtexto. $O$ pensamento tem que passar primeiro pelos significados e depois pelas palavras" (Vygostsky, 1991:128-129). 
Isto nos faz pensar que o pensamento generalizado ou conceito (construído socialmente e coletivamente pelos indivíduos de acordo com sua percepção do real) só poderá ser expresso parcialmente, e não em sua totalidade, devido a sua dependência do contexto de comunicação. Logo, em termos enunciativos, esta ordem pensamento-significado-palavra está condicionada à situação social, que, por sua vez, determina a escolha discursiva:

"[...] Le sens du mot est entièrement déterminé par son contexte. Autant de contextes, autant de significations possibles [...]. Le mot comme signe est extrait par le locuteur d'un stock social de signes disponibles, la réalisation de ce signe social dans l'énonciation concrète est elle-même entièrement déterminée par les relations sociales [...]. La situation sociale la plus immédiate et le milieu social plus large déterminent entièrement, et cela de l'intérieur, la structure de l'énonciation. " (Bakhtine, $1977: 115$ -124).

Deste modo, a relação entre a linguagem (fenômeno psicológico), a língua (fenômeno da linguagem), e a cultura se daria em níveis mais profundos, que compreenderiam:

- A formação dos conceitos (que se refletirá no aspecto semântico da língua e cujo núcleo é o significado das palavras);

- A construção de um sistema de representações que releva da percepção da realidade (sistema simbólico com base na realidade da comunidade lingüística em questão).

Se a verdadeira comunicação requer, então, significado, ou seja, generalização (Vygotsky, 1991:5), essa realidade generalizada releva, portanto, da prática social, da interação e da convenção estabelecida entre os membros de uma 
dada sociedade, caracterizando, desta forma, o modo de expressão particular de cada comunidade lingüística, que, por sua vez, se caracterizará como um dado cultural, como podemos verificar na seguinte afirmação de Gauthey e Xardel (1990:35):

"Toute organisation [...] communique à travers l'utilisation d'un système de symboles. [...] La communication englobe tous les comportements qu'un être vivant perçoit et interprète, messages verbaux et non verbaux, conscients ou inconscients.[...] La communication est un processus interactif, car la nature des messages se modifie au cours des échanges » (Gauthey e Xardel, 1990:35).

Sendo assim, se a base do pensamento verbal se encontra no significado das palavras, a compreensão de que as línguas (embora apresentem um mesmo tronco comum, como as línguas latinas) são um fenômeno da linguagem (que, por sua vez, se caracteriza como um sistema simbólico de representação do mundo) auxiliará o indivíduo a perceber que para penetrar uma outra cultura é necessário compreender que a língua é a base da comunicação verbal cuja função central é a de fundar e assegurar a comunicação visto que ela exerce o papel de mediadora das relações entre os indivíduos (Culioli). Todavia, para que os interlocutores assegurem a comunicação é necessário se compreender que a língua utilizada nessa comunicação se formou a partir de um fenômeno perceptivo e construtivo de representação do mundo que resultou na formação de conceitos acerca da realidade ${ }^{19}$.

Desta maneira, embora seja importante percebermos em que níveis a relação entre língua e cultura se dá, nos parece ainda mais importante ressaltar que é no nível sócio-discursivo que a língua, como um todo complexo que é, se atualizará e exercerá a sua função de fundadora, asseguradora e mediadora da comunicação entre os indivíduos, uma comunicação que requer significado. Os níveis são, desta

\footnotetext{
${ }^{19}$ A questão das representações será abordada posteriormente.
} 
forma, interdependentes, e é essa imbricação entre eles que torna as línguas singulares, particulares.

No entanto, Culioli (1967) faz uma ressalva, em seu artigo La communication verbale, a respeito do termo refletir, freqüentemente empregado nas concepções de língua como reflexo da realidade. Através justamente das nuances de sentido e mesmo das diferenças de significado entre refletir e refratar, Culioli privilegia o segundo em detrimento do primeiro. Para ele, as línguas não refletem a realidade, visto que há relações extremamente complexas entre o lingüístico e o extralingüístico. Na verdade, as línguas refratam a realidade tendo em vista que $o$ ângulo de refração pode variar de acordo com as classes e as categorias. Compreendemos então que a ação de refletir nos remete ao reflexo de uma imagem ou à idéia de uma imagem simétrica e pontual da língua que contestaria a teoria da arbitrariedade dos signos e de certa forma a autonomia das línguas no que se refere à maneira de apreender a realidade e de reconstruí-la simbolicamente.

Assim como a cultura compreende uma teia de significados articulados que só poderão ser apreendidos dentro de seu próprio contexto (Geertz:1978), o discurso permeado de simbologias e representações discursivas só poderá ser analisado, interpretado e compreendido se levarmos em consideração o seu contexto de ocorrência, dentro do qual os agentes da comunicação interagem e através do qual não somente o conhecimento do código lingüístico mas também o conhecimento do código sócio-cultural subjacente permitirá que a comunicação entre membros de sociedades diferentes possa se efetuar. Voltamos, assim, a nossa relação entre língua e cultura.

A justificativa em se estudar uma língua como meio de acesso a cultura contempla, portanto, a concepção de língua como um fenômeno social que permite a interação do indivíduo no grupo. Se a cultura é um fenômeno humano, social, coletivamente pensado e aceito, interpretado simbolicamente e que se reflete no comportamento verbal e não verbal dos indivíduos, a língua passa a ser uma das maneiras pela qual a cultura de determinada sociedade será construída.

Deste modo, poderíamos concluir que a importância do estudo de uma língua estrangeira reside no fato de que ela é não somente um meio de comunicação, mas um instrumento de acesso a um mundo permeado de símbolos, representações, acordos tácitos e rituais comunicativos, que diferem em vários níveis do nosso próprio sistema de representação. 
3. A construção das representações do Outro pelo discurso: $O$ Brasil na imprensa francesa.

Antes de procedermos à análise do corpus constituído por artigos publicados sobre o Brasil na imprensa francesa durante o ano de 2005 (Ano do Brasil na França), e a partir dos quais procuraremos demonstrar como as representações de uma outra cultura podem ser construídas pelo discurso, abordaremos a questão das representações dentro das Ciências Humanas, nos centrando na área da Sociologia, onde nasceu e evoluiu a noção de representação social, e da Análise do Discurso dentro da teoria da esquematização proposta por Jean-Blaise Grize.

\section{a. A noção de representação dentro das Ciências Humanas}

Atualmente, a noção de representação está presente de forma constante no discurso de várias ciências como a Sociologia, a Antropologia, a Psicanálise, a Psicologia e a Linguística, cada uma se servindo desta noção de acordo com o seu 
objeto de estudo. Entretanto, de sua origem em Durkheim (1898) até os nossos dias, ela conheceu um período de estagnação que se explica, de uma forma geral, pela hegemonia dos estudos behavioristas em Psicologia e pela predominânica do modelo marxista dentro das Ciências Sociais (Jodelet, 2003:55).

Serge Moscovici (2003:99-100), responsável pela retomada da noção de representação dentro da Psicologia Social na década de 60, explica as razões pelas quais o estudo das representações se mostra, atualmente, uma noção de fundamental importância para se explicar, em regra geral, o que rege ou como são regidas as relações sociais:

"[...] la nécessité de faire de la représentation une passerelle entre le monde individuel et le monde social, de l'associer ensuite à la perspective d'une société qui change, motive la modification en question. II s'agit de comprendre, non plus la tradition mais l'innovation, non plus une vie sociale déjà faite mais une vie sociale en train de se faire. Qu'elle n'ait pas eu lieu plus tôt, et que les efforts déployés pour comprendre les représentations se soient limités aux sociétés dites primitives explique en partie pourquoi, après un départ fulgurant, la notion est restée si longtemps à l'abandon. Un abandon également dû au fait qu'elle dénote une structure cognitive spécifique et non une vaste classe d'idées ou de connaissances toutes d'origine collective [...] ». (Moscovici, 2003:99-100)

Desta maneira, a Psicologia Social estabelece suas bases no estudo dos aspectos cognitivos e sociais do processo de construção das representações, tendo como objetivo compreender a difusão dos saberes, a relação entre o pensamento $e$ a comunicação e a gênese do sentido comum (Moscovici, 2003:80).

As representações passam, desde então, a interessar outros domínios das Ciências Humanas onde a sua trandisciplinaridade se justifica na amplitude de entradas que ela favorece para a compreensão de fatos sociais e culturais a partir de 
seu processo psico-social de construção. Deparamo-nos, deste modo, com várias terminologias como representações sociais dentro da Sociologia e da Psicologia Social, representações culturais dentro da Antropologia, interdiscursividade e dialogismo na Análise do Discurso, esquematização e representação discursiva para a "lógica natural" segundo Grize (1997). Sendo assim, um cerne comum referente à sua construção as coloca em estreita relação: o de processo psico-sociológico desencadeado pela percepção do indivíduo sobre os objetos do mundo e na sua interação com o seu meio social.

Dentro desta perspectiva, as representações são sempre mentais e se apresentam como "pontos de referência" do indivíduo, orientando o agir e o interagir em sociedade. A esse respeito, Jodelet (2003:47) declara que a necessidade do ser humano de fabricar representações se deve ao fato de que:

"Nous avons toujours besoin de savoir à quoi nous en tenir avec le monde qui nous entoure. II faut bien s'y ajuster, s'y conduire, le maîtriser physiquement ou intellectuellement, identifier et résoudre les problèmes qu'il pose [...] Elles nous guident dans la façon de nommer et définir ensemble les différents aspects de notre réalité de tous les jours, dans la façon de les interpréter, statuer sur eux et, le cas échéant, prendre une position à leur égard". (Jodelet, 2003:47)

O fato de "sempre" precisarmos saber à quoi nous en tenir avec le monde qui nous entoure determina um permanente e dinâmico processo de construção e reconstrução de nossas representações, compreendidas como um produto social resultante de um ato tanto individual quanto coletivo na medida em que ele se constrói através da percepção individual (processo cognitivo) e da adesão da coletividade (processo de interação social) que the confere valor real e funcional a fim de que possa orientar a ação:

"Les représentations mentales sont des actes de perception et d'appréciation, de connaissance et de reconnaissance, où les agents investissent leurs 
intérêts et leurs présupposés [...] En tant que processus, la représentation s'intègre dans une dynamique articulée, d'une part sur la structure psychologique de l'individu et d'autre part, sur la structure sociale. De ce fait, une représentation n'est jamais statique, elle évolue avec le sujet, le temps, la société, l'histoire...et est l'objet de modifications périodiques [...] La représentation est un produit social né de l'interaction du sujet avec son environnement social... la représentation traduit l'état de la collectivité qui l'a produite». (AbdallahPretceille, $1996: 29-30$ )

Moscovici (2003: 99-100) salienta, deste modo, o papel fundamental das interações na construção das representações sociais, ao afirmar que uma noção representada não pertence ao indivíduo, pois o que geramos e o que transmitimos é um produto elaborado progressivamente em inumeráveis lugares e de acordo com regras variadas:

" En se représentant une chose ou une notion, on ne se fait pas uniquement ses propres idées et images. On génère et transmet un produit progressivement élaboré dans d'innombrables lieux selon des règles variées. Dans ces limites, le phénomène peut être dénommé représentation sociale. [...] En reconnaissant que les représentations sont à la fois générées et acquises, on leur enlève ce côté préétabli, statique, qu'elles avaient dans la vision classique. Ce ne sont pas les substrats, mais les interactions qui comptent ». (Moscovici, 2003: 99100)

A formação de uma representação social, ou seja, a construção de um sentido comum sobre os objetos do mundo passa, primeiramente, pela objetivação 
destes objetos antes de se estabelecer como tal no seio da comunidade social. Esta objetivação que declina processos dependentes da comunicação e da interação social através da construção seletiva e da esquematização estruturadora do objeto em questão atinge a sua fase final na naturalização que consiste na assimilação coletiva das noções constitutivas do objeto representado, tornando-se, deste modo, referência para se ler o mundo e guiar as práticas sociais (Jodelet ${ }^{20}, 2003: 73$ ):

“Ce processus (d'objectivation) est décomposé en trois phases "construction sélective - schématisation structurante - naturalisation" dont les deux premières, surtout, manifestent [...] l'effet de la communication et les contraintes liées à l'appartenance sociale des sujets sur le choix et l'agencement des éléments constitutifs de la représentation. [...] Contenus et structure sont infléchis par un autre processus, l'ancrage [...]. En amont, l'ancrage enracine la représentation et son objet dans un réseau de significations qui permet de les situer en regard des valeurs sociales et de leur donner cohérence. Mais, à ce niveau, l'ancrage joue un rôle décisif essentiellement en ce qu'il réalise leur inscription dans un système d'accueil notionnel, un déjà-là pensé [...] En aval de la formation représentative, l'ancrage sert à l'instrumentalisation $d u$ savoir en lui conférant une valeur fonctionnelle pour l'interprétation et la gestion de l'environnement [...] La "naturalisation" des notions leur donne valeur de réalités concrètes directement lisibles et utilisables dans l'action sur le monde et les autres.[...] la structure imageante de la représentation devient guide de lecture, et, par

\footnotetext{
${ }^{20}$ Jodelet (2003:73) esclarece que os processos de formação das representações foi ilustrado e enriquecido por vários autores. Ela nos oferece, portanto, o resultado de todos esses estudos.
} 
"généralisation fonctionnelle", théorie de référence

pour comprendre la réalité." (Jodelet, 2003:73)

Em função do seu caráter determinante do comportamento social dos indivíduos, as representações tornam-se, deste modo, passíveis de observação e estudo, como afirma Le Ny (1985:232):

"Telle est bien la voie que la psychologie cognitive a commencé d'explorer, et apparemment avec quelque succès: reconstruire la notion de "représentation" à partir d'inférences basées sur des observables : d'une part les situations et les stimulus [...] d'autre part les comportements et les conduites " (LE NY, 1985 :232)

De acordo com essa abordagem adotada pela psicologia cognitiva, o estudo da noção de representação levará em conta a articulação entre situação/estímulo e comportamentos/condutas partindo do princípio de que a conduta de um indivíduo em determinada situação está submetida a uma certa representação que ele colocou em prática através de várias operações.

A noção de estímulo em Erlich (1985) consistirá no elemento desencadeador, na válvula propulsora de um agenciamento particular de conceitos que, relacionados a outros conceitos, organizarão e construirão um todo significativo, uma representação.

Ao falarmos então de conceitos, entramos na questão das representações semânticas constituídas a partir do processo de ativação, inter-relação, seleção e hierarquização de conceitos definidos por Erlich (1985:287) como um grupo de conhecimentos gerais ou específicos, abstratos ou concretos, relativos a um objeto, um acontecimento, um personagem, uma ação, uma qualidade [...] pertencente ao universo físico, biológico ou social, real ou imaginário do indivíduo.

A representação semântica é assim definida por Erlich (1985:286) como:

«[...] un arrangement particulier de concepts momentanément actifs. Le message, les 
événements auxquels il réfère ainsi que toutes les stimulations contextuelles externes, fournissent des informations au sujet et régulent la construction des représentations ». (Erlich, 1985:286).

Tais operações cognitivas de ativação, inter-relação, seleção e hierarquização de conceitos estarão, pois, condicionadas à experiência e ao conhecimento do indivíduo traduzidos na sua capacidade de realizar combinações conceituais a fim de expandir o campo nocional dos elementos representados. Isto tornará possíveis ativações posteriores que adquirirão o estatuto de pré-construídos, isto é, de um bloco conceitual que funciona como uma totalidade associativa.

Dentro da Análise do Discurso, a noção de pré-construído está estreitamente relacionada, assim como a noção de representação, à de interdiscursividade e dialogismo. Um pré-construído denota assim o traço de discursos anteriores, opondo-se ao que é construído no momento da enunciação:

"La notion de préconstruit, élaborée par P. Henry (1975), puis développée dans M. Pêcheux (1975) est une reformulation des théories de la présupposition d'O. Ducrot. Le préconstruit peut être approché comme la trace, dans l'énoncé, d'un discours antérieur; il s'oppose donc à ce qui est construit au moment de l'énonciation [...] La notion de préconstruit est étroitement liée à celle d'interdiscours* : elle contribue à déstabiliser l'opposition entre l'extérieur et l'intérieur d'une formation discursive* au profit de la notion d'intrication entre discours, et de relations à d'autres formations discursives extérieures et antérieures qui entrent dans le discours d'un sujet." (Dictionnaire d'Analyse du Discours, 2002 :464)

De acordo com Maingueneau (2000:114), o termo pré-construído é por vezes utilizado, dentro da Análise do Discurso, de maneira mais vaga, sendo empregado 
para designar qualquer conteúdo admitido numa coletividade, interferindo, desta forma, com termos como "preconceitos", "estereótipos, "topoi", "scripts" etc.

Grize (1997:30) descreve a noção de pré-construídos culturais (PCC) considerando duas dimensões em torno da palavra. Uma primeira dimensão nos remete aos elementos estáveis de um conceito ou noção e pressupõe a existência de um núcleo de sentido comum ativado pelos membros de uma mesma comunidade lingüística; e uma outra que releva do conhecimento enciclopédico dos participantes da ação de comunicação.

Os PCC de Grize compõem um dos elementos da sua teoria da esquematização, elaborada dentro do quadro da "lógica natural"21", em sua obra fundadora Logique et Langage (1997). Dentro desta teoria, a noção de representação desempenha um papel importante para a análise da interação verbal, visto que ela é mobilizada, assim como os PCC, no processo de construção de uma esquematização ou representação discursiva.

A noção de esquematização ou representação discursiva proposta por Grize (1997) consiste num processo de construção e reconstrução permanente do discurso em função das representações que os interlocutores têm sobre si mesmos, sobre o seu destinatário, sobre o referente e sobre a situação de comunicação. Estas representações orientarão a elaboração do discurso segundo as intenções comunicativas dos interlocutores. A atividade discursiva se caracteriza, desta maneira, como uma atividade dialógica permeada de ajustes constantes de sentidos.

A linguagem, neste caso, constitui uma das formas de manifestação destas representações, e de acordo com as mesmas noções veiculadas pelas representações sociais, atualiza-se somente na prática social.

As ações de linguagem ${ }^{22}$ são, desta maneira, dependentes dos elementos constituintes da atividade discursiva, ou seja, do estatuto social dos interlocutores, de suas intenções comunicativas e, evidentemente, das representações que têm sobre si mesmos, sobre o destinatário e sobre o referente, como declara Bronckart (1987:41):

\footnotetext{
${ }^{21}$ Grize (1997:65) define a "lógica natural" como l'étude des opérations logico-discursives qui permettent de construire et de reconstruire une schématisation.

${ }_{22}$ Segundo o Dictionnaire d'Analyse du Discours (2002:25), o termo action langagière, defendido por Bronckart no quadro do interacionismo sócio-discursivo, não se refere a uma entidade de ordem lingüística. Este termo recebe duas definições correspondentes a dois pontos de vista distintos: sociológico e psicológico. Do ponto de vista sociológico, a ação de linguagem compreende a atividade de linguagem do grupo, recortada pelo mecanismo geral das avaliações sociais e imputada a um organismo humano singular. Do ponto de vista psicológico, ela compreende o conhecimento, disponível no organismo ativo, das diferentes facetas de sua própria responsabilidade na interação verbal. (tradução nossa).
} 
"Si elles sont socialement orientées, les actions langagières [...] constituent aussi des comportements observables, ancrés dans une réalité matérielle: elles émanent d'un agent concret, [...] producteur ou lecteur, et elles sont émises à un moment et à un lieu donnés (espace-temps de la production), éventuellement en présence d'autres agents potentiels (co-producteurs ou interlocuteurs) » (Bronckart, 1987:41)

Logo, o sujeito enunciador procede a uma leitura desta cena discursiva em função da qual ele construirá o seu discurso.

Porém, Bronckart (1987:46-47) ressalta que o contexto social e material não intervém direta e mecanicamente na ação de linguagem. A sua influência é exercida sobre as produções de linguagem de acordo com o que o "agente" ativo conhece dele:

"L'action langagière est donc articulée à son
contexte social par l'intermédiaire des
représentations que l'agent s'est constituées dans sa
pratique des rapports sociaux, c'est-à-dire par la
connaissance propre qu'il a développée à l'égard
des valeurs de chacun des paramètres disponibles
dans le groupe à un moment de son histoire. C'est
par rapport à ces représentations de l'acte de
production que se prend la décision discursive
essentielle "(Bronckart, $1987: 46-47$ )

Acrescentando ao que Bronckart declara sobre o papel das representações para a escolha discursiva, Grize $^{23}$ ressalta que não podemos garantir que o nosso interlocutor reconstruirá, através do nosso discurso, as mesmas representações que temos, visto que ele mobiliza as suas próprias representações sobre todos os

${ }^{23}$ Op.cit. 
elementos que constituem o discurso. É aí que reside a riqueza de construção de sentidos na comunicação:

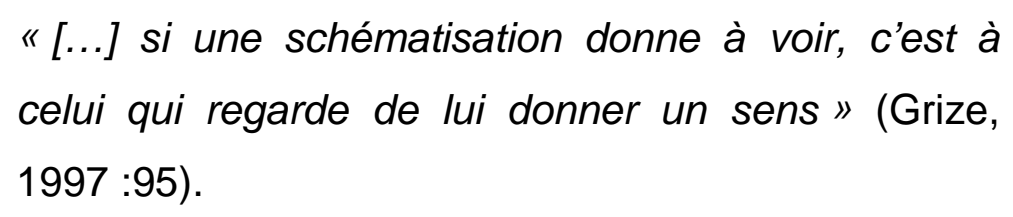

\section{b. As representações discursivas}

Ao falarmos sobre representações discursivas, primeiramente nos parece importante definirmos o que entendemos por discurso. Para isso, nos serviremos da definição proposta pelo Dictionnaire d'Analyse de Discours (2002:186) que compreende o discurso como a marca de um ato de comunicação sóciohistoricamente determinado.

Enquanto marca de um ato, ele possui traços que the são inerentes, descritos por Maingueneau (1998:38-41) da seguinte maneira:

- Le discours est une organisation au-delà de la phrase : il est soumis à des règles d'organisation en vigueur dans un groupe social déterminé [...]

- Le discours est orienté : parce qu'il est conçu en fonction d'une visée du locuteur et parce qu'il se développe dans le temps, de manière linéaire; il se construit en fonction d'une fin, mais il peut dévier en cours de route, revenir à sa situation intiale, changer de direction [...]

- Le discours est une forme d'action: toute énonciation constitue un acte qui vise à modifier une situation [...] et qui s'intègre dans des discours d'un genre déterminé [...] qui visent à produire une modification sur des destinataires ;

- Le discours est interactif : [...] toute énonciation, 
même produite sans la présence d'un destinataire, est prise dans une interactivité constitutive (dialogisme), elle est un échange, explicite ou implicite, avec d'autres énonciateurs, virtuels ou réels [...]

- Le discours est contextualisé : le discours contribue à définir son contexte, qu'il peut modifier en cours d'énonciation [...]

- Le discours est pris en charge par un sujet: qui indique qui est le responsable de ce qui est dit ;

- Le discours est régi par des normes : toute acte d'énonciation ne peut se poser sans justifier d'une manière ou d'une autre son droit à se présenter tel qu'il se présente ;

- Le discours est pris dans son interdiscours : le discours ne prend sens qu'à l'intérieur d'un univers d'autres discours à travers lequel il doit se frayer le chemin [...]. (Maingueneau, $1998: 38-41$ )

O discurso compreendendo uma organização, uma orientação em função de um objetivo de comunicação e de um destinatário, dependente da interação entre os dois agentes da ação comunicativa de acordo com um contexto para que os sentidos sejam construídos, e que se apresenta de forma heterogênea em função de discursos outros que the compõem implica, desta maneira, operações cognitivas e de linguagem inteiramente dependentes da interação social para que se constitue efetivamente na marca de um ato de comunicação sócio-historicamente determinado (Dictionnaire d'Analyse du Discours, 2002:186).

A intricação entre as operações cognitivas e de linguagem resultará, de acordo com FALL e alii (2005:33-34), em quatro operações de discurso: a de seleção, onde o enunciador escolherá e selecionará os objetos do seu discurso; a de caracterização que consiste na atribuição de propriedades ou características feitas a tais objetos e que determinarão (operação de determinação) a sua existência enquanto tal através de um jogo de integração ou exclusão de propriedades (fronteiras de sentido); e finalmente, as operações de julgamento que operam sobre 
as representações visando à generalidade para a compreensão de um fato, de uma situação ou de uma noção.

Ao considerarmos o discurso como a marca de um ato de comunicação que implica as operações acima citadas, compreendemos melhor a noção de representação discursiva desenvolvida por Grize $^{24}$ (1997) de acordo com os princípios da "lógica natural", a qual ele denominou esquematização. A esquematização consiste, como dito no capítulo anterior, na construção de um micro-universo ${ }^{25}$ representativo da situação de comunicação e interação verbal. Dentro deste micro-universo construído, os interlocutores representam ou esquematizam o seu discurso em função de suas representações sobre o referente e sobre si mesmos:

" [...] tout locuteur construit un micro-univers à l'intention du destinataire; il ne dit pas tout mais schématise ce qu'il veut dire en fonction des représentations qu'il se fait de l'autre, de lui-même et du thème dont il parle, ce qui s'inscrit dans la matérialité verbale sous forme d'images (image que le locuteur donne de lui-même, image qu'il donne de l'autre, image qu'il donne du thème" (Moirand ${ }^{26}$ )

Segundo Grize (1997:35), a esquematização é criadora de sentidos, e esta criação de sentidos se faz face a um interlocutor e lhe é destinada. Entretanto, ela também é uma questão de diálogo (1997:37), ou seja, de negociação e de reconstrução de sentidos por parte dos interlocutores na interação verbal.

Um outro elemento constitutivo do processo de esquematização é os préconstruídos culturais (PCC), citados no capítulo anterior. Esta idéia de que a palavra comporta duas dimensões, uma referente ao seu noyau dur, isto é, os sentidos

\footnotetext{
${ }^{24}$ Op.cit.

${ }^{25}$ Grize (1997:36) emprega o termo micro-univers para explicitar a idéia de esquematização como resultado de um processo.

${ }_{26}$ Esta definição de esquematização é dada por Moirand num pequeno glossário oferecido aos estudantes de Master 2 Recherche da École Doctorale: Langage et Langues: Descriptions, Théorisation, Transmission (ED 268), UFR Didactique du Français Langue Étrangère, da Université Paris 3 - Sorbonne Nouvelle.
} 
dicionarizados, e uma outra dependente do conhecimento de mundo dos participantes, estabelece uma estreita relação com as representações sociais:

«L'emploi d'une langue naturelle fait que les signes utilisés ont toujours déjà un sens. Même si les mots de la langue renvoient à des notions, chacun d'eux possède un noyau suffisamment commun pour permettre la communication. Je n'exprime pas la même pensée - et mon interlocuteur le sait - si je parle de «chat » ou si je parle de «chien ». Or, ce qui est remarquable, c'est que non seulement ce sens est préconstruit, mais qu'il est encore de nature culturelle » (Grize, $1997: 30)$.

No processo de esquematização, os PCC serão mobilizados pelos interlocutores no ato de seleção dos traços mais pertinentes de um conceito para a construção dos sentidos desejados a fim de atingir seus objetivos de comunicação:

«Toute manipulation de mots a pour effet d'en aménager le sens [...] l'aménagement du sens est fonction de la finalité de $A$ (o locutor). Il s'agira donc, d'une part, de sélectionner dans le noyau dur des mots les traits qui vont concourir à l'effet souhaité et, d'autre part, de les accompagner d'aspects nouveaux dont on espère qu'ils vont contribuer au résultat »(Grize, 1997 :35).

Bakhtine (1929:123-124) nos lembra da importância da atualização dos sentidos das palavras dentro do contexto e pela interação social:

«Le mot s'adresse à un interlocuteur [...] Cette orientation du mot en fonction de l'interlocuteur a une grande importance. En fait, tout mot comporte deux faces. Il est déterminé tout autant par le fait qu'il 
procède de quelqu'un que par le fait qu'il est dirigé vers quelqu'un. II constitue justement le produit de l'interaction du locuteur et de l'auditeur. [...] Le mot est une sorte de pont jeté entre moi et les autres. S'il prend appui sur moi à une extrémité, à l'autre extrémité il prend appui sur mon interlocuteur. Le mot est le territoire commun du locuteur et de l'interlocuteur » (Bakhtine, 1929 :123-124).

De acordo com Bakhtine (1929:124), o locutor somente é o único mestre incontestável da palavra no instante do ato fisiológico de sua materialização, pois, a partir do momento de sua interação com o interlocutor ele a possui pela metade.

Deste modo, a marca da interação social e verbal é evidenciada na atividade discursiva por uma série de ajustes de sentido operada pelos interlocutores dentro da situação de comunicação, o que contribuirá à construção dos objetos de discurso definidos, de acordo com a "lógica natural", como:

«[...] des entités [...] actualisées dans les textes par des expressions nominales et qui, en fonction $d u$ caractère dynamique de la schématisation, sont susceptibles d'être reformulées, enrichies ou simplifiées, au fil du discours. [...] Certains éléments du faisceau d'un objet sont préconstruits, d'autres sont transformés ou construits dans le discours " (Dictionnaire d'Analyse du Discours, 2002 :406).

No mesmo sentido, Pietraróia (2001:22) afirma que:

"A linguagem transforma representações do mundo em representações verbais, ou seja, faz dos objetos e fatos representações que se constituem em objetos de discurso e adquirem com isso um estatuto de referente" (Pietraróia, 2001:22). 
Em resumo, os princípios básicos da representação discursiva estão calcados, de acordo com Grize, na esquematização da cena discursiva realizada em função das representações que um locutor mobiliza em relação ao seu interlocutor, ao referente e à situação de interlocução, lembrando-nos sempre que toda esquematização é parcial, pois compreende um ato dialógico.

Deste modo, Fall e alii (2005:26) nos descreve quatro funções inerentes a todo discurso. A primeira compreende tanto a escolha dos objetos de discurso quanto a maneira de apresentá-los. A segunda diz respeito à leitura feita pelo enunciador de tais objetos, processo esse realizado através da atribuição de propriedades e de determinações de existência. A terceira função se caracteriza pela construção do objeto em função dos esquemas locais, ligando-se à quarta pela necessidade de um permanente processo de releitura e reconstrução das propriedades de tais objetos de discurso decorrentes da interação social.

O nosso objetivo daqui para frente é demonstrar como o discurso constrói representações do Outro a partir da atribuição de propriedades feitas pelo enunciador ao seu objeto, ou seja, a partir das operações de designação e caracterização.

\section{c. A construção das representações interculturais pelo discurso : 0 Brasil na imprensa francesa.}

A fim de demonstrarmos a importância da construção de representações dentro do processo de ensino-aprendizagem do francês língua estrangeira e como estas representações influenciam as relações com membros de outras culturas, optamos por analisar artigos sobre o Brasil publicados na imprensa francesa. O nosso intuito é o de apresentar os perigos do olhar redutor que possamos dar a uma outra cultura. Acreditamos que a melhor forma de demonstrar isso é confrontar as representações que os brasileiros têm de si mesmos às representações que o Outro constrói sobre o Brasil e o seu povo.

Falar sobre a construção das representações do Brasil na imprensa francesa nos conduz a estabelecer algumas características da nossa fonte. Para isso, nos servimos da obra de Pierre Albert, La Presse Française (Paris: 2004, col. Les études de la documentation française), publicada pela editora La documentation Française. 
A imprensa escrita na França existe há mais de três séculos e se apresenta solidamente estabelecida entre os meios de comunicação de massa deste país, embora tenha que enfrentar, como todas as outras imprensas no mundo, a concorrência crescente da internet. De acordo com Albert (2004:29), a imprensa continua a ser, mesmo assim, o primeiro suporte publicitário na França, recebendo $49,6 \%$ dos investimentos "grandes mídias", estando à frente da televisão $(30,7 \%)$ et da rádio $(7,5 \%)$.

No que se refere às estatísticas sobre o número de leitores (os dados apresentados por ele provêem do Insee ${ }^{27}$ ), $28 \%$ dos indivíduos com idade superior a 15 anos lêem irregularmente um quotidiano nacional contra $63 \%$ de um quotidiano regional (50\% revista de informações gerais). Em contrapartida, o consumo de revistas quase se equipara ao do audio-visual: $96 \%$ dos Franceses com mais de 15 anos lêem aproximadamente sete por semana (dados apresentados por Albert de acordo com a AEPM/2002 ${ }^{28}$ ), e destinam, em média, 35 minutos à leitura, sendo que quase a metade deste tempo é destinada à leitura de um quotidiano (dados de 2002 recolhidos pelo autor junto à Médiamétrie).

Em relação aos leitores da imprensa francesa, Albert (2004:109) declara que a leitura deste ou daquele jornal, desta ou daquela revista, continua sendo uma escolha subjetiva, e por esta razão, difícil de ser interpretada e diagnosticada. Sendo assim, ele declara que:

"Les rapports entre la presse et ses lecteurs sont mal connus. Leur nature échappe à l'analyse objective, tant sont variables, selon les individus, les organes et l'actualité du moment, les motivations et les modalités de lecture. Quant à mesurer les effets de cette dernière, outre la diversité et la complexité des réactions individuelles, on voit mal comment on pourrait isoler l'influence de la presse de tous les autres facteurs qui agissent sur les attitudes et l'opinion des lecteurs. En réalité, ni la connaissance

\footnotetext{
${ }^{27}$ INSEE - Institut National de la Statistique et des Études.

${ }^{28}$ AEPM - Audience et Études de Presse Magazine.
} 
empirique, quasi intuitive, que les professionnels de l'information ont des attentes ou des réactions de leurs clients, ni les résultats obtenus par enquête sur le comportement et les goûts des lecteurs ne permettent d'éclairer l'ensemble des liens qui les attachent à "leur " journal ou à «leur » magazine. La lecture de la presse est autant affaire d'habitudes acquises que de choix déterminé, comme le journalisme est autant le produit de recettes que d'improvisation face à l'événement. La lecture de la presse est irréductiblement individuelle: chacun choisit son périodique, le feuillette, ne lit ou ne regarde, avec une attention très variable, que ce qui correspond à ses goûts, à ses intérêts ou à sa curiosité du moment; chacun réagit en fonction de ses conceptions morales, politiques ou culturelles. $[\ldots] \gg$ (Albert, $2004: 109$ )

De acordo com Albert, a dificuldade em se explicar a preferência do leitor por este ou aquele periódico reside no fato de que a leitura enquanto ato individual está submetida a gostos e interesses variados. Se o que está em jogo é somente o gosto e o interesse particular de cada um, nada impediria que o leitor interessado em moda comprasse indiferentemente tanto Claudia, quanto Marie Claire, ou Vogue (se não fosse pelo preço) ou qualquer outra revista do gênero. Perguntamo-nos, então, o que levaria o leitor frente a uma gama de periódicos a sua disposição a escolher ou assinar este ou aquele? Como explicar a necessidade crescente das empresas de comunicação de se diferenciar da concorrência a fim de fidelizar o seu leitorado e conquistar novos leitores? Parece-nos importante ressaltar dois pontos passíveis de influenciar o leitor em suas escolhas por tal ou tal periódico, além de seus gostos e interesses pessoais. O primeiro diz respeito ao lugar social, à imagem ou representação que ele faz de si mesmo e da fonte escolhida. O segundo diz respeito à relação de identificação que se estabelece entre ambos, leitorado e fonte, decorrente da ideologia que subjaz em cada organismo de imprensa. 
Sendo assim, partindo do princípio que um texto sempre é destinado a alguém, o discurso dirigido a esse leitorado é construído com bases nas representações que o emissor constrói deste público virtual. Em contrapartida, o destinatário deposita mais ou menos confiança naquilo que lê em função das representações que ele possui da fonte ou do emissor, o que pode influenciar as possíveis leituras de um documento:

"Le type de relations et/ou surtout les représentations que le lecteur se fait à propos $d u$ scripteur (et donc de ses intentions) influent sur les lectures possibles du document". (Moirand, $1979: 11)$

Desta maneira, as relações entre leitor e emissor são dialógicas e, o papel do primeiro como co-enunciador se mostra de fundamental importância na construção dos sentidos de um texto. Parece-nos importante estabelecer aqui a diferença feita entre o leitor interactante, ou seja, aquele que co-constrói sentidos, e o leitoradodestinatário de um dado discurso, identificado e caracterizado de acordo com a idade, o sexo, a cidade onde mora, o grupo social ao qual pertence, etc (Dictionnaire d'Analyse du Discours, 2002:338). Inserimos, portanto, a nossa concepção de leitor dentro de uma perspectiva dialógica de (re)construção de sentidos, como afirma Grize (1997:92):

"[...] pour qu'il y ait sens, il est nécessaire de postuler une double activité, celle du locuteur d'une part et celle du locuté [...]. Le locuteur propose ${ }^{29}$ des signes dans l'intention de faire sens et le locuté leur donne sens » (Grize, $1997: 92)$.

O papel do leitor na co-construção de sentidos de um texto reside, desta forma, tanto na recepção, quanto no acordo e na adesão ao que está sendo dito:

\footnotetext{
${ }^{29}$ Grifos nossos.
} 
"Recevoir, c'est être disposé à reconstruire la schématisation et être en état de le faire. Accorder, c'est ne pas avoir d'objections à présenter et adhérer, c'est faire sienne la schématisation. [...] L'adhésion demande plus que la non-objection, elle réclame une participation entière de l'interlocuteur [...] Je dirai déjà qu'il ne s'agit plus d'éviter des contre-discours (por parte do leitor), mais qu'il faut en quelque sorte provoquer des "pro-discours »" (Grize, $1997: 41-45)$.

Entretanto, algumas competências se apresentam como base para a construção de sentidos pelo leitor. Grize (1997:94) se serve da distinção de quatro tipos proposta por $\mathrm{C}$. Kerbrat-Orecchioni: a primeira diz respeito a sua competência lingüística, ao seu conhecimento da língua; a segunda refere-se à competência enciclopédica que se traduz em seu conhecimento de mundo; a terceira relaciona-se à competência lógica para a dedução e a inferência e, por fim, a competência retórico-pragmática que não se apresenta independente das três primeiras e que se manifesta no exercício mesmo do discurso.

Ao considerarmos a necessidade de mobilização dessas competências para a construção de sentidos, inferimos que as leituras possíveis de um texto estão condicionadas à capacidade do leitor de fazê-las interagir e ao nível de desenvolvimento dessas competências em cada um. "Autant de lecteurs, autant de lectures possibles."

\section{O momento discursivo : O Ano do Brasil na França}

De acordo com o Dictionnaire d'Analyse de Discours (2002 :389), o momento discursivo se caracteriza por uma grande produção discursiva, na mídia, em torno de um acontecimento. Este momento discursivo que foi o "Ano do Brasil na França" nos permitiu, deste modo, constituir um corpus heterogêneo no que diz respeito aos gêneros de discurso com vistas a estudar a emergência das representações do Brasil na imprensa francesa observada a partir das operações de designação e caracterização deste objeto do discurso. Servi-mo-nos, portanto, de um primeiro 
corpus exploratório composto de trechos de jornais e revistas publicados pela imprensa regional e nacional, assim como de três artigos na íntegra das revistas bimestrais Ulysse Télérama e Match du Monde, e da revista mensal Vibrations dos quais propomos uma análise mais detalhada sobre como as representações (no caso, as representações do Brasil) podem ser construídas pelo discurso.

"Brésil, Brésils". Tal é a divisa que celebrou o ano do Brasil na França, aberto oficialmente em 22 de março de 2005, tendo sido organizado pelo Ministério da Cultura, pelo Ministério das Relações Exteriores e pelo Comissariado Brasileiro, no Brasil, e pelo Ministério da Cultura e da Comunicação, pelo Ministério das Relações Exteriores (Ministério des Affaires Etrangères) e pelo Comissariado Francês, na França. Como divulgado na própria imprensa francesa, a intenção foi a de homenagear o país de várias faces ou facetas, o país mestiço, o país plural, buscando ultrapassar os clichés e celebrar os antigos laços de amizade que une essas duas nações ( www.culture.gouv.fr : conferência do lançamento do ano do Brasil):

1) «2005, année do Brazil » «[...] à l'honneur, en effet, de l'événement baptisé Brésil, Brésils, la diversité des cultures de ce pays, nourri depuis longtemps par l'immigration. Indiens, Portugais, peuples d'esclaves africains, Italiens, Français, Hollandais, Allemands, Turcs, Libanais, Japonais (...) ont apporté leur culture, leur religion, leur langue, donnant naissance à une société brésilienne plurielle » (La Dépêche - 18/01/05)

2) “2005, l'année de tous les «Brésils " en France. Une saison «à trois temps », chatoyante et bariolée » (France-Antilles - jornal diário do interior - 19/01/05)

3) “Les Brésils passent l'année en France: Après les festivités de l'année de la Chine, la France change de cap. Tout au long de l'année, à travers le pays, on va découvrir le Brésil, ou plutôt les Brésils. Pour tailler dans certains clichés » (Ouest France - jornal diário do interior - 21/01/05)

4) “Accents du Brésil au musée d'Art Naïf : Dans le cadre de la saison culturelle “Brésil, Brésils " consacrée en France, le musée international d'art naïf présente une exposition temporaire intitulée «Accents du Brésil ». Le Brésil, par son étendue, la complexité de son histoire et les nombreuses influences dues à la multitude 
d'ethnies présentes sur le territoire offre une culture plurielle et métissée dont l'art naïf constitue un des éléments [...] 》 (Revista semanal do interior da França - Le Courrier des Yvelines Ed. Saint Germain - 28 /01/05)

5) “L'Année de tous les Brésils » Rio entre en Seine - Cinq cents journalistes étaient présents à la conférence de presse de l'Association française d'action artistique pour le lancement de la saison "Brésil, Brésils », au Quai d'Orsay. C'est un record! Et vous pouvez vous attendre à être gavé de thèmes brésiliens tout au long de l'année. Mais si vous associez uniquement le Brésil à ces déesses en string 365 jours par an, lascivement allongées sur la plage de Copacabana, il vous faut abandonner tous vos a priori et plonger dans le programme qui vous attend. Vous verrez comment 182 millions d'habitants pratiquent une fascinante culture à trois temps » (Revista Mensal Paris Capitale - 15 de fevereiro à 15 de março de 2005)

6) "Le Brésil colore la France: De mars à décembre, la France se met aux couleurs du Brésil. L'occasion d'oublier les clichés et de partir à la découverte d'une culture impressionnante de diversité » (Revista Mensal TGV, Março de 2005)

O programa elaborado em torno de três temas centrais privilegiou as "Raízes do Brasil", indígenas e africanas, a "Verdade Tropical" relacionada à variedade musical, à diversidade cultural, o meio ambiente e a cidadania, e por fim, "Galáxias" representando e apresentando a dança, o teatro e as artes plásticas. A partir deste dado, buscamos, primeiramente, na imprensa francesa, as publicações que, de certa maneira, procuraram apresentar artigos que correspondessem ao programa em questão.

As três revistas nacionais que compõem o quadro abaixo (Ulysse Télérama e Match du Monde - revistas bimestrais; L'Express - revista semanal) publicaram dossiês sobre o Brasil no mês de março de 2005. A partir do sumário dos artigos, procedemos a uma classificação dos temas abordados em: "Cidades ou Estados representando o Brasil", "Personalidades Brasileiras", "Artes", "Contrastes e Problemas Sociais" e "História", através dos quais pudemos identificar uma concentração de artigos centradas em torno das regiões Norte, Nordeste e Sudeste do país: 


\begin{tabular}{|c|c|c|c|}
\hline \multicolumn{4}{|c|}{ Temas abordados nas revistas Ulysse Télérama, Match du Monde, L’Express } \\
\hline \multirow{6}{*}{ 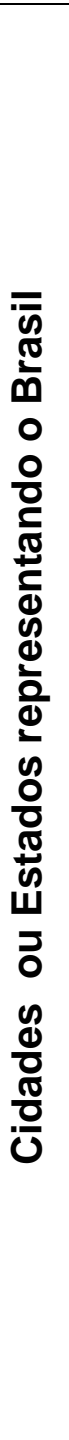 } & Ulysse Télérama & Match du Monde & L'Express \\
\hline & $\begin{array}{l}\text { Carnet de Voyage à } \\
\text { Rio }\end{array}$ & $\begin{array}{l}\text { La religion du corps } \\
\text { Rio : la « cidade maravilhosa » } \\
\text { ouvre les portes de l'aventure } \\
\text { dans un pays chatoyant et } \\
\text { métissé }\end{array}$ & $\begin{array}{l}\text { Les très riches heures } \\
\text { de Rio }\end{array}$ \\
\hline & Que linda Olinda! & $\begin{array}{l}\text { Au cœur du Minas } \\
\text { incandescent }\end{array}$ & $\begin{array}{l}\text { Mato Grosso, les } \\
\text { aventures de l'or vert }\end{array}$ \\
\hline & $\begin{array}{l}\text { Parati, voie royale } \\
\text { vers l'Eldorado }\end{array}$ & & \\
\hline & $\begin{array}{l}\text { A Cachoeira, } \\
\text { bacchanale avec les } \\
\text { Dieux }\end{array}$ & & \\
\hline & $\begin{array}{l}\text { Bahia de toutes les } \\
\text { musiques }\end{array}$ & & \\
\hline & $\begin{array}{l}\text { Brasilia, vue par } \\
\text { Oscar Niemeyer }\end{array}$ & & \\
\hline \multirow{4}{*}{ 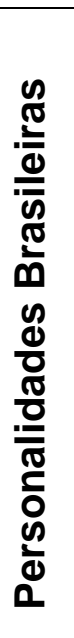 } & Niemeyer & $\begin{array}{l}\text { Niemeyer, le génie des } \\
\text { courbes : rencontre avec le } \\
\text { célèbre architecte de } 96 \text { ans }\end{array}$ & $\begin{array}{l}\text { Deux voix pour le } \\
\text { Brésil : Cristiana Reali } \\
\text { et Gilberto Gil }\end{array}$ \\
\hline & & $\begin{array}{l}\text { Génération Senna : dix ans } \\
\text { après la mort du champion, sa } \\
\text { famille reprend le flambleau }\end{array}$ & Abílio Diniz \\
\hline & & $\begin{array}{l}\text { Allez Lula ! Dans l'intimité du } \\
\text { «président des pauvres » }\end{array}$ & $\begin{array}{l}\text { Lula, comme Pelé, } \\
\text { est un mythe vivant }\end{array}$ \\
\hline & & Gisele Bündchen, la femme la & Fernando Henrique \\
\hline
\end{tabular}




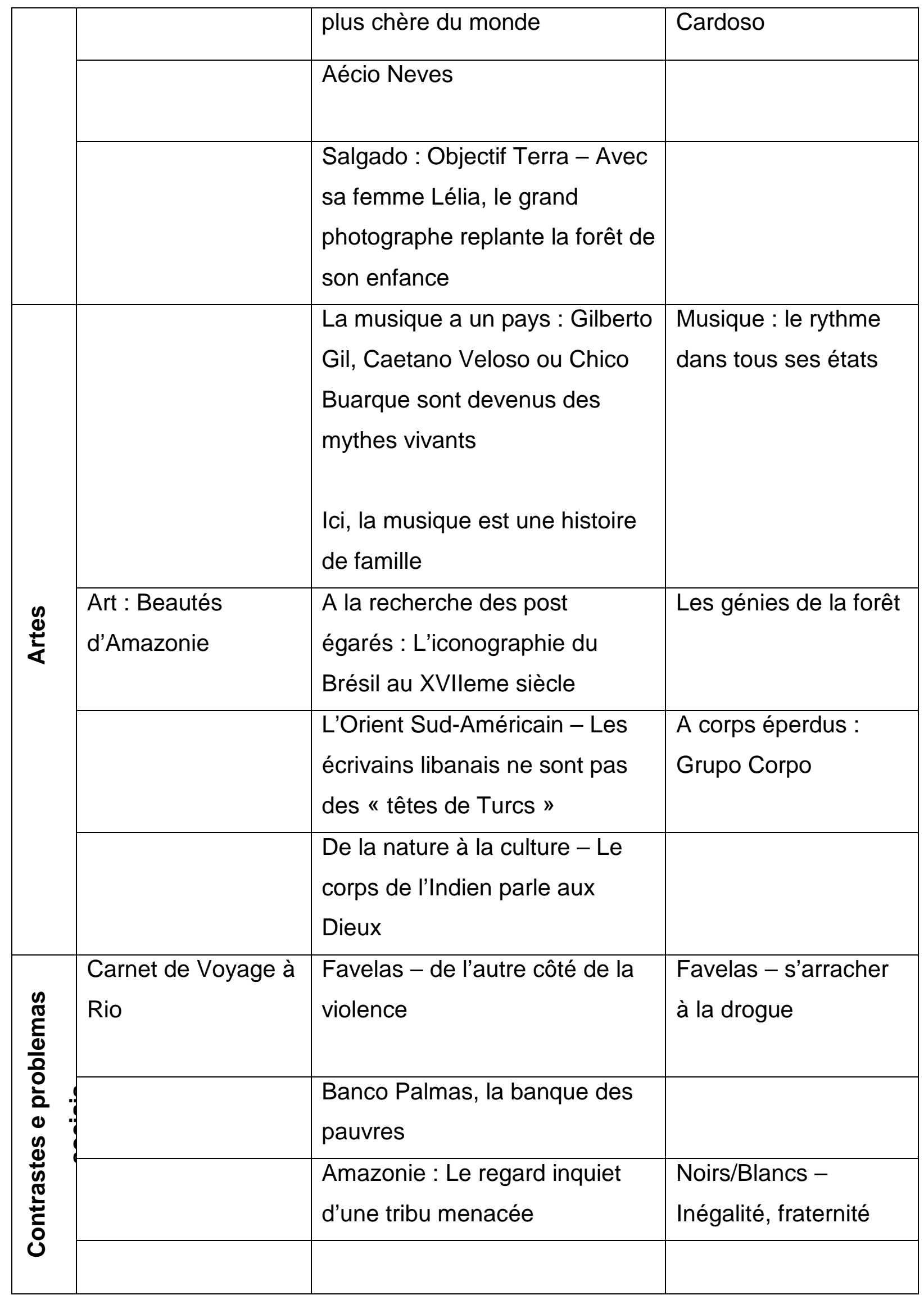




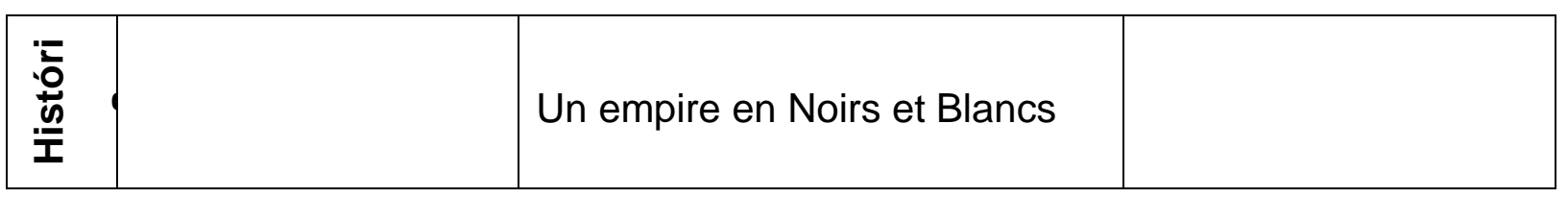

No que se refere às cidades ou Estados representanto o Brasil nestas três revistas, verifica-se a inexistência, nas revistas Ulysse Télérama e L'Express, de artigos sobre a cidade ou o Estado de São Paulo, maior pólo econômico do país, sendo que a revista Match du Monde apresenta somente uma legenda de foto da cidade de São Paulo. Da mesma maneira, os Estados do Sul não ocuparam nenhuma página destas três revistas.

Em relação à produção musical, teremos uma concentração dos ritmos do samba carioca, dos ritmos baianos, da bossa-nova e das novas vozes do Brasil, como Maria Rita, Lenine, Seu Jorge, entre outros. Nas artes, prevalecerá o artesanato indígena cuja escolha pode ser interpretada como uma introdução a esse universo artístico decorrente da proximidade da inauguração da exposição que abriria o Ano do Brasil na França, Les Arts des Amérindiens.

O objetivo de verificar a hipótese (levantada a partir da análise do sumário dessas três revistas) de concentração de publicações sobre as regiões Norte, Nordeste e Sudeste em outros periódicos se deve ao fato de que, se concentração houve, tais regiões passam a representar o Brasil como um todo. A escolha dos editores consistiria, deste modo, em uma primeira representação do país, evidenciada na seleção dos elementos que eles julgaram os mais representativos para mostrar as várias faces do Brasil.

A partir das pesquisas realizadas junto às revistas de imprensa elaboradas pela Associação Francesa de Ação Artística (AFAA - www.afaa.asso.fr) dentro do período de janeiro à março de 2005, selecionamos títulos e sub-títulos de jornais e revistas se referindo ao "Ano do Brasil na França", assim como trechos de alguns artigos, notas, etc. Esta seleção nos possibilitou igualmente a identificação de representações recorrentes do Brasil, isto é, de alguns clichés que, segundo as próprias intenções dos promotores do "Ano do Brasil na França", não deveriam fazer parte do programa, pois um dos objetivos dessa homenagem era o de retratar a pluralidade e a riqueza de um país além dos estereótipos. 
Dos trinta trechos selecionados entre os vários periódicos (de moda, gastronomia, decoração, música, informativos, etc), 43,3\% se servem dos clichés, dentre os quais o samba, o carnaval, as praias e a beleza das mulheres brasileiras; $33,3 \%$ fazem referência às regiões Norte, Nordeste e Sudeste a partir dos Estados e cidades do Rio de Janeiro, da Bahia, do Recife e do Rio Grande do Norte, assim como dos elementos característicos dessas regiões (ritmos, arquitetura, natureza, dança) (somente 1 cita a cidade de Florianópolis, mas, ao mesmo tempo, refere-se ao samba e à beleza das mulheres dessa cidade); e 33\% designam e caracterizam o Brasil a partir de sua dimensão territorial, dos seus contrastes socias ou da sua mestiçagem.

Nesses trechos, o Brasil é designado e caracterizado como:

1) ce pays-continent (Le Figaro, 31/01/05)

2) géant sud-américain (L'Humanité, 25/01/05)

3) [...] un pays de la taille d'un continent. Avec une superficie égale à seize fois celle de la France, [...] un véritable foisonnement de paysages, d'atmosphères, de cultures (Figaro Madame, 22/01/05)

4) cet étonnant pays (Piano Magazine, revista bimestral - janeiro/fevereiro de 2005)

5) ce pays contrasté (L'Hebdo Le Monde des Ados, revista semanal, 29/12/04 à 04/01/05).

6) le plus grand pays de l'Amérique Latine (Femme Actuelle, seção multimédia, 03/01 à 09/01/05)

7) un pays de 176 millions d'habitants, aux inégalités criantes (Pèlerin Magazine, 30/12/04 à 05/01/05)

8) ce pays dont le prince est un ouvrier (Pèlerin Magazine, 30/12/04 à 05/01/05)

9) Un gigantesque kaléidoscope culturel (Le Quotidien, 19/01/05, imprensa regional)

10) ce pays aux mille rêves (Midi Libre, 04/02/05)

11)[...] "Brésil, Brésils, le programme de l'Année du Brésil en France, se veut multiculturel, créatif et festif. [...] (L'Echo Touristique, 18/02 à 24/02/05)

12) ce grand pays dont le potentiel reste à découvrir (L'Echo Touristique, $18 / 02$ à 24/02/05) 
13) I'un des pays les plus envoûtants de la planète (Paris Match, 17/02 à 23/02/05)

14) Seize fois la surface de la France, cent quatre-vingts millions d'habitants, deuxième exportateur mondiale de produits agricoles (L'Humanité, 25/03/05 - nota sobre a difusão do programa na rede de televisão francesa France 2, às 22h40).

15)un pays sur lequel beaucoup de clichés sont encore entretenus (L'Humanité, 25/03/05 - idem)

16) ce pays « émergent » (L'Humanité, 25/03/05 - idem)

17) ce pays merveilleux (Point de vue, 09/03 à 15/03/05 - seção sobre os acontecimentos da semana «Quelle semaine!»)

Os clichés são recorrentes :

1) Prévisions 2005 - Les temps forts de 2005 [...] Le Brésil : La France vivra au rythme de la samba et du carnaval pour l'année du Brésil. L'occasion de mieux connaître ce pays contrasté (L'Hebdo Le Monde des Ados, revista semanal, 29/12/04 à 04/01/05).

2) “Beauté Brésilienne» (Le Journal du Dimanche, 16/01/05 - título da reportagem sobre a implantação da empresa de cosméticos Natura em Paris)

3) En attendant le carnaval... Entre samba, bossa nova et capoeira, le Brésil s'invite à Boulogne-sur-Mer le temps de quatre concerts (Fémina, revista regional semanal, 25/12 au 31/12/04)

4) Pour le prix d'une consommation, venez onduler du corps sur des rythmes endiablés du Brésil au bar restaurant club le Favela Chic. Título do anúncio : “Version fièvre latino » [...] Pour onduler du corps, quand sensualité rime avec fessiers, rendez-vous à la Favela Chic les mardis, mercredis et jeudis [...] » (Le Parisien, Edition des Yvelines, 21/01/05)

5) [...] rendez-vous de la bijouterie sous le signe du mouvement et de la couleur. Couleur Samba (Affiches de la Loire, 17/01 à 23/01/05. Nota sobre o mercado de jóias)

6) André Luquet et Bernard Romezin effectueront prochainement un court séjour à Florianopolis, ville connue pour la qualité de ses écoles de samba et la beauté de ses filles. A leur retour - s'ils reviennent!_- les deux hommes 
réfléchiront à une animation exotique pour la foire 2005. " (La Gazette de la Loire Ed. St Etienne Metropole, 14/01 à 20/01/05)

7) Fièvre Brésilienne. Samba, salsa, capoeira avec Sabor do Brasil (La Semaine dans le Boulonnais, 06 de janeiro de 2005 - nota sobre a apresentação do grupo Sabor do Brasil)

8) La décade brésilienne commence à l'Arsenal. Transformer certains endroits de Metz en plage de Copacabana et faire danser toute la cité au rythme des musiques brésiliennes, tel est le pari de la Fédération des commerçants [...] (Le Républicain Lorrain, 19/01/05)

9) “Chez nous, il fait 28… " Le gouverneur du Para et plusieurs secrétaires de cet Etat du nord du Brésil, invité de la prochaine Foire expo, ont passé la journée d'hier à Nancy. Loin des 28 degrés de Belém, leur capitale... » (Primeiro parágrafo do texto: "On vous arrête tout de suite: si vous imaginez que la délégation brésilienne qui a passé la journée d'hier à Nancy, en repérage pour la soixante et onzième édition de la Foire expo (28 mai-6 juin), est arrivée dans la cité ducale avec moult couleurs, des danseurs de salsa et des costumes traditionnelles, vous vous trompez [...] (L'Est Républicain, 23/01/05)

10)Mais si vous associez uniquement le Brésil à ces déesses en string 365 jours par an, lascivement allongées sur la plage de Copacabana, il vous faut abandonner tous [...] (Paris Capitale, 15/02 à 15/03/05)

11)2005: L'Année du Brésil Au rythme de la samba![...] Avec de beaux costumes colorés, une musique entraînante et un repas typique, l'animation Brésil plaira à vos convives. " (Cuisine Collective, fevereiro de 2005)

12) «Faites-vous un corps à la Brésilienne " "Leur beauté solaire, leur chute de reins étourdissante - ces fesses bombées qu'on leur envie - leur image sexy ont fait le tour du monde. Dénudées par le climat tropical, folles de leur plastique, les Brésiliennes sont prêtes à tout pour se façonner un corps de rêve. A l'occasion de l'année du Brésil, ce numéro "Spécial Forme" se penche sur leurs... formes. Vous découvrirez des exercices ciblés selon sa silhouette pour se modeler un "bum-bum 》 de Carioca, la capoeira ou le forro, les danses les plus rythmées et les plus en vogue de Rio à Bahia, et le vanity d'une bimbo joliment dorée au soleil 
d'Ipanema. Le printemps est là: “Entre na dança!" (entrez dans la danse). " (Votre beauté, abril de 2005)

13)2005, Année du Brésil sur un air de samba... [...] Laissez-vous conduire directement à l'été, au soleil des plages de sable fin de Copacabana ou dans la moiteur de la forêt amazonienne. Jouez à fond le dépaysement et hissez haut les couleurs brésiliennes, jaune et vert, dans vos boutiques et vos vitrines. Misez aussi sur le voyage des sens : quelques airs de samba ou bossa-nova savamment distillées devraient créer l'atmosphère adéquate. " (Table \& Cadeau, março/abril de 2005 - produtos decorativos de interiores)

As cidades escolhidas e seus elementos representativos compreendem igualmente os lugares onde a maior parte dos clichés podem ser encontrados:

1) "La France à l'heure de Rio" "Lancement hier au Ministère des Affaires Etrangères de l'Année du Brésil en France " (L'Humanité, seção L'essentiel, 19/01/05)

2) André Luquet et Bernard Romezin effectueront prochainement un court séjour à Florianopolis, ville connue pour [...] (La Gazette de la Loire Ed. St Etienne Metropole, 14/01 à 20/01/05)

3) Le Brésil aussi à la Courtaisière [...] Au menu : conférence, repas typique, musique et démonstration de Capoeira. (Le journal du pays Yonnais, 03/02/05)

4) Le Brésil vu de cheval [...] Gilles Audejean présente [...] sa nouvelle création. Sous un chapiteau de 600 places, inspiré par la coupole de l'Opéra de Manaos, l'opus veut évoquer l'Alegria propre à la culture brésilienne. Une joie qui ne fait pas abstraction de la grande misère d'un pays souvent résumé à des clichés de carnaval, plages et de strings ficelle. " (Jornal La Marseillaise, 31/01/05).

5) La décade brésilienne commence à l'Arsenal. Transformer certains endroits de Metz en plage de Copacabana et faire danser toute la cité [...] (Le Républicain Lorrain, 19/01/05)

6) [...] Le théâtre La Vista accueille [...] un cabaret brésilien sur le thème "Les sens du Brésil ». Un instant d'évasion vers les charmes de la cuisine, de la 
musique et de la danse de ce pays aux mille rêves. La soirée débute par un spectacle de danses traditionnelles et de démonstrations de capoeira, elle se poursuit par un moment de détente autour des cocktails typiques et de tapas brésiliens, pour se terminer dans un concert et bal forro, avec Fernando Lorenalis et le maître capoeiriste Sorriso. C'est à une fête populaire brésilienne que sont conviés les spectateurs." (Midi Libre, 04/02/05)

7) L'Année de tous les «Brésils » Rio entre en Seine. Cinq cents journalistes étaient présents à la conférence de presse de l'Association Française d'Action Artistique pour le lancement de la saison « Brésil, Brésils, au Quai d’Orsay [...] (Paris Capitale, 15/02 à 15/03/05)

8) Flamboyante de couleurs, Olinda la ville aux 300 artistes. "Dans la région du Nordeste au Brésil, découverte de la "superbe ». "Année du Brésil oblige, c'est l'occasion de (re)découvrir son riche patrimoine. Dans le nord du pays, juste au-dessus de Recife, Olinda apparaît comme l'un des purs joyaux de l'architecture coloniale brésilienne. Classée au Patrimoine Mondial de l'Unesco en 1982, la ville est parsemée de maisons colorées et d'églises centenaires [...] (Le Quotidien du tourisme, 18/03/05)

9) Le parfum de l'Année du Brésil. «Bahiane », parfum créé par «Maître Parfumeur et Gantier » [...] une fragrance où se mêlent le musc et le coco. (Point de vue, 09/03 à 15/03/05 - seção « Quelle semaine ! »)

10) 2005, Année du Brésil sur un air de samba..." [...] Laissez-vous conduire directement à l'été, au soleil des plages de sable fin de Copacabana ou dans la moiteur de la forêt amazonienne [...] (Table \& Cadeau, março/abril de 2005 - produtos decorativos de interiores)

Caracterizado nesse corpus exploratório como um país gigante, um paíscontinente, o maior da América Latina, um país de contrastes, de desigualdades sociais, cujo presidente "é" um operário, um país emergente, surpreendente, maravilhoso, um gigantesco caleidoscópio cultural, e um dos mais sedutores do planeta, o Brasil é representado, através de suas cidades e Estados, Rio de Janeiro, Bahia, Olinda, Manaus, com uma carga forte de erotismo, pelo clima, pelo calor, pela febre, pelo carnaval, pelas danças (sobretudo o samba) que transformam o corpo 
em objeto de desejo. Os Brasileiros são o Brasil, e deste modo, todas essas propriedades lhes são atribuídas por inclusão nessa categoria.

Esse corpus exploratório nos serviu de base para a escolha dos três artigos que analisaremos a seguir, e que apresentam, como objetos de discurso, a cidade do Rio do Janeiro (que por si só engloba todos os clichés conhecidos), a importância do corpo na sociedade brasileira e o país rico e diverso que ultrapassa os clichés. Entretanto, um outro texto analisado por nós (e apresentado no exame de qualificação) contribuiu e orientou, de certa maneira, a constituição de nosso corpus em busca da construção das representações de uma outra cultura pelo discurso. Sendo assim, ele representará o ponto de partida antes de entrarmos efetivamente na análise dos três artigos citados acima.

Procuraremos demonstrar em nossas análises como o enunciador representa discursivamente o seu objeto e como o leitor poderá reconstruir essa representação através das marcas deixadas no discurso. Gostaríamos de lembrar que a construção de sentidos consiste numa atividade dialógica que possibilita várias interpretações em função das representações que enunciador e co-enunciador possuem de si mesmos e do objeto do discurso.

\section{d. O jogo das representações discursivas}

A fim de exemplificarmos o jogo das representações discursivas, o papel do contexto da enunciação e a reconstrução destas representações por parte do coenunciador na recepção, passaremos pela leitura e análise de um curto texto introdutório sobre o Brasil contido num guia turístico francês de reputação internacional, Le Guide du Routard ${ }^{30}$ (Hachette, 1999). Este guia, cujo objetivo é supostamente o de fornecer informações factuais e/ou pragmáticas e sócio-culturais sobre o destino desejado, destina-se aos falantes de língua francesa, franceses e francófonos, de diversas faixas etárias e níveis sócio-culturais, interessados em

\footnotetext{
${ }^{30} \mathrm{O}$ texto analisado consta na edição de 2006 do mesmo guia turístico.
} 
visitar ou morar no país e em ampliar os seus conhecimentos sobre o mesmo. Temos assim como emissor a editora Hachette representada pela sua equipe de autoria dos textos e como destinatários, franceses e francófonos. O levantamento destes componentes da situação de enunciação (emissor, destinatário, contexto, etc...) é relevante, pois, segundo as palavras de Moirand (1979:11) :

"Le type de relations et/ou surtout les représentations que le lecteur se fait à propos $d u$ scripteur (et donc de ses intentions) influent sur les lectures possibles du document» (Moirand, 1979:11).

Transcreveremos, na íntegra, o texto escolhido para análise. A escolha se deve ao fato de ser um texto curto, de introdução sobre o país, e que nos pareceu rico no que se refere ao número de representações culturais que o leitor pode construir a partir de sua leitura.

\section{GÉNÉRALITÉS}

Plus qu'un pays d'Amérique du Sud, le Brésil est un continent dans le continent : $8.511 .965 \mathrm{~km} 2,286$ fois la Belgique, 16 fois la France !

Terre de contrastes, a dit l'anthropologue Roger Bastide, dans une formule qui fit succès: matérialisme brutal contre mysticisme halluciné, splendeur fastueuse du carnaval contre misère quotidienne, délicatesse $d u$ baroque colonial contre délires futuristes de Brasília, ardente ferveur chrétienne et transes de possession des dieux d'Afrique, fortunes colossales contre sous-alimentation endémique... on ne finirait pas d'en dresser la liste.

De l'Amazonie infinie aux colossales chutes d'lguaçu, du quadrilatère de la sécheresse au continent marécageux du Pantanal, ici la nature atteint les extrêmes de la démesure, et la démesure est peut-être la clé du Brésil. 
Une civilisation qui se construit, se défait, renaît avec des craquements, des explosions et une vitalité incroyable.

Qu'est-ce que la culture brésilienne? C'est Oswald de Andrade, père du modernisme brésilien, qui la définit d'un mot: «l'anthropophagie culturelle». "Seule l'anthropophagie nous unit. Socialement. Economiquement. Philosophiquement. Une conscience participante, une rythmique religieuse...Toutes les religions. Aucune église. Et surtout, beaucoup de sorcellerie. La joie est la preuve par neuf. Tupi or not tupi, that is the question. " Tupi, ce sont les Indiens cannibales qui dévorèrent les premiers jésuites pour s'en approprier les vertus !

Alors, venez au Brésil pour ses plags, pour son soleil, pour sa musique, pour la folie unique au monde de son carnaval, pour ses forêts tropicales et la jungle de ses villes... et surtout pour vous laisser dévorer, délicatement, sans résister, par les «Indiens » et les «Indiennes » natives..., pour ébranler vos certitudes. Le Brésil, dernière frontière culturelle à franchir. »

O guia apresenta, na rubrica Généralités, várias informações úteis àqueles que pretendem visitar o Brasil. Uma breve apresentação do país situa-o geograficamente e o descreve como Terre de contrastes. No primeiro parágrafo, o autor pretende dar ao leitor-turista, através da comparação do Brasil a outros países como a Bélgica e a França, a dimensão territorial desta terra de contrastes oferecendo-Ihe dados que lhe possibilitem mensurar os seus $8.511 .965 \mathrm{~km} 2 \mathrm{de}$ extensão. Encontramos neste trecho a primeira representação, visto que a comparação entre as dimensões territoriais do Brasil, da França e da Bélgica remete o leitor ao seu universo representativo dos países europeus. Esta recorrência às dimensões territoriais da França e da Bélgica ativa no leitor europeu a representação da sua realidade a fim de auxiliá-lo na construção/reconstrução de uma nova representação, no caso, a do Brasil. Além disto, o leitor encontra, neste parágrafo, dois dados informativos sobre 0

país: o primeiro é o de que o "Brasil é um país da América do Sul", e o segundo é o de que o "Brasil tem 8.511.965 km2". Sua atenção estará voltada muito mais para as comparações. 
Em seguida, no segundo parágrafo, dá-se continuidade à descrição deste país como Terra de contrastes (caracterização do referente) encadeando-se uma série de oposições que fornecerá ao leitor, através de sintagmas nominais de valores antagônicos, os meios lingüísticos que o ajudarão a construir mentalmente e a dimensionar esta terra de contrastes designada pelo enunciador.

Nestes dois parágrafos iniciais, podemos depreender as duas primeiras operações de "mise en texte" descritas por Moirand (1990:9). A primeira, denominada de operação de referência ou designação, consiste em se levantar, no estoque do léxico disponível (do enunciador), as noções aptas a representar a realidade (do referente) tal qual ela foi percebida e como se quer contá-la. De acordo com Dahlet (1992:23) :

"L'opération de désignation qui exerce un rôle majeur dans la construction des représentations sociales [...] est l'opération fondatrice de tout discours. En produisant des mots pour des notions, non seulement elle conditionne l'existence même d'un discours, mais elle en dirige toute la lecture, puisque c'est par rapport aux représentations qu'elle fabrique que seront interprétées et évaluées les prises de position d'un sujet en discours" (Dahlet, 1992:23).

Esta operação dirige toda a leitura, pois as representações que serão construídas e sugeridas a partir da escolha do léxico serão a base da compreensão do texto, sobretudo no que diz respeito às intenções de comunicação do enunciador. Entretanto, isto não anula a ativação das representações anteriores do próprio leitor sobre o referente, pois ao considerarmos a diversidade de leitores e, por conseguinte, de conhecimentos de mundo, a construção final dos sentidos do texto terá passado certamente pelo crivo das suas próprias representações sobre o referente.

A segunda operação, denominada por Moirand (1990:9) de operação de caracterização ou predicação, tem por função ou fornecer elementos mais precisos 
sobre a situação ou descrever as coisas e as pessoas, a fim de que se possa estabelecer as relações entre os atores e os objetos do discurso.

Neste segundo parágrafo, o autor contrasta o "belo e o grotesco", ou melhor, o "belo no grotesco" através de adjetivos que qualificam de forma exacerbada os seus substantivos e que se mostram diametralmente opostos ao grupo nominal que Ihes serve de oponente. Esta teia de contrastes desmedidos e de valores antagônicos tece de forma exacerbada e estereotipada o efeito contrastivo que o autor quer suscitar no leitor (intenção de comunicação).

Vale ressaltar que a escolha do léxico empregado, que compreende muitas vezes as operações de designação e de caracterização, não é aleatória visto que esta escolha advém também das operações de enunciação no ato de produção do texto. Segundo Moirand (1990:10), a escolha do léxico possui :

«[...] une visée sémantique (la référence au monde), mais aussi une visée communicative (l'intention de communication: ce que je veux dire aux autres) 》 (Moirand, 1990:10).

Dentro desta teia de efeitos contrastivos, o autor-enunciador, através da língua e da escolha do léxico, além de tecer as suas próprias representações sobre o país, ativa, no leitor, as representações verbais que serão evocadas através de cada adjetivo e substantivo selecionados: matérialisme brutal/mysticisme halluciné // splendeur fastueuse du carnaval/misère quotidienne // délicatesse du baroque colonial/délires futuristes de Brasília // ardente ferveur chrétienne/transes de possession des dieux d'Afrique // fortunes colossales/sous-alimentation endémique.

Através da análise deste trecho, depreendem-se as representações de um país caracterizado por uma grande variedade de religiões cristãs e de cultos africanos; a variedade de uma arquitetura barroca datada da época colonial até uma arquitetura futurista representada pela capital na época atual; o grande abismo econômico que divide o país entre fortunas colossais e subalimentação; além do esplendor suntuoso do carnaval - que acontece uma vez ao ano, logo temporário (conhecimento sócio-cultural da cultura estrangeira) - da miséria diária. 
A intenção de descrever uma terra de contrastes salta aos olhos dos leitores através da desmedida e do exagero dos adjetivos empregados e da realidade exacerbada. Entretanto, a construção dos sentidos do texto se fará de forma diversa se considerarmos a leitura deste mesmo texto por um leitor brasileiro que lê em língua estrangeira um texto sobre o seu país, e por um leitor francês ou francófono, desprovido de conhecimentos mais profundos sobre a outra cultura, que lê o texto em língua materna sobre um país estrangeiro. Neste caso, as representações não mais verbais, mas sociais ativadas através da leitura serão diferentes e por vezes conflitantes, pois, como afirma Moirand (1979:64):

\section{«[...] un lecteur étranger se trouve beaucoup plus démuni qu'un natif devant un certain nombre de ces données d'ordre sócio-culturel ». (Moirand,1979:64)}

Segundo Carrell (1990:10), existe uma influência clara e profunda dos esquemas de conteúdo (conhecimentos individuais de mundo) de origem cultural sobre a compreensão escrita. No entanto, para que se tenha uma boa compreensão do texto, é necessária a interação tanto dos esquemas de conteúdo (conhecimentos e crenças sobre o mundo), quanto dos esquemas formais (conhecimento de vários tipos de textos, da sua organização e da sua estrutura típica) e dos esquemas lingüísticos (conhecimentos lexicais, sintáticos, semânticos e pragmáticos), acrescidos dos conhecimentos sobre o processo de leitura em si e os objetivos pessoais de leitura. Além disto, o emissor destas informações (equipe responsável pela redação do texto) e que goza da credibilidade e da confiança do leitor francês e francófono - pois é sustentado pela renomada editora francesa de reputação internacional (relação entre o leitor e o autor-fonte da informação) - pode de certa forma influenciar a construção de certas representações estereotipadas sobre os leitores mais desavisados.

Neste caso, as interações entre aquele que toma a palavra, aqueles aos quais ele a destina, e o local de onde ele fala entram em jogo através da terceira operação de mise en texte denominada por Moirand (1990:10) de operação de comunicação ou enunciação. É neste momento que o leitor vai buscar, nos componentes da situação de enunciação, a confirmação dos sentidos que ele construiu durante a sua 
leitura. Portanto, estas interações entre leitor, texto e contexto condicionam a sua leitura.

O referido texto é, ao nosso ver, inteiramente composto de apreciações de seu(s) autor(es), e se fundamenta e se apóia igualmente na citação dos intelectuais Oswald de Andrade (brasileiro) e Roger Bastide (francês), a fim de dar às informações maior credibilidade e veracidade. Sendo assim, duas inferências são passíveis de ocorrência a partir da seguinte frase: "Qu'est-ce que la culture brésilienne? C'est Oswald de Andrade, père du modernisme brésilien, qui la définit d'un mot : «l'anthropophagie culturelle ».

Possivelmente, um leitor melhor informado e conhecedor pelo menos de artes e de suas respectivas escolas ou movimentos, chegaria à primeira inferência de que o «modernismo brasileiro » corresponde a uma fase ou movimento das artes brasileiras. O texto não nos oferece maiores informações sobre a qual modernismo ele se refere, se o das artes plásticas, da pintura, da escultura, ou o da literatura, nem a qual momento do modernismo brasileiro ele se refere, visto que este se divide em três. Neste caso, o processo de inferência do leitor será da ordem pragmáticacultural segundo a estruturação proposta por Marcuschi (1999:105). Tais inferências, segundo ele, são feitas com base nos conhecimentos pessoais, nas crenças e ideologias dos indivíduos sendo a formação individual e a condição sócio-cultural responsáveis por ela.

Supondo que o leitor consiga fazer esta primeira inferência, automaticamente e concomitantemente ele inferirá que, sendo o modernismo brasileiro uma fase das artes brasileiras, e sendo Oswald de Andrade o «pai do modernismo brasileiro », Oswald de Andrade seria um intelectual. Duas representações são ativadas neste caso: a primeira é a representação verbal da palavra intelectual que nos remete imediatamente a algo ligado à inteligência, ao conhecimento e ao entendimento. A segunda é a representação social de um intelectual, cidadão engajado social e politicamente, dotado de discernimento e de esclarecimento da sua realidade superiores aos dos demais cidadãos, homem letrado e culto, conhecedor de várias outras culturas e aberto ao novo.

Jogando com estas representações, o enunciador sustenta a sua própria opinião ao integrar ao seu discurso o pensamento de um "nativo" célebre na cultura em questão que seria teoricamente incontestável. Ao definir Oswald de Andrade como o "pai do modernismo brasileiro", o enunciador passa a palavra e, por 
conseguinte os seus efeitos a uma "autoridade nativa" que não seria tão facilmente contestada pelos leitores que desconhecem a nossa literatura.

O perigo encontrado neste empréstimo feito a Oswald de Andrade é que o autor do presente texto descontextualizou o emprego da concepção do termo Antropofagia Cultural de todo o momento histórico, cultural e de revolução na produção artística pelo qual passava o país no início do século XX. Além disso, houve um desvio do sentido dado por Oswald de Andrade ao termo antropofagia que preconizava a devoração cultural das técnicas importadas dos países desenvolvidos, para reelaborá-las com autonomia, convertendo-as em produto de exportação ${ }^{31}$ - em detrimento do sentido que o autor-enunciador quis dar ao termo em seu texto. Sendo assim, ele acaba por empregar a palavra «antropofagia » no seu sentido primeiro: ato de comer carne humana, ao citar como exemplo os índios canibais do início da colonização. Tal ilustração servirá ao seu objetivo de recuperar, no parágrafo seguinte, este mesmo sentido, e por meio de analogia, sugerir ao leitor que se deixe devorar delicadamente pelos índios e índias nativos. Em nenhum outro momento no texto, o autor faz referência, explica ou explicita as verdadeiras intenções de Oswald de Andrade expostas em seu Manifesto Antropófago, publicado, em maio de 1928, no primeiro número da Revista de Antropofagia que daria início à primeira fase do movimento Modernista no Brasil.

Da mesma forma, o autor-enunciador, ao se servir da obra de Roger Bastide Brasil, Terra de Contrastes (1976) para legitimar o seu discurso, descontextualiza todo o pensamento e vivência do renomado sociólogo acerca do Brasil.

$\mathrm{Na}$ introdução do seu livro, Roger Bastide (1976:9) apresenta o Brasil como uma terra de contrastes geográficos, econômicos e sociais. Porém, sua descrição está calcada em sua experiência de mais de quinze anos no país e em seu olhar científico, mas também poético que se volta para essa comunidade cultural:

"Brasil, terra de contrastes... Contrastes geográficos, contrastes econômicos, contrastes sociais. País que sozinho é tão grande quanto toda a Europa, excetuando-se a URSS; alonga-se desde a Floresta

\footnotetext{
${ }^{31}$ Grande Enciclopédia Larousse Cultural, Nova Cultural, 1998.
} 
Amazônica até os pampas do Uruguai, alternando planícies, montanhas e altiplanos, plantações e pastagens, clima temperado sucedendo ao clima tropical: a Amazônia líquida, em que terra e água, rio e floresta fundem-se numa imensa sinfonia verde; 0 polígono das secas, de solo calcinado pelo sol, eriçado de cactos, o gado mugindo a pedir chuva; o litoral dos canaviais, velhos engenhos adormecidos, negros dançando ao luar junto de igrejas barrocas: terra gaúcha de capinzais cobrindo vastas extensões, homens-centauros guardando as fronteiras do Sul..." (Bastide, 1976:9)

Nessa descrição, a dimensão territorial e os contrastes do Brasil são sentidos e compreendidos de forma oposta à sugerida pelo autor do texto do guia. $O$ léxico empregado por Bastide oferece ao leitor uma visão poética, mas nem por isso utópica dessa realidade. O solo calcinado pelo sol, eriçado de cactos, com o gado mugindo a pedir chuva, nos mostra de forma muito mais dramática do que sensacionalista o problema da seca nessa região. A desmedida de sua extensão é traçada por Bastide na alternância de paisagens que contam planícies, montanhas e altiplanos, plantações e pastagens, clima temperado sucedendo ao clima tropical. A verticalidade de um país que se estende da Amazônia líquida, em que terra e água, rio e floresta fundem-se numa mesma sinfonia verde, até os pampas do Uruguai, se vê transformada pelo autor do texto do guia numa verticalidade que se estende da Amazônia infinita até as colossais cataratas do Iguaçu. O país que sozinho é tão grande quanto a Europa excetuando-se a URSS, transforma-se num continente dentro do continente, 286 vezes a Bélgica e 16 vezes a Franca. Essa grandeza caótica e contrastante descrita pelo autor do texto do guia dá ao leitor o "tom" de sua leitura refletido na ordenação de fatos como o ardente fervor cristão e transes de possessão dos deuses da Africa. Entretanto, nas palavras de Bastide, esses transes de possessão são descritos como fatos culturais pertencentes à comunidade negra e, em princípio, mantidos por ela como forma de preservação de sua identidade. Ao mesmo tempo, a preservação desses fatos 
culturais se perpetuou na sua transmissão ao branco, a partir do contato entre as duas culturas, de tal forma que hoje faz parte da cultura brasileira:

"O negro que, a princípio, guardou seu folclore africano, suas danças eróticas, seus instrumentos de música, seus contos de animais, transmitindo-os ao branco por intermédio das criadas, da ama-de-leite, do velho contador de histórias, ou da amante de cor, introduziu-se pouco a pouco no folclore europeu, nos bailes pastoris do Natal, nas procissões de Reis, no Carnaval" (Bastide, 1976:14).

\section{O materialismo brutal, a delicadeza do barroco colonial e os delírios} futuristas de Brasília são tratados por Bastide segundo as seguintes palavras de Jacques Lambert (apud Bastide,1976:11-12):

"No próprio interior do Brasil, apresenta-se de maneira bastante acusada a mesma diferença que separa um país novo e próspero, de um velho país colonial e miserável, diferença observada no plano internacional, por exemplo, entre os países novos do Prata e as velhas sociedades coloniais da América Andina. O Brasil reproduz em seu seio os contrastes do mundo: nele encontramos aspectos que lembram os de Nova lorque ou Chicago, ao lado de outros que evocam os da Índia e do Egito" (Lambert apud Bastide).

E completadas por Bastide (1976:12):

"De um modo geral, o norte é a região por excelência do velho país colonial, enquanto o país 
novo se localiza ao sul: o sul das cidades industriais e das culturas experimentais [...] E não são apenas os povos que se mesclam, mas também os tipos de arquitetura, os gêneros de vida, os sotaques, as línguas. [...] Vilas normandas, pátios mexicanos, arranha-céus de cimento armado, velhas habitações coloniais arruinadas, invadidas por negros $e$ imigrantes, palácios florentinos construídos por italianos enriquecidos [...] alinham-se em São Paulo ao longo da mesma rua [...]" (Bastide, 1976:12).

\section{As fortunas colossais contra a subalimentação endêmica são} exemplificadas por Bastide da seguinte maneira:

"Nos campos, as casas dos senhores erguem-se sobranceiras dominando os casebres de escravos. No centro da cidade, palácios principescos; nos arrabaldes, cortiços de negros" (Bastide, 1976:1011).

\section{Para Bastide (1976:11):}

"O antagonismo mais visível é o constituído por dois tipos de Brasis: o Brasil do Norte, com engenhos de cana-de-açúcar, canaviais como oceanos verdejantes, negros importados da África, senhores brancos ricos e voluptuosos - e o Brasil do Sul, de população mais pobre, mais mesclada de índios, composta de pioneiros, de desbravadores de terras virgens, de conquistadores do sertão. Dois métodos de tomada de posse do Brasil. A conquista horizontal dos bandeirantes de São Paulo, 
continuando o nomadismo do índio, homens destemidos mergulhados no desconhecido [...] e $o$ outro tipo de conquista, mais espiritual que geográfica, as dos senhores da Bahia ou do Recife, agarrados ao solo arrancado à floresta, fixando populações em torno da firmeza de seus solares bem enraizados na terra, verdadeiros fundadores da civilização luso-tropical. Hoje, quando não há mais novas terras por descobrir, quando as fronteiras do país estão definitivamente fixadas, a mesma oposição subsiste ainda entre esses dois tipos de Brasil" (Bastide, 1976:11).

Os contrastes sociais aqui ilustrados são explicitados com bases históricas que revelam dois métodos de tomada de posse do país. A "fórmula" de sucesso atribuída a Roger Bastide pelo autor do texto que estamos analisando, embora evidencie os contrastes salientados, não corresponde em nenhum aspecto à maneira escolhida por Bastide em descrevê-la. Em nenhum momento do seu discurso, encontramos as fórmulas citadas: materialismo brutal, misticismo halucinado, esplendor fastuoso do carnaval... Ao contrário, segundo Bastide (1976:14), até no contraste existe harmonia.

A ordenação escolhida pelo autor do texto do guia francês na contraposição dos elementos culturais citados foi tomada de empréstimo e mais uma vez descontextualizada. Nas palavras de Bastide (1976:13), diante desses contrastes e antagonismos, o Brasil poderia ter se fragmentado em uma multidão de nações diferentes, segundo os recortes geográficos, étnicos e sociais. Entretanto, a contraposição de elementos culturais feita por Bastide em nada se assemelha àquela que se construiu com bases sensacionalistas:

"Os choques entre esses diversos tipos de Brasil [...] sempre existiram; houve movimentos separatistas, revoltas sangrentas de civilizações diferentes. 0 
sertão da seca contra o litoral da cana-de-açúcar. As cidades senhoriais contra os portos do comércio. A aristocracia rural contra os comerciantes portugueses. Mas todas estas lutas eram, no fundo, apenas lutas de família, entre gente da mesma língua, com o mesmo Deus, educada nas mesmas escolas religiosas ou nos mesmos conventos jesuítas" (Bastide, 1976:13).

Ainda no quarto parágrafo, ao final da citação de Oswald de Andrade em que ele parodia a célebre frase de Shakeaspeare «To be or not to be, that is the question », o autor-enunciador explica ao leitor o que ou quem seriam os Tupis mencionados por Oswald. De forma exclamativa (modalidade apreciativa) faz saber que a tribo indígena em questão era composta por índios canibais que devoraram os primeiros jesuítas a fim de se apropriarem de suas virtudes. Para os leitores brasileiros, conhecedores das origens de sua cultura, além de canibais, os Tupis foram responsáveis por grande parte do vocabulário atual da língua portuguesa do Brasil e que as mais variadas tribos indígenas muito contribuíram na formação da cultura brasileira, desde o folclore até a gastronomia. Deste modo, a frase exclamativa e a escolha de "canibais" como o único adjetivo qualificativo da tribo Tupi nos fazem perceber que a informação privilegiada pelo enunciador é aquela que causa maior impacto. Inferimos então que uma segunda intenção de comunicação é a de chamar a atenção do leitor de forma apelativa, através do exagero e de fatos inusitados, para todos os contrastes até então descritos. Além disso, embora o uso do tempo verbal passé simple (índice formal) na frase "[...] les Indiens cannibales dévorèrent les premiers jésuites..." nos remeta a um passado remoto e a uma realidade que não mais existe, o autor-enunciador se serve do campo nocional de "índios" numa posterior definição do povo brasileiro onde há claramente um apelo sexual, do prazer carnal.

Finalmente, no último parágrafo do texto, o leitor é convidado a visitar o país de contrastes gritantes não por estas razões, mas "pour ses plages, pour son soleil, pour sa musique, pour la folie unique au monde de son carnaval, pour ses forêts tropicales et la jungle de ses villes...". Aqui são evocadas as representações de um 
país tropical - sol, praia, florestas, natureza - mas também as representações do país tropical Brasil - a loucura (apreciação do enunciador) do carnaval (elemento cultural que ativa as representações do leitor sobre o carnaval em geral, em seguida, sobre o carnaval brasileiro) e a selva (apreciação do enunciador) de suas cidades.

Servindo-se do campo nocional de "índios" e das características descritas pelo próprio autor que nos remetem a canibais, a carne, devorar a carne, a nudez, a selvageria, evocado no parágrafo anterior, o enunciador ressalta ao leitor que ele deve visitar o país surtout pour vous laisser dévorer, délicatement, sans résister, par les "Indiens" et les "Indiennes" natives... pour ébranler vos certitudes. Tal convite nos parece evocar e perpetuar a representação de um país sensual, promissor de prazeres carnais. Desta maneira, o autor se serve mais uma vez do antagonismo dévorer délicatement, sans résister - a fim de convencer o leitor a se permitir desestabilizar - pour ébranler vos certitudes - frente a uma cultura totalmente "inédita" em relação às que o leitor conhecia até então. Este processo de inferência analógica é possível justamente pela recuperação e pela ativação da representação evocada na descrição dos "índios" feita anteriormente. Logo, a representação implícita no texto de um país tropical cujas cidades-selvas escondem os seus mistérios e perigos, e seus habitantes, "índios e índias nativas" - "nus", "canibais", "selvagens" - prometem experiências nunca então "experimentadas", sugere ao leitor as razões pelas quais le Brésil est la dernière frontière culturelle à franchir.

As reticências contidas nas frases "[...] et la jungle de ses villes ..." e "[...] par les "Indiens" et les "Indiennes" natives..." abrem um leque de interpretações possíveis ao leitor que lhe permite preencher automaticamente as lacunas deixadas intencionalmente pelo enunciador, lacunas estas cuja função, segundo Marcuschi (1999:101) é a de tornar explícito o que esta implícito semanticamente na imanência de relações entre proposições ou ítens lexicais.

Para finalizar essa análise, gostaríamos de partir da seguinte afirmação de Umberto Eco (apud Pietraróia, 2001:20) a respeito das relações entre o enunciador de um discurso, o seu produto, ou seja, o próprio discurso, e o seu destinatário:

"Le texte est [...] un tissu d'espaces blancs, d'interstices à remplir, et celui qui l'a émis prévoyait qu'ils seraient remplis et les a laissés en blanc pour deux raisons. D'abord parce qu'un texte est un 
mécanisme paresseux (ou économique) qui vit sur la plus-value de sens qui $y$ est introduite par le destinataire; [...] Ensuite parce qu'un texte veut laisser au lecteur l'initiative interprétative, même si en général il désire être interprété avec une marge suffisante d'univocité. Un texte veut que quelqu'un l'aide à fonctionner ${ }^{32}$ ” (ECO apud Pietraróia, $2001: 20)$.

O leitor interessado no Brasil pode ou não já ter as suas próprias representações sobre o país. No caso de não possuir nenhum conhecimento anterior, o texto acabará por direcionar a sua leitura e por fazê-lo construir uma representação folclórica do Brasil. Caso contrário, ele ativará as suas próprias representações que podem ou não corresponder às evocadas no texto, pois a leitura adulta é uma atividade que envolve elaborações semânticas, pragmáticas, lógicas e culturais...Depende de uma série de fatores lingüísticos e extralingüísticos, sendo algo muito mais complexo que a decifração de um suposto sentido litera ${ }^{\beta 3}$. Além disso, os conhecimentos individuais afetam decisivamente a compreensão, de modo que o sentido não reside no texto ${ }^{34}[. .$.$] Embora ele permaneça como ponto de$ partida para a sua compreensão, ele só se tornará uma unidade de sentido na interação com o leitor ${ }^{35}$. Se os conhecimentos do leitor sobre o referente forem mais profundos do que os informados no texto, pode ser que este venha a questionar a veracidade dos fatos narrados, interrompendo o processo de folclorização salientado por Le Berre (1998), a partir da contextualização destes mesmos fatos dentro do quadro cultural que thes deu origem. Se eventualmente as representações do leitor sobre este mesmo referente coincidirem com as reconstruídas no decorrer da leitura, além de não the acrescentar nenhuma informação nova poderá reforçar as representações anteriores do leitor-turista condicionando de certa forma a sua conduta no país visitado. Neste caso e considerando um espaço curto de contato entre as duas culturas que impossibilitará um melhor conhecimento do Outro, as

\footnotetext{
${ }^{32}$ U. Eco apud Pietraróia, Cristina Casadei. Questões de leitura - aspectos práticos e teóricos da leitura em Francês Língua Estrangeira, Annablume, São Paulo, col. Parcours, 2001, p.20

${ }^{33}$ Marcuschi, Luiz Antonio. Leitura como processo inferencial num universo cultural-cognitivo in Barzotto, Estado de Leitura, Mercado de Letras, Campinas, 1999, pp. 94-95

${ }^{34}$ Spiro apud Marcuschi, 1999, p.96

${ }^{35}$ Marcuschi, 1999, p.96
} 
representações que temos de uma dada sociedade poderão intervir nas nossas relações com os seus membros, pois as relações são dependentes das representações ${ }^{36}$.

i. Rio de Janeiro: pólo de concentração das representações do Brasil

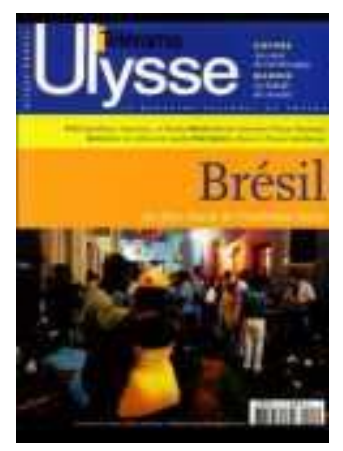

Revista: Ulysse Télérama - le magazine culturel du voyage ${ }^{37}$

Capa : Brésil, au plus chaud de l'Amérique Latine

Legenda da capa: RIO Copacabana, Ipanema... et favelas BRASILIA une interview d'Oscar Niemeyer BAHIA Sur un rythme de samba PRATIQUE La France à l'heure brésilienne.

Título do artigo: "Rio, de morro en morro"

Autor: Olivier Bauer

O dossiê publicado na revista de turismo Ulysse Télérama (março/2005) é composto de reportagens sobre as cidades do Rio de Janeiro, de Olinda, Parati e Cachoeira, assim como a Bahia.

A nossa escolha em analisar o texto sobre o Rio de Janeiro em detrimento dos outros publicados nesse dossiê se deve ao fato de que, a partir da análise feita no corpus exploratório, o Rio de Janeiro se apresenta como uma cidade que engloba

\footnotetext{
${ }^{36}$ Abdallah-Pretceille, Martine. Vers une pédagogie interculturelle, Anthropos, Paris, 1996, p. 32

${ }^{37}$ A revista Ulysse Télérama - le magazine culturel du voyage é uma revista bimestral publicada pelo grupo Publications de la Vie Catholique (PVC). Este número foi publicado em março de 2005.
} 
todos os clichés em geral atribuídos ao país como um todo: praia, belas mulheres, sensualidade, samba, violência; clichés estes evidenciados e explorados no artigo escolhido.

A análise feita do referido artigo nos possibilitou levantar os temas do culto ao corpo e à beleza, dos constrastes sociais e da violência, do ambiente de festa permanente e do futebol em função do itinerário escolhido pelo enunciador. A nossa proposta é a de demonstrar como cada um desses temas são construídos pelo discurso e como o conjunto desses clichés constrói as representações do seu objeto de discurso - a cidade do Rio de Janeiro.

Já a partir do título "Brésil, au plus chaud de l'Amérique Latine", podemos observar a evocação de uma das propriedades que em geral é atribuída ao país, a sensualidade. $O$ título é sugestivo na medida em que ele remete a dois sentidos : o primeiro do calor ardente e sensual, e o segundo do lugar onde há animação, paixão (Dictionnaire Le Robert). O título oferece, igualmente, ao leitor três outras informações sobre o país. A primeira diz respeito à localização do Brasil dentro de um espaço geográfico - a América Latina. A segunda refere-se à propriedade "ser sensual" atribuída aos outros países deste espaço. E a terceira refere-se à potencialização desta propriedade no espaço brasileiro, inferência que pode ser feita a partir da marca lingüística (superlativo) au plus chaud de l'Amérique Latine.

Com exceção da entrevista de Oscar Niemeyer sobre a cidade de Brasília (capital do país), as outras informações dadas na capa da revista (título, legenda e foto) mobilizam as representações do Brasil na França ${ }^{38}$ : praia (Rio/Copacabana, Ipanema), miséria e violência (favelas do Rio de Janeiro), samba (Bahia), ambiente festivo (foto), e por extensão, calor sensual. A foto da capa complementa e justifica esta última propriedade: muitas pessoas numa rua agitada à noite; ambiente festivo de bares, de animação, onde temos, em primeiro plano, um casal, cuja moça de costas (mulata) veste um vestido de cor clara, justo e curto, com corpo tipo "violão".

Antes de iniciar a sua viagem pelo Rio de Janeiro, o enunciador apresenta a cidade sob a perspectiva do escritor romancista, novelista e ensaísta austríaco Stefan Zweig (1881-1942) que se refugiou no Brasil, junto com sua esposa, durante

\footnotetext{
${ }^{38}$ É possível que as representações sobre o Brasil acima citadas possam ser compartilhadas por outros países. Entretanto, nos limitamos à França em função do corpus escolhido para análise (composto de artigos da imprensa francesa) e também da nossa vivência e contato com este país enquanto professores de Francês Língua Estrangeira (FLE).
} 
a Segunda Guerra Mundial. Zweig, autor do livro Le Brésil, terre d'avenir, publicado em 1941 descreve o país sob a forma de um diário de viagem, e narra, entre outras coisas, a beleza natural que encontrou ao desembarcar na cidade do Rio de Janeiro (pp. 206-208). Ao reproduzir este trecho, o testemunho de Zweig (argumento de autoridade) fornece ao enunciador um argumento que reforça a imagem do Rio de Janeiro como "Cidade Maravilhosa", embora inserida no contexto dos anos 40. É interessante notar que o título escolhido pelo enunciador - "Manoeuvres d'Approche" - para reproduzir a passagem do livro de Zweig apresenta-se de forma ambígua, pois ao mesmo tempo em que ele nos remete às manobras feitas pelo barco ao se aproximar da Baía de Guanabara, ele permite implicitamente a inferência da sua "manobra para abordar o seu objeto de discurso".

Sob a forma similar do "journal de voyage" de Zweig (intertextualidade), o enunciador descreverá em seu "carnet de voyage" o percurso efetuado em sua visita à cidade: Copacabana, Pão de Açúcar, centro histórico, Ipanema, bairros de Santa Teresa e São Conrado, Rocinha, estádio do Maracanã, Canecão e Mangueira. A partir da caracterização desses lugares, veremos como o enunciador representa 0 seu objeto e como o leitor reconstruirá essas representações.

No primeiro parágrafo, o enunciador delimita o espaço-tempo da enunciação: Rio de Janeiro, praia de Copacabana, época do Natal (dezembro); e procede à caracterização da cena discursiva: ${ }^{2}{ }^{\circ} \mathrm{C}$ (verão no $\mathrm{B}$ rasil), praias cheias, um garoto de 17 anos disfarçado de Papai Noel vende alegremente côco na praia, policiais musculosos, garotas "formosas".

"Lorsque son bonnet lui tombe une énième fois sur les yeux, le Père Noël éclate de rire. "Jingle bell, jingle bell! Mes noix de coco sont les meilleures de tout Copacabana... " Le Père Noël a 17 ans, un bonnet trop grand, une fausse barbe et un slip de bain rouge fluo. II fait $32 \mathrm{C}$. Les plages sont bondées. C'est Noël à Rio. Trois policiers bodybuildés assis sur leur quads surveillent les formes des filles. ” 
O clima festivo é caracterizado não somente pelo tempo da enunciação - mês de dezembro/Natal, mas também pela reação do vendedor de côcos que éclate de rire (morre de rir ao ver que seu gorro de Papai Noel cai mais uma vez em cima de seus olhos), e pela quantidade de pessoas na praia (plages bondées). O clima de descontração pode igualmente ser observado no comportamento dos policiais que surveillent les formes des filles. O sentido de "controle militar", de "verificação", de "observação atenta" expresso no verbo surveiller e reforçado pelos agentes da ação "policiais musculosos" é atenuado pela escolha do objeto que está sob vigilância: as formas das garotas, evocando as representações das belas mulheres brasileiras.

O enunciador coloca em cena, deste modo, logo no primeiro parágrafo, os elementos que, em geral, representam a cidade do Rio de Janeiro: a praia de Copacabana, o calor, as praias lotadas, corpos trabalhados (policiais) e garotas bonitas, e que serão reiterados nos seguintes enunciados:

«[...] Au bout de plage de Copacabana [...]. Les pêcheurs reprisent leurs filets et ne lèvent même pas la tête au passage de belles brunes aux tenues légères. Ils sont bien les seuls (apreciação do enunciador). Sur et autour de la célèbre bande de sable fin, chacun se regarde au coin de l'œil. Les filles présentent leur plus beau profil, les hommes exhibent leurs tatouages et leur adresse au ballon. C'est comme ca depuis la nuit des temps, sur un fond de samba. "

O culto ao corpo e à beleza e o exibicionismo das formas físicas são evidenciados na descrição das atitudes dos cariocas, homens e mulheres. Deste modo, tanto o verbo présenter (mettre à la portée, sous les yeux de quelqu'un, faire connaître au public par une action spécialement organisée; remettre quelque chose à quelqu'un en vue d'un examen, d'une vérification, d'un jugement - Dictionnaire Le Robert), quanto o verbo exhiber (montrer avec ostentation ou impudeur) oferecem ao leitor a construção de um traço comportamental (narcisista) dos cariocas em relação ao seu corpo. O exibicionismo masculino ostenta tanto a exposição do corpo, quanto a habilidade com a bola - adresse au ballon (este dado nos parece 
uma evocação da estreita relação existente entre brasileiros e futebol, ainda que a habilidade com a bola possa estar se referindo ao volley de praia. Neste caso, o enunciador joga com esta representação, cabendo ao leitor construir os sentidos). O dêitico espacial sur et autour expande o ângulo de visão assim como o comportamento para além dos limites da praia. O clima festivo - de eterno carnaval evocado no lead do artigo - e o exibicionismo são apresentados, pelo enunciador (enunciado apreciativo) como uma verdade incontestável cuja duração no tempo determina o que sempre foi e "como" sempre foi: "C'est comme ça depuis la nuit des temps (verdade incontestável / marca temporal indicando duração determina no tempo o que sempre foi), sur un fond de samba ("como" sempre foi).

A caracterização da cidade do Rio como uma cidade que embora litorânea, não está voltada para o largo (não possui tradição marítima), mas para suas praias, circunscreve os limites de um lugar voltado para si mesmo, fechado em si mesmo, denotando e, de certa maneira, refletindo o comportamento narcisista de seus habitantes, e ao mesmo tempo, delimitanto o espaço e dirigindo o olhar do leitor:

"Rio est une ville de bord de mer sans tradition maritime. La ville n'est pas tournée vers l'océan, mais vers ses plages. Le port de plaisance de Gloria, à proximité des pistes de Santos Dumont, est réduit à quelques mâts immobiles. Les seuls bateaux que l'on voit au loin sont les gigantesques navires de croisière et les ferries qui font la navette avec Niterói, sur l'autre rive de la baie de Guanabara. ”

As praias apresentam-se, deste modo, tanto como o local de exibição do corpo e da beleza (claramente identificado em um de seus comentários sobre a praia de Ipanema: "Là où il faut voir, là où il faut être vu"), quanto como o local onde podem ser vistas as desigualdades sociais, como afirma o enunciador no parágrafo seguinte:

"Loin des vagues, des jeunes à la peau chocolatée sculptent d'étonnants châteaux de sable au bord des trottoirs de céramique portugaise. Un groupe de 
touristes scrute l'horizon, les mains agrippées à leur appareil photo. De rares Indiens, égarés de ce côtéci du littoral, vendent des souvenirs bon marché en bord de mer. Les inégalités sociales existent aussi sur les plages. L'Atlantique vient s'enrouler sur le sable, comme un dos qui se fait rond devant tant de beauté (apreciação do enunciador - atitude de reverência do oceano frente à cidade narcisista), le célèbre Pain de Sucre veille sur sa ville et l'on se dit que les cartes postales sont parfois fidèles à la réalité ».

Neste parágrafo, o enunciador sugere três elementos representativos da cultura brasileira: as origens africanas estampada nos jovens de pele achocolotada, a colonização portuguesa marcada nas calçadas de cerâmica portuguesa, e as origens indígenas evocadas na presença dos raros índios perdidos deste lado do litoral vendendo souvenirs baratos à beira-mar. Este último enunciado oferece igualmente ao leitor a possibilidade de inferência sobre a atual condição dos índios no Brasil: o quantificador raros remete à "extinção", perdidos - longe ou fora do seu "habitat" natural, e vendedores de souvenirs baratos a sua condição social.

Através da vista da praia de Copacabana oferecida pelo Pão de Açúcar, o enunciador traça uma linha de demarcação natural (oceano e morros) que divide em dois tempos a história brasileira, contrapondo, deste modo, tempo passado (a chegada dos colonizadores armados de fusis e de bíblias vindos do Atlântico) e tempo presente (os morros, junto aos quais a verticalidade dos prédios de concreto formam tantos ' $i$ '). A vista do oceano (que evoca os acontecimentos históricos, ao mesmo tempo em que o enunciador fornece ao leitor um fragmento da maneira como o país foi colonizado - armados de fusis e de bíblias) é subjulgada, dominada pela visão panorâmica do continente para o qual a cidade do Rio de Janeiro está voltada:

"Depuis le Pain de Sucre, la plage de Copacabana semble ouvrir une nouvelle page dans le livre du Brésil. D'un côté l'Atlantique, par lequel sont arrivés les premiers colons armés de fusils et des bibles ; de 
l'autre les morros (mornes) à l'abri desquels les immeubles de béton forment autant de « $i$ ».

A categoria de cidade turística (que demonstra mais uma vez o caráter de uma cidade litorânea voltada para si mesma) onde o Rio de Janeiro se insere pode ser observada tanto através da exploração comercial da subida do Pão de Açúcar (feita pela companhia de helicópteros), quanto pela presença de turistas (americanos e outros não especificados).

"Sous leur casquette, quelques Américains rigolards regardent un avion s'avancer vers le téléphérique. Après avoir effectué un tour circulaire devant le morne, l'engin se place dans l'alignement de la piste de l'aéroport Santos Dumont. Les touristes filment la scène, espérant secrètement un amerrissage et des histoires à raconter au pays. La montée sur le Pain de Sucre est devenue un commerce des plus fructueux. Une compagnie d'hélicoptères vend des tours de quelques minutes autour du Christ Rédempteur, du lagon et de Maracanã à partir de 150 reals. "

O enunciador se serve, igualmente, da vista panorâmica da cidade do Rio para articular o seu discurso com vistas a antecipar ao leitor a sequência do seu itinerário:

"Divisée en quartiers bien distincts, souvent séparés par les frontières naturelles que constituent les mornes, la ville s'étire à perte de vue. Au nord, les faubourgs de Botafogo, Flamengo, Lapa, Santa Teresa et le centre historique. Au sud, les plages de Copacabana, Ipanema, Leblon, São Conrado et Barra da Tijuca. Chacun avec son identité et ses particularités. 》 
A partir dos bairros citados, o enunciador procede a uma seleção dos locais que comporão o seu trajeto e através da qual ele representará discursivamente a identidade e as particularidades de cada um deles. Esta seleção nos evidencia, sobretudo, a representação que o enunciador construiu dos interesses do seu público. Deste modo, após ter partido de Copacabana (praia lotada, célebre faixa de areia fina, vendedores de côco, índios vendedores de souvenirs, belas garotas, homens tatuados e hábeis com a bola, policiais musculosos, jovens de pele achocolatada, pescadores, barcos alinhados na areia apresentando quase um lado exótico, vista do Pão de Açúcar) em direção ao Pão de Açúcar (vista da cidade e da praia de Copacabana, do aeroporto Santos Dumont, teleférico, turistas, comércio frutífero), ele conduzirá o leitor ao centro histórico, em seguida à Ipanema (praia mítica, garota de Ipanema, local de belas mulheres, bossa nova), ao estádio do Maracanã (futebol), ao bairro de Santa Teresa (que embora evoque a colonização pela arquitetura, centra-se sobretudo na questão das favelas), ao Canecão (casa de espetáculos localizada na zona sul do Rio/ música popular) e à quadra da escola de samba Mangueira (localizada na zona norte do Rio / samba/carnaval).

A caracterização do centro histórico da cidade do Rio de Janeiro revela ao leitor uma outra concepção de um "centro histórico". À medida em que o enunciador vai tecendo a sua descrição, cria-se no leitor francófano ou no leitor conhecedor dos vieux quartiers, das vieilles villes européias um estranhamento decorrente de duas representações que não coincidem. Ao caracterizar esse lugar como histórico, automaticamente mobilizamos elementos e imagens que nos remetem a um tempo passado, sobretudo no que diz respeito à arquitetura. Entretanto, seus prédios são modernos, suas calçadas largas, sua catedral possui ares de cápsula espacial, sua nave cônica, ares futuristas.

"Dans la rua da Alfandega, les magasins affichent Noël sur leur vitrine. A l'ombre des immeubles modernes, les larges trottoirs sont animés par des échoppes de noix de coco [...] Au centre-ville, la cathédrale aux allures de capsule spatiale (Apollo VI a-t-elle échoué sur les rives brésiliennes?) (apreciação do enunciador) est dotée de quatre 
vitraux géants aux couleurs criardes. Des fidèles rencontrés sur le parvis jurent que "pendant les fêtes, l'endroit accueille près de 20000 personnes en liesse!" Mais sa nef conique aux allures futuristes est déserte aujourd'hui. »

A religiosidade e a superstição, assim como os contrastes sociais compõem igualmente a descrição do centro histórico. Ao mesmo tempo em que o comportamento religioso (que se sobressai ao supersticioso: avant d'être superstitieux) dos cariocas, caracterizados como des fervents croyants, é reafirmado nos seguintes enunciados onde as marcas apreciativas do enunciador podem ser observadas: "Il n'est pas rare de les voir se signer avant d'entrer dans les magasins et les restaurants. Du haut de son morne, le Christ Rédempteur ne domine-t-il pas la ville? "; essa religiosidade se vê negada na descrição de uma catedral deserta (onde até mesmo o presépio se encontra na expectativa da chegada do menino Jesus), pois todos os fiéis encontram-se no subsolo da igreja onde foi organizado um mercado de caridade (cujos produtos colocados à venda - vinhos chilenos, champagne, whisky - nos fazem inferir o contraste social). Isto nos leva a inferir que prática e crença nem sempre caminham juntas:

"Place Largo da Carioca, une diseuse de bonne aventure tire les cartes pour seulement quelques reals. "Je vais être grand-mère et Lula sera réélu aux prochaines élections!", s'exclame, toute heureuse, une vieille dame très chic. Avant d'être superstitieux, les Cariocas sont des fervents croyants. II n'est pas rare de les voir se signer avant d'entrer dans les magasins et les restaurants. Du haut de son morne, le Christ Rédempteur ne domine-t-il pas la ville ? [...] La cathédrale sonne creux et même la crèche est dans l'expectative: Marie et les rois Mages attendent l'arrivée de l'enfant Jésus. L'animation est au sous-sol de l'édifice religieux, où un marché a été installé pour une petite 
semaine de charité. Sur une moquette bleue immaculée, des familles font leurs emplettes de vins chiliens et argentins, de champagne et de whisky...»

Os contrastes sociais tornam-se observáveis, dentro do discurso, nas várias profissões citadas: cireurs de chaussures (engraxates), diseuse de bonne aventure (vidente) que tire les cartes pour seulement quelques reals para uma vieille dame très chic; no comércio de rua: échoppes de noix de coco (barraquinhas de água de côco), camionnettes dont le coffre a été transformé en stand hot-dogs; e no mercado de caridade instalado no subsolo da igreja onde as famílias compram vinhos chilenos e argentinos, champagne e whisky:

«[...] A l'ombre des immeubles modernes, les larges trottoirs sont animés par des échoppes de noix de coco, des cireurs de chaussures et des camionnettes dont le coffre a été transformé en stand à hot-dogs. [...] une diseuse de bonne aventure tire les cartes pour seulement quelques reals. "Je vais être grandmère et Lula sera réélu aux prochaines élections! ”, s'exclame, toute heureuse, une vieille dame très chic. »

De uma forma ainda mais evidente, os contrastes sociais emergem nas descrições da favela da Rocinha e do shopping Fashion Mall, localizado no bairro de São Conrado, e também entre os moradores da favela e os frequentadores do shopping:

\begin{tabular}{|c|l|}
\hline Favela da Rocinha & Shopping Fashion Mall - São Conrado \\
\hline 1) Habitée par une population & 1) riche quartier \\
déshéritée, venue du Nordeste & 2) Des boutiques les plus \\
2) Les hommes, réputés forts et & \multicolumn{1}{|l|}{ prestigieuses de la ville } \\
travailleurs, sont nombreux à être & 3) Des galeries de luxe
\end{tabular}




\begin{tabular}{l|l|}
\hline employés (à faible coût) dans le & 4) Service de sécurité discret (pacto \\
secteur du bâtiment & entre a polícia que não se \\
3) des femmes de tout âge font des & intromete no tráfico da Rocinha / \\
ménages dans les beaux quartiers & favelados que não vêm incomodar \\
4) l'unique route bitumée (sinal de & a vida bairro) \\
precariedade) est empruntée par & 5) Le défilé des femmes au corps \\
une fourmilière de motos-taxis & trop parfait pour être vrai \\
5) flancs abrupts & 6) Effluve de parfums français \\
6) des escaliers si étroits que l'on ne & \\
peut s'y croiser & \\
7) des venelles sans lumières & \\
8) abandonnés des politiques et des & \\
forces de l'ordre &
\end{tabular}
9) la favela est " gérée » par la locale

E continuam a ser evocados tanto nas caracterizações do Canecão e da quadra da Mangueira, quanto na descrição dos dois espetáculos e na atitude do público:

\begin{tabular}{|c|c|}
\hline Canecão & \multicolumn{1}{c|}{ Mangueira } \\
\hline 1) au nord de Copacabana & 1) stade de Maracanã - quartier de \\
2) l'une des plus importantes salles & 2) Mangueira \\
de concert de Rio & samba traditionnelle / l'une des \\
& plus anciennes de la ville, bien \\
& classée au sein du défilé du \\
3) des hôtesses pressées proposent & 3) fête improvisée dans la rue, à la \\
à boire & lisière de la favela \\
4) la caipirinha coule à flots & 4) vente de brochettes, de fruits et \\
& de bières au son des percussions \\
5) La nuit est tombée depuis bien & 5) Un type édenté, une serpillière à \\
longtemps lorsque Gilberto Gil fait & la main, saoul de musique nous
\end{tabular}




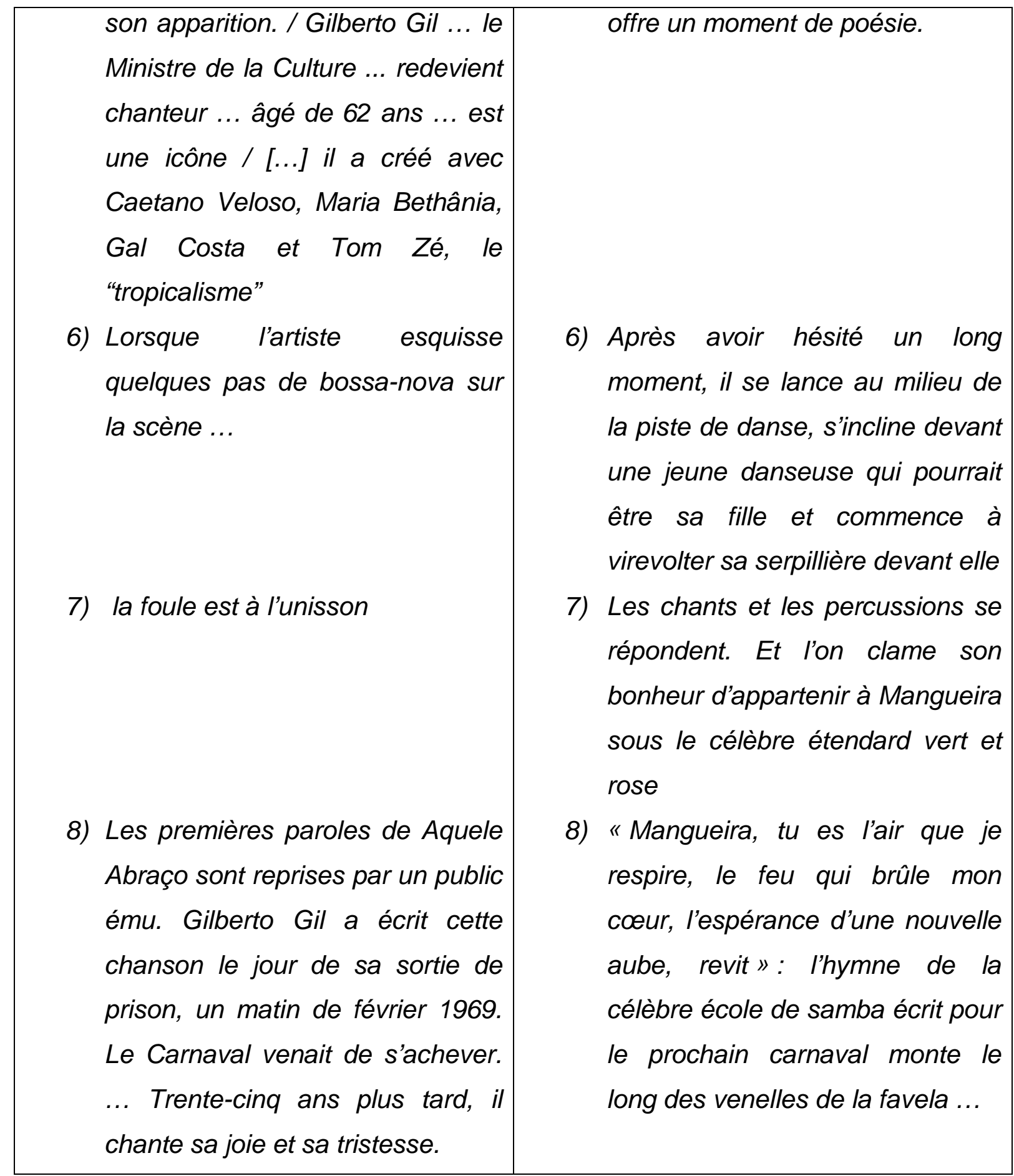

As duas figuras emblemáticas representando o Canecão (Gilberto Gil) e a quadra da escola de samba Mangueira (um tipo desdentado) despertam no público as mesmas reações, embora façam parte de mundos socialmente distantes. É interessante notar a maneira com que o enunciador constrói essas duas imagens através das designações de seus atores e das escolhas lexicais operadas em sua descrição que vão possibilitar ao leitor reconstruir as representações evocadas: Gilberto Gil, Ministre de la Culture, chanteur (que foi preso e exilado sob a ditadura) 
fait son apparition / Un type édenté (sem identidade), balayeur se lance au milieu de la piste de danse. Gilberto Gil âgé de 62 ans est une icône / Un type édenté, saoul de musique s'incline devant une jeune danseuse qui pourrait être sa fille. L'artiste esquisse quelques pas de bossa nova sur la scène / Un type édenté commence à virevolter sa serpillière devant elle (a jovem dançarina), il tournoie, enroule danseuse et serpillière.

Da mesma maneira, os contrastes podem ser percebidos e reconstruídos na

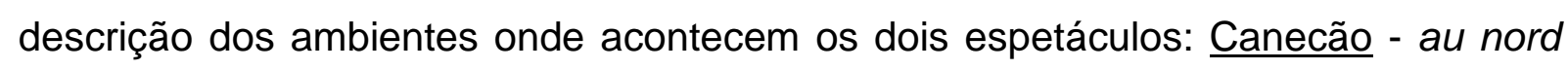
de Copacabana, l'une des plus importantes salles de concert de Rio, des hôtesses pressées proposent à boire, la caipirinha coule à flots; quadra da Mangueira - stade de Maracanã - quartier de Mangueira; Mangueira est la garante de la samba traditionnelle / l'une des plus anciennes de la ville, bien classée au sein du défilé du carnaval ; fête improvisée dans la rue, à la lisière de la favela ; vente de brochettes, de fruits et de bières au son des percussions. E, igualmente, no comportamento do

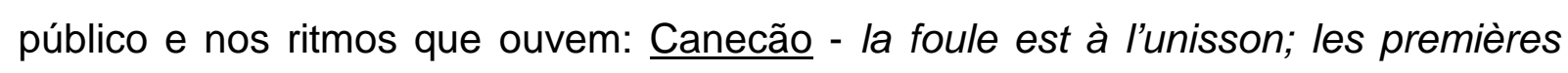
paroles de Aquele Abraço sont reprises par un public ému. Gilberto Gil a écrit cette chanson le jour de sa sortie de prison, un matin de février 1969. Le Carnaval venait de s'achever. ... Trente-cinq ans plus tard, il chante sa joie et sa tristesse. Quadra da Mangueira: les chants et les percussions se répondent. Et l'on clame son bonheur d'appartenir à Mangueira sous le célèbre étendard vert et rose ; "Mangueira, tu es l'air que je respire, le feu qui brûle mon cœur, l'espérance d'une nouvelle aube, revit »: I'hymne de la célèbre école de samba écrit pour le prochain carnaval monte le long des venelles de la favela.

Através da descrição do comportamento do público emocionado, que canta em uma única voz, em oposição aos cantos e percussões através dos quais os mangueirenses clamam a sua felicidade de pertencer à Mangueira, o enunciador caracteriza os ritmos do tropicalismo e do samba, e constrói, pelo conjunto de todos os elementos acima citados (a designação e a caracterização dos atores, a localização espacial das duas "casas de espetáculo", a descrição das duas "festas") as representações "sociais" dessas duas manifestações artísticas.

A mítica praia de Ipanema torna-se, no discurso, o cenário para a introdução do terceiro gênero da música brasileira, a bossa nova, assim como o cenário da retomada do tema da beleza feminina e do exibicionismo. Caracterizada como um mito datado no tempo (ano de 1962) e delimitado no espaço (au café Veloso, rue 
Montenegro), e cujo nascimento decorre da composição de uma música (Garota de Ipanema) que narra a beleza mais "bela" e mais graciosa da jeune fille au corps doré du soleil d'Ipanema Helô Pinheiro (beleza que se estenderá à carioca e à mulher brasileira em geral), a praia de Ipanema (caracterizada como [...] une lagune en forme de coeur (o que nos evoca o amor, o romantismo) [...] dominée par la forêt et les favelas ) é "imortalizada" na letra de Tom Jobim e Vinícius de Moraes. Deste modo, a música-mito (Reprise par Sinatra sous le titre de The Girl from Ipanema, e cuja melodia a fait le tour du monde) "mitificou" o bairro e a garota em questão, e por inferência e extensão, a beleza das cariocas relatada pelo enunciador no seguinte enunciado:

"Certains cariocas (heterogeneidade mostrada) prétendent que toutes les jolies filles de Rio s'y donnent rendez-vous"

Entretanto, o enunciador atenua a "veracidade" do mito (ou dos mitos) através de dois outros discursos relatados:

"La plage d'Ipanema est un mythe. Pour les uns, c'est un univers surfait, pour les autres, c'est l'endroit « in ». Là où il faut voir, là où il faut être vu. »

embora ele oponha, na legenda da foto da praia de Ipanema (p. 34 do artigo), o discurso citado desses "alguns" (pour les uns...que ele identifica ou designa como les blasés) a sua própria apreciação:

"Ipanema: Rendue célèbre par la chanson de Tom Jobim et Vinícius de Moraes, "Garota di Ipanema ", écrite en 1962, la plage d'lpanema accueillerait les plus jolies filles de Rio. Même si certains prétendent qu'elle est surfaite (les blasés), elle reste toutefois la plage chic de Rio, Copacabana étant considérée plus «populaire ». » 
O enunciado "Là où il faut voir, là où il faut être vu" reforça e retoma o comportamento exibicionista (já identificado em outros trechos do texto nesta análise) dos/das cariocas que também pode ser inferido a partir da seguinte

informação fornecida pelo enunciador (ao leitor) sobre a antiga musa de Ipanema Helô Pinheiro:

"Il y a quelques années, l'ancienne égérie du tout Ipanema a même posé en compagnie de sa charmante fille dans le Play Boy brésilien. " (a beleza hereditária).

Através dos contrastes sociais, observa-se a introdução do tema da violência. De certa maneira, desde o início do seu discurso, o enunciador oferece pistas ao leitor da presença do perigo que ronda. Estas pistas podem ser observadas nos seguintes enunciados:

1) Trois policiers bodybuildés assis sur leur quads surveillent les formes des filles (a presença de policiais na praia é indício de violência)

2) D'un côté de l'Atlantique, par lequel sont arrivés les premiers colons armés de fusils et de bibles... (podemos inferir que o próprio processo de colonização feito através da força das armas e da conversão imposta já é um ato de violência)

E prosseguem nas descrições do bairro de Santa Teresa:

3) Le long des ladeiras ... des jeunes garnements à la peau sombre tentent des figures d'équilibristes, posés sur les marche-pieds des wagons.

4) Les mains agiles de ces garçons venus des favelas voisines ont attiré ... le courroux des responsables du tourisme local.

5) A l'arrière du wagon, un policier en arme veille d'un œil attentif sur ces petites canailles. 
Nos três enunciados acima citados ( 3,4 e 5 ), o enunciador localiza no espaço a origem desses delinquentes (venus des favelas voisines), caracteriza-os segundo a faixa etária (jeunes garnements, ces garçons, petites canailles) e a cor de sua pele (à la peau sombre). Entretanto, um pouco mais adiante no seu discurso, o enunciador contrapõe a desonestidade dos jovens "trombadinhas" à honestidade de outros moradores da favela, ao evocar os homens e mulheres trabalhadores que compõem essa population déshéritée, principalement venue du Nordeste. Isto nos permite inferir que as dificuldades financeiras enfrentadas por esses deserdados não levam todos obrigatoriamente à prática de atos ilícitos:

1) Les hommes, réputés forts et travailleurs, sont nombreux à être employés (à faible coût) dans le secteur du bâtiment.

2) Des femmes de tout âge font des ménages dans les beaux quartiers.

A favela encerra, desta maneira, em seu seio, os deserdados de um sistema social e político que os abandonou, e do qual o enunciador se serve para explicar a questão do tráfico de drogas como meio de subsistência dos próprios traficantes e como uma maneira de ajudar a comunidade (para esta última explicação, observa-se o desengajamento do enunciador frente a esse dado ao se servir do discurso relatado explicitado na expressão dit-on):

3) La drogue et les petits trafics font vivre une partie des habitants

4) Depuis sa création, dans les années 40, Rocinha est abandonnée des politiques et des forces de l'ordre

5) La favela est "gérée " par la mafia locale qui, dit-on, redistribue une partie de ses gains aux plus défavorisés.

6) La favela est "gérée " par la mafia locale qui, dit-on, redistribue une partie de ses gains aux plus défavorisés

O tema do futebol é abordado na visita ao estádio do Maracanã caracterizado como um estádio decadente, embora mítico:

1) vide de supporteurs

2) ils sont à peine 9000 aujourd'hui (marca temporal da enunciação) 
3) ce qui fut le plus grand stade du monde (avec une capacité de 180000 places)

4) n'est qu'une cité fantôme

5) La vista de Garrincha, la vision du jeu de Socrates et même les accélérations de Ronaldo ne sont plus ici que de lointains souvenirs

6) [...] le Christ Rédempteur ne regarde que d'un œil distrait le pauvre spectacle (apreciação do enunciador) sur la pelouse fatiguée

O gosto do brasileiro pelo futebol é demonstrado em uma única citação (heterogeneidade mostrada) que faz referência à possibilidade da equipe do Flamengo de ser rebaixada para uma divisão inferior (além da citada anteriormente na habilidade dos cariocas com a bola):

1) "Ça entraînerait une révolution à Rio, voire dans tout le pays"

Para encerrar a nossa análise, propomos um resumo sob a forma de tópicos dos clichés observados a partir do próprio itinerário escolhido pelo enunciador para representar a cidade do Rio de Janeiro:

- Copacabana e Ipanema: praias legendária e mítica, sol, calor, mulheres e homens belos, local de exibição do corpo e da beleza (Fidèle à sa réputation, elle (Copacabana, legenda da foto p.30 do artigo) est l'un des lieux de rendez-vous des belles cariocas / Ipanema - là où il faut voir, là où il faut être vu), Helô Pinheiro - garota de Ipanema;

- Copacabana, Centro Histórico, Santa Teresa, Favela da Rocinha, bairro de São Conrado: contrastes sociais e violência

- Estádio do Maracanã: futebol

- Ipanema, Canecão, Mangueira: bossa nova, música popular brasileira / tropicalismo; samba; carnaval

O ambiente de festa permanente, o eterno carnaval como evocado no lead, pode ser percebido em todo o discurso através das caracterizações dos locais visitados (pontos turísticos): 
- das praias de Copacabana e Ipanema (calor, praias lotadas, bar "Garota de Ipanema" que recebe des touristes en mal de repères (em função da mudança do antigo nome deste bar chamado "Veloso") onde les chopp coulent à flots, onde des jeunes musiciens tentent un rythme de bossa nova)

- do centro histórico (o comércio de rua; a animação no subsolo da igreja)

- do Canecão e da quadra da Mangueira (La nuit est tombée depuis bien longtemps lorsque Gilberto Gil fait [...]; Plus tard, nous longeons le stade Maracanã pour rejoindre le quartier de Mangueira. $\underline{\| \text { est deux heures du }}$ matin, les artères sont bouchées.)

E é corroborado no enunciado "C'est comme ça depuis la nuit des temps, sur un fond de samba ».

Como dito no início desta análise, a reportagem sobre o Rio de Janeiro engloba todos os clichés sobre o Brasil. Da mesma maneira, a seleção de cidades feitas pelos responsáveis desta publicação (Rio, Brasília, Olinda, Parati, Cachoeira, Amazônia, Bahia) evidencia, ao nosso ver, o que dissemos a respeito da concentração de reportagens (de acordo com o nosso corpus exploratório) sobre as regiões Norte, Nordeste e Sudeste. Entretanto, como já mencionado, elas não serão analisadas em sua totalidade, e nos propomos, aqui, de forma breve, a trabalhar somente com seus títulos e subtítulos.

1) Título: Une interview d'Oscar Niemeyer: “A Brasilia, j'ai dessiné les courbes".

Subtítulo: Brasilia. Conçue à la fin des années 1950, au centre du pays, dans une région désertique, la capitale, Brasilia, illustre la volonté du Brésil de s'enraciner à l'intérieur, loin de la mer et de l'Europe. Son architecte, Oscar Niemeyer, 97 ans, est le symbole de cet esprit hautement indépendant et audacieux.

Autor : Olivier Bauer

2) Título: Que linda Olinda!

Subtítulo: Nordeste. A quelques kilomètres de la grande ville du Nordeste, Recife, célèbre pour sa plage et son carnaval, la ville d'Olinda la joue 
discrète. Perchée au-dessus de l'océan, parsemée d'églises baroques et de belles villas du XIXème siècle, elle offre au visiteur des joyaux artistiques dans un site naturel d'exception.

Autor : Hélène Grisoli

3) Título: Parati, Voie royale vers l'Eldorado

Subtítulo: Costa Verde. Port d'entrée vers les richesses de l'intérieur, Parati a prospéré au XVIIlème siècle grâce au commerce de l'or et des diamants. Inscrite au patrimoine de l'humanité par l'Unesco, elle a su bien préserver son prestigieux passé que vous y croiserez peut-être le descendant du dernier empereur du Brésil.

Autor : Jean-François Guggenheim

4) Título: A Cachoeira, bacchanale avec les Dieux

Subtítulo: Religion. Le Brésil foisonne de communautés religieuses dont les rituels sont irrigués par les cultes Chrétien et animiste. L'une des plus authentiques est la "Irmandade de Boa Morte ", formée exclusivement de femmes. Lors de la fête de la Vierge, elles convoquent les esprits à une cérémonie rythmée par les danses et les transes.

Autor : Jean-François Guggenheim

5) Título: Bahia de toutes les musiques

Subtítulo: Nordeste. Un mélange fort épicé d'Afrique, de Portugal, de Brésil, baigné dans la chaleur du Nordeste, voilà Bahia. Une ambiance de tous les diables, qui irrigue la nouvelle musique brésilienne. Ici jouent les meilleurs groupes "d'Afro Bloco », qui puisent leur force dans les origines africaines de la ville.

Autor : Florent Mazzoleni

A partir dos títulos e subtítulos das cidades selecionadas pelos responsáveis desta publicação podemos destacar dois temas evocados: a colonização portuguesa e as origens africanas.

No que se refere à colonização, observamos a centração, por um lado, não no processo em si, mas nas marcas deixadas por ela em certas cidades (como Olinda) 
e visíveis na arquitetura das igrejas barrocas e das belas mansões do século XIX. Por outro lado, a caracterização desses lugares fornece ao leitor fragmentos da história do país ilustrados nas riquezas (minerais) do interior, no comércio do ouro e do diamante responsável pela prosperidade da cidade de Parati, mas que implicitamente remete o leitor (conhecedor da história do processo de colonização no Brasil) à exploração sofrida pelo país. Esses fragmentos da história brasileira são introduzidos, igualmente, pelo enunciador, em dois outros enunciados. O primeiro, através do título da reportagem Parati, voie royale vers l'Eldorado (indica o período do Reinado); o segundo, no momento em que o enunciador dialoga com o seu leitor evocando a possibilidade de "se cruzar", em Parati, com o descendente do último imperador brasileiro, informando-o, deste modo, sobre o sistema de governo vigente antes do país se tornar uma República.

As origens africanas que se inserem, na verdade, dentro do processo de colonização portuguesa (tráfico de negros/escravidão) são evocadas através da herança cultural expressa nos ritos religiosos (culte animiste), caracterizados na convocação dos espíritos em uma cerimônia ritmada por danças e transes; assim como através da música dos Afro Blocos da Bahia (ambiance de tous les diables), e explicitadas no enunciado "Ici jouent les meilleurs groupes d'Afro Bloco, qui puisent leur force dans les origines africaines de la ville".

A "mistura" destes dois elementos (ou "ingredientes") da cultura brasileira, colonização portuguesa e herança africana, caracteriza a Bahia picante que encerra em si a mistura que representa o Brasil : "Un mélange fort épicé d'Afrique, de Portugal, de Brésil, baigné dans la chaleur du Nordeste, voilà Bahia".

O campo semântico de algumas palavras pode ser atualizado pelo contexto e pelas intenções do enunciador. Deste modo, as "curvas" desenhadas por Niemeyer em Brasília nos remetem às "formas das cariocas" evocadas na reportagem sobre o Rio de Janeiro. A construção da capital do Brasil numa região desértica é utilizada como argumento que justifica uma predisposição ao encerramento em si mesmo, evocando, desta maneira, através do predicado s'enraciner à l'intérieur, loin de la mer et de l'Europe a mesma atitude do Rio de Janeiro caracterizado como uma cidade não voltada para o oceano. O Eldorado (pays merveilleux, de rêve, de délices, éden, paradis - Dictionnaire Le Robert) em direção ao qual a cidade de Parati dirigia os que chegavam em seu porto designa e caracteriza ao mesmo tempo 
o Brasil das riquezas, o paraíso que será encontrado. O verbo foisonner (être pourvu abondamment de - Dictionnaire Le Robert) expressa a multiplicidade de religiões presentes no Brasil, enquanto a palavra bacchanale constrói o sentido de festas religiosas com danças, jogos e mistérios retomado na palavra animiste. A mistura picante (fort épicé) que caracteriza não somente a Bahia, mas por extensão o Brasil joga com as representações do país "mais quente" da América Latina.

Finalmente, a seção Brésil Pratique oferece ao leitor da revista Ulysse Télérama três possibilidades de visita do país elaboradas em função do gosto de cada um, divididas em mito (Rio de Janeiro, São Paulo e Brasília), charme das cidades coloniais (Salvador, Recife, Olinda e Ouro Preto) e natureza (Amazônia, Pantanal, Chapada Diamantina, Foz do Iguaçu e Jericoacoara), evidenciando, deste modo, a partir de duas representações recorrentes (país mítico e país de natureza exuberante) os atrativos do Brasil no exterior.

O próximo artigo analisado apresenta, como objeto de discurso, a religião do corpo, o culto da beleza na sociedade brasileira. Em função das frequentes generalizações operadas pelo enunciador (extensão a todo o povo brasileiro das propriedades atribuídas aos cariocas), a cidade do Rio de Janeiro se torna, pelo discurso, a metonímia do Brasil. 


\section{ii. Rio de Janeiro: a metonímia do Brasil}

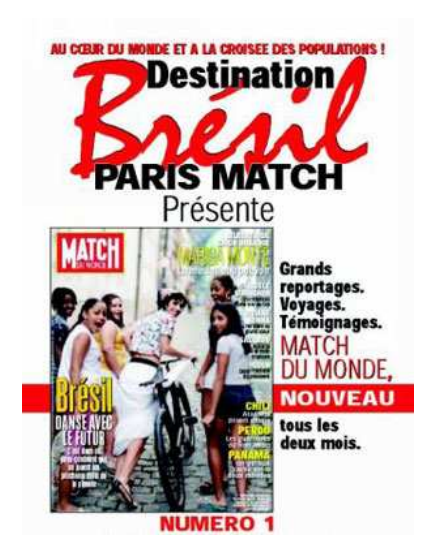

président.

\section{Revista: Match du Monde ${ }^{39}$}

\section{Capa: Brésil danse avec le futur}

Legenda : "C'est dans ce pays-continent que se jouent les prochains défis de la planète »

Subtítulos: Gilberto Gil, Chico Buarque, Marisa Monte - la musique au pouvoir / Gisele Bünchen : confidence d'une star au top / Viviane Senna: L'héritière au grand cœur / Salgado replante la forêt tropicale / Lula: dans l'intimité du

Título do artigo : «La religion du corps »

Autor : Regina Guerreiro (ex-diretora das revistas Elle e Vogue no Brasil

Lead: "Venu de la plage, partout s'impose le culte de la beauté, une ode à la sensualité devenu obsession nationale »

O lead do artigo nos fornece três informações a respeito do seu objeto de discurso "a religião do corpo": a origem (la plage); a difusão que se estende e se inflige a todo o território nacional (partout/ obsession nationale); e a relação do povo deste país com o seu corpo (culte/ode/obsession). Ao mesmo tempo, podemos

\footnotetext{
${ }^{39}$ Esta revista bimestral é publicada pelo grupo Hachette Filipacchi Médias, que publica igualmente a revista Paris Match. Este é o primeiro número de Match du Monde, lançado em 17 de fevereiro de 2005.
} 
identificar algumas propriedades pertencentes ao objeto/religião/ só que aplicadas não ao espírito, mas à matéria (culte de la beauté, obsession). Do mesmo modo, o verbo s'imposer denota a obrigatoriedade do culto, indicando uma ação que deve ser reconhecida por todos.

O parágrafo seguinte que se apresenta como um resumo do que foi desenvolvido no artigo será analisado em enunciados separados, pois ele fornece ao leitor-destinatário a dimensão e a extensão desta religião do corpo, deste culto à beleza, justificando de imediato o título do artigo:

"Ici, à la force des muscles ou à la pointe du bistouri, on forge son physique. C'est la patrie de la chirurgie plastique que son grand maître, le professeur Ivo Pitanguy, l'homme aux mains d'or, n'hésite pas à qualifier de "chirurgie du bonheur". D'innombrables salles de sport sont ouvertes jour et nuit afin de permettre à chacune et à chacun de "travailler" sa silhouette jusqu'à la perfection. Certes, avec $8000 \mathrm{~km}$ de plages et un climat tropical, le pays invite à la quasi-nudité. D'autant qu'en maillot de bain les inégalités sociales disparaissent. Reste à montrer comme un triomphe un corps ferme, bronzé, sain, aux courbes harmonieuses. Jeune. Regina Guerreiro, ancienne directrice d' "Elle " et de "Vogue " pour le Brésil, analyse sans pitié ce phénomène qui rend tout un peuple sexy. ”

1) "Ici, à la force des muscles ou à la pointe du bistouri, on forge son physique. C'est la patrie de la chirurgie plastique que son grand maître, le professeur Ivo Pitanguy, l'homme aux mains d'or, n'hésite pas à qualifier de "chirurgie du bonheur ». D'innombrables salles de sport sont ouvertes jour et nuit afin de permettre à chacune et à chacun de " travailler » sa silhouette jusqu'à la perfection. "

O dêitico temporal Ici remete à situação de enunciação e retoma, ao mesmo tempo, os lugares citados no enunciado anterior onde o culto da beleza se impõe. 
«Partout» e «nationale» nos remetem, deste modo, ao Brasil caracterizado no enunciado seguinte como "la patrie de la chirurgie plastique ». Ici determina, portanto, o espaço nacional.

A expressão francesa "à la force des muscles" se serve dos sentidos integrados a uma outra expressão "à la force du poignet » que significa "par ses seuls moyens, et en faisant de grands efforts ». Em relação de adição com a expressão "à la pointe du bistouri" através da conjunção "ou", podemos inferir que os meios empregados para se forjar o físico conta com um esforço que caracterizaremos como "natural" em oposição à "à la pointe du bistouri » que caracterizaremos como "artificial". Isto para dizer que o "estar belo" ou o "mostrar-se belo" é um estado que se almeja atingir a qualquer preço. $O$ argumento utilizado e que nos demonstra que este esforço é feito a qualquer preço encontra-se nas frases "on forge son physique " e "les innombrables salles de sport, ouvertes jour et nuit", onde, por sua vez, o quantificador "innombrables" e a dêitico temporal "jour et nuit" determinam não somente a quantidade de salas e o tempo dedicado para se forjar o fisico, mas também indica implicitamente o número de pessoas que se dedicam, a qualquer momento disponível, a isso. O emprego do verbo “forger" corrobora essa interpretação, pois nos remete à idéia de "façonner " e "fabriquer ", ou seja, " on façonne son physique, on fabrique son physique". As "innombrables salles de sport" compreendem, deste modo, em contraposição a uma "sala de cirurgia" (onde também se pode forjar o fisico à la pointe du bistourı), o espaço "natural" para se atingir esse objetivo.

O sentido expresso na frase "travailler sa silhouette jusqu'à la perfection" contribui igualmente à construção da dimensão do esforço realizado para se "forjar o físico à qualquer preço", nos remetendo à "religião do corpo" e ao "culto da beleza":

2) "Certes, avec $8000 \mathrm{~km}$ de plages et un climat tropical, le pays invite à la quasinudité."

A concessão expressa por "Certes" concede a este "fenômeno nacional" um argumento que se traduz nos "8000 km de plages et un climat tropical". Os $8000 \mathrm{~km}$ de praias que compreendem a extensão do litoral brasileiro justificam, deste modo, a difusão deste culto sobre todo o território nacional assim como o "clima tropical" nos remete ao calor dos trópicos justificando a "quasi-nudité" da população. 
3) "D'autant qu'en maillot de bain les inégalités sociales disparaissent." Esta afirmação opõe-se ao que foi dito no artigo da revista Ulysse Télérama onde as desigualdades sociais podem ser vistas também "sur la plage" através do trabalho

dos índios vendedores de "souvenirs". O "maillot de bain" não corresponde, desta maneira, a uma marca externa de riqueza. Despidas de seus aparatos sociais, que podemos inferir como sendo as "roupas em geral" excluindo o "maillot de bain", as pessoas tornam-se iguais socialmente falando (bem como Adão e Eva antes de cometerem o pecado no Paraíso"!!!).

4) "Reste à montrer comme un triomphe un corps ferme, bronzé, sain, aux courbes harmonieuses. Jeune." A expressão "reste à..." nos indica que o único elemento que fará a diferença aflorar, mesmo que esta não seja social, é o corpo, mostrado como um triunfo. Mas não qualquer corpo, é o corpo "ferme, bronzé, sain, aux courbes harmonieuses. Jeune.", pois alguma coisa tem que existir para se marcar a diferença, para se distinguir ou se destacar do Outro ou dos Outros. O adjetivo "jeune" exclui, portanto, desta categoria, os mais velhos (a partir de que idade não sabemos.).

5) "Regina Guerreiro, ancienne directrice d' "Elle » et de "Vogue » pour le Brésil, analyse sans pitié ce phénomène qui rend tout un peuple sexy."

A religião do corpo e o culto da beleza são designados aqui como um "fenômeno", ou seja, um acontecimento anormal e surpreendente que torna "todo um povo sexy". O pronome indefinido "tout" expande a todo o povo brasileiro a propriedade de "ser sexy". Este "fenômeno" é, deste modo, "analisado" e comentado por uma "autoridade" cuja credibilidade é sustentada tanto pela sua nacionalidade (brasileira) quanto pelo seu curriculum (ex-diretora das revistas Elle e Vogue no Brasil), servindo de referência ao leitor para atestar a veracidade dos fatos.

"Vieillir, grossir ou simplement se laisser aller, laisser tomber, c'est du suicide. Toutes les portes se ferment, celles du travail comme celles de l'amour." 
O atingir uma das etapas naturais da vida que é a velhice ou então o engordar (que pode se produzir tanto de forma involuntária, em decorrência de problemas hormonais que acarretam o ganho de peso ou a até mesmo a obesidade, quanto voluntariamente, como o não se importar com a saúde nem com a aparência) demonstra que nem voluntária nem involuntariamente se é permitido "não estar belo(a)", "não mostrar-se belo". O "se laisser aller / laisser tomber" que podem ser compreendidos igualmente como um ato voluntário daquele(a) que simplesmente não possui tais preocupações caracteriza-se como uma das formas de suicídio evocada pelo enunciador, pois "todas as portas se fecham, as da profissão e as do amor". O fato de arriscar a vida sem necessidade ("fait de risquer sa vie sans nécessité") traduzido na expressão "c'est du suicide" indica que morre-se em vida, apaga-se para o mundo dos vivos sem se entrar literalmente para o mundo dos mortos, a partir do momento em que a consequência de um ato voluntário (se laisser aller, laisser tomber) ou involuntário (vieillir, grossir) coloca tais indivíduos à margem de sua própria vida, mostrando-se, desta maneira, como uma das formas de exclusão social. $O$ não respeito a essa exigência acarreta tanto 0 fracasso profissional quanto o fracasso no amor. Este enunciado transmite uma tensão permanente decorrente da exigência do"estar constantemente belo(a), do "mostrarse belo(a)", de uma necessidade vital.

"Ivy Margareth est pendant trois jours et trois nuits la reine du carnaval. C'est la fête la plus délirante du monde et son corps explose comme un feu d'artifice. Suivie par son roi, sa cour, ses princesses, Ivy défile dans toutes les écoles de samba. Sa beauté afroaphrodisiaque"éclate et la terre tremble. Chaque mouvement de son corps d'ébène raconte l'histoire du Brésil. Un pays-paradis, libre, glorieux, plein de sève, de sensualité, de force, de vie. Oh, my God, toutes les têtes tournent, les coeurs battent la chamade, la foule entre en transe." 
Ao resgatarmos o campo nocional de "religião" e de "culto" evocados no título e no lead do artigo, nos pareceu possível estabelecer uma relação metafórica entre o ritual religioso e o ritual carnavelesco da seguinte maneira:

As escolas de samba = 0 "templo" de realização do culto da beleza, o local onde se cultua a beleza.

O desfile de carnaval $=0$ rito, a cerimônia "religiosa", mas também 0 rito de passagem

O samba $=0$ canto que entoa 0 rito, a oração

$\mathrm{O}$ corpo $=0$ elemento que materializa os efeitos do canto e do rito

A rainha e o rei do carnaval $=$ chefes desta cerimônia religiosa

Sua côrte $=$ os seguidores, os fiéis

Ses princesses $=$ as sucessoras, aprendizes de rainha

Sa beauté afro-aphrodisiaque = beleza de essência divina, a de Afrodite, deusa do amor, que excita o desejo sexual; afro que determina as suas origens africanas assim como o seu corpo de ébano conta a história do Brasil. Possuir um corpo de ébano que "raconte l'histoire du Brésil" nos remete à capacidade de narrar, de descrever a história deste país que conta, entre outras, com a influência do povo africano na sua cultura. O corpo é como um elemento arqueológico que, contrariamente aos expostos em museus e que compõem a história de uma cultura passada, apresenta-se vivo, em movimento, fazendo parte e contribuindo para a compreensão de sua própria cultura. Seu corpo que explode como fogos de artifício carrega em si, por extensão, toda a personalidade do país tropical.

Os efeitos do ritual = la terre tremble / toutes les têtes tournent / les coeurs battent la chamade / la foule entre en transe. 
Em seguida, temos a designação do Brasil como un pays-paradis cujos atributos integram o paradigma religioso, caracterizando-o como : livre, glorioso (que participa da glória celeste), pleno de seiva (princípio vital), de sensualidade, de força, de vida.

Através de todas as atribuições de propriedades feitas ao Brasil até aqui, percebe-se a reiteração constante de elementos que representam este país tropical: sexy, sensual, paradisíaco, livre, tropical (ensolarado, quente), desnudado, afrodisíaco. A frase do parágrafo seguinte acrescenta a exuberância, a extroversão e a desinibição estendendo ao povo todos esses atributos.

"Dans cette société exubérante, extravertie et désinhibée, le corps est devenu une obsession, presque une religion. D'abord parce qu'il fait chaud, très chaud: $30 \mathrm{C}, 40 \mathrm{C}$ et même davantage, ce qui rend la nudité presque obligatoire. D'autant que 8000 $\mathrm{km}$ de côtes, cela fait autant de kilomètres de plages. Il n'est donc pas surprenant que la femme de Rio, de Salvador de Bahia ne s'habille pas mais se déshabille. ”

No parágrafo acima, encontra-se a recuperação do que foi dito no texto introdutório do artigo "Certes, avec $8000 \mathrm{~km}$ de plages et un climat tropical, le pays invite à la quasi-nudité" expresso em "d'abord parce qu'il fait chaud, très chaud: $30 \mathrm{C}, 40^{\circ} \mathrm{C}$ et même davantage, ce qui rend la nudité presque obligatoire. D'autant que $8000 \mathrm{~km}$ de côtes, cela fait autant de kilomètres de plages. II n'est donc pas surprenant que la femme de Rio, de Salvador de Bahia ne s'habille pas mais se déshabille."

Através de cada um desses argumentos ou premissas (Grize:1997) que justificam a nudité no país, é possível se chegar à conclusão explicitamente mostrada pela conjunção donc:

$1{ }^{\text {a }}$ premissa: $8000 \mathrm{~km}$ de côtes

$2^{\mathrm{a}}$ premissa: $8000 \mathrm{~km}$ de plages 
3믈 premissa: un climat tropical

4a premissa : il fait chaud, très chaud: $30^{\circ} \mathrm{C}, 40^{\circ} \mathrm{C}$ et même davan tage ...

Conclusão: il n'est donc pas surprenant que la femme de Rio, de Salvador de Bahia ne s'habille pas mais se déshabille.

Esta conclusão apreciativa do enunciador, embora restrinja a nudez feminina às mulheres do Rio de Janeiro e da Bahia, acaba implicitamente por estender essa prática do despir-se a todas as brasileiras tendo em vista que as praias e o clima tropical compreendem toda a extensão do território nacional.

Deste modo, temos em quase todo o texto a expansão das características atribuídas aos cariocas a todo o povo brasileiro, como se pode observar nos primeiros enunciados deste parágrafo. Além disso, o enunciador acrescenta outras razões que justificam a prática da nudez além das premissas listadas acima:

"Evidemment, il y a encore mille autres raisons. Dans les veines du peuple brésilien, le sang bout fort, très fort, assemblage complexe d'un multiculturalisme indigène, européen, africain, arabe, japonais... Le Brésil est un "pays métis ", ni blanc, ni noir, ni indigène, ni jaune, ni rouge. Les "Brésilindiens" et les Afro-Brésiliens vivaient sur une "terra de ninguém", c'est-à-dire une terre n'appartenant à personne. A partir de cette carence essentielle, ils ont dû créer leur propre identité. Notre identité. Ensoleillée. Si voluptueuse qu'elle en est lascive. "La Brésilienne est pur sexe ", assène le photographe Luiz Tripolli, le click le plus sensuel du pays. Eperdument exotique, naïve et primitive, aujourd'hui encore la culture brésilienne demeure infantile et le corps, l'instrument à travers lequel l'individu sent qu'il existe. "Le corps est un capital 
symbolique ", dit le psychanaliste Reinaldo Lobo. Les esclaves beaux et forts ont toujours su qu'ils avaient plus de chances auprès des maîtres. Les beautés noires, le luxe de ces "honorables Messieurs ", valaient deux fois le prix d'un grand mulâtre. Elles jouaient plusieurs rôles : maîtresse de Monsieur, chambrière de Madame, nourrice du petit héritier. C'était un beau sein noir qui allaitait, pour ne pas abîmer le corps de la femme blanche. Au secours! la libido de l'enfant commençait dès le berceau à se développer. ”

Uma dessas razões é o sangue "mestiço », como o país. Um sangue que pela sua composição apresenta-se como uma "poção" onde, ao se misturar vários ingredientes - indigène, européen, africain, arabe, japonais..., ferve nas veias.

O "viver numa terra de ninguém" remete à "carência essencial" de um povo sem terra, sem pátria, sem referências. Em função disso, houve a necessidade desses dois povos criarem uma identidade que, hoje, corresponde à identidade brasileira, na qual o enunciador se insere ao dizer "Notre identité". Uma identidade caracterizada como ensolarada, voluptuosa e lasciva, isto é, carregada de erotismo e de sensualidade. Assim determinada, tem-se desta maneira a expansão das propriedades da classe-objeto "identidade brasileira" à classe-objeto "povo brasileiro".

A asserção do fotógrafo Luiz Tripolli (argumento de autoridade) corrobora a sensualidade e a voluptuosidade atribuídas à mulher brasileira caracterizada como sendo "pur sexe". A escolha do verbo introdutório do discurso indireto "asséner" exclui a possibilidade de diálogo a respeito da declaração de Luiz Tripolli, apresentando-se como um fato, pois até mesmo o click do fotógrafo é descrito como o mais sensual do país. O verbo empregado oferece ao leitor-destinatário a representação da atitude do fotógrafo ao fazer essa afirmação, descrevendo assim um ato de fala no momento da comunicação.

Um outro argumento de autoridade é introduzido pelo enunciador nas palavras do psicanalista Reinaldo Lobo que explica a importância do corpo nesta sociedade. O corpo é um capital, um patrimônio que embora simbólico, não exclui o 
sentido de "bem ativo do qual as pessoas se servem para empreender algum negócio". Esta noção do corpo como um "bem de valor e um bem negociável" integrada na palavra "capital" é explicitada através da contextualização histórica da negociação dos negros no Brasil, que de acordo com o enunciador, tinham consciência de que "ser belo" e "ser forte" consistia em um trunfo junto aos seus senhores. Ao mesmo tempo, essas "belezas negras" (les beautés noires) uma vez adquiridas como objetos de luxo capitalizariam o patrimônio do senhor, a partir do momento em que serviam como amantes, amas de leite e mucamas. A beleza física é assim interpretada, desde os tempos mais remotos desta sociedade, como um patrimônio que abre portas.

As origens do culto ao "bumbum" na sociedade brasileira remonta, deste modo, segundo o psicanalista, a esse período da história do país:

«Le culte des fesses dans la société brésilienne d'aujourd'hui, comparable à l'obsession des seins chez les Américains, commencent exactement à ce moment de la trajectoire de notre colonisation » assure le Dr Reinaldo Lobo. C'est des « mucamas » (esclaves noires) que les Brésiliennes ont hérité les hanches larges, la "malemolência (démarche chaloupée), ainsi que le goût des couleurs vives, des bijoux bizarres, des épices (ouh la la!) aphrodisiaques mais aussi des superstitions le plus souvent absurdes. De la musculature noire, les hommes brésiliens ont hérité l'esprit de compétition et le côté extraverti qui explosent dans la samba et le football. La nudité naturellement resplendissante chez les indigènes était innocente. »

O discurso representado do enunciador sobre a herança genética e cultural das brasileiras que herdaram das escravas negras as formas dos quadris, a maneira de andar balançando as "ancas" ( a malemolência), o gosto das cores vivas, das bijouterias bizarras, das ervas afrodisíacas e das superstições frequentemente 
absurdas se faz presente ainda hoje nos homens brasileiros caracterizados como competitivos, extrovertidos, e que explodem no samba e no futebol.

Ao contextualizar historicamente as origens e as razões do culto da beleza no Brasil e ao se servir da autoridade de um psicanalista, a intenção do enunciador é a de convencer os seus leitores-destinatários da veracidade dos fatos narrados, visto que eles se fundamentam na história do país e fazem parte desta cultura. Como declara Grize (1997: 45)

«[...] L'argument d'autorité ne correspond peut-être pas à un certain idéal de rationalité, il ne manque cependant pas d'être omniprésent et souvent décisif dans la mesure où sa nature est de faire taire l'interlocuteur, donc de l'empêcher de tenir un contre-discours. L'autorité a des sources multiples, mais toutes d'origine sociale. Il peut s'agir, ..., de l'autorité que confère la fonction, de celle qui relève de l'appartenance à un groupe d'experts ou encore d'un certain charisme de nature toujours plus ou moins inexplicable, donc sacrée (Max Weber). Il faut d'ailleurs encore ajouter que l'autorité peut être au second degré. L'orateur, en tant que tel, n'en jouit pas, mais il renvoie à une autorité extérieure à lui... II s'agit de ce que l'on peut appeler "l'effet parapluie » puisque, si objection il y a de la part de l'auditeur, elle ne touche pas l'orateur mais son garant " (Grize, $1997: 45)$

O mesmo procedimento se repetirá na explicação das origens indígenas da nudez tida como natural, resplandecente e inocente. Entretanto, em oposição às heranças africanas, o enunciador evidencia (através de um dado que remete o leitordestinatário à situação de enunciação) que, nos dias de hoje (ano de 2005), a nudez não é mais nem inocente nem natural, pois ela tem consciência do seu poder de sedução, o que não acontecia entre os índios: 
"[...] La nudité 2005 est différente. Elle porte une charge sexuelle maximale, elle arrive pleine de désirs, elle éclate sans peur, sans pudeur, parce qu'elle connaît sa puissance. ”

Os verbos "porter ", " arriver » e "éclater " propõem uma gradação que parte do que é inerente, o avoir sur soi, o porter, que caminha em direção ao que emerge ou arrive pleine de désirs, chegando, finalmente, na manifestação abrupta, destemida e despudorada expressa no predicado éclater sans peur, sans pudeur. Uma nudez consciente de seus efeitos. Entretanto, não se trata de uma nudez pura e simples, pois o corpo que ela desnudará está submetido aos padrões de beleza impostos nesta sociedade, ou seja, um corpo ferme, bronzé, sain, aux courbes harmonieuses. Jeune. A conjunção adversativa "mais" opõe, desta maneira, um poder de sedução inerente a qualquer nudez ao poder de sedução da nudez consciente e trabalhada fisicamente, exigindo esforço daquele que se serve dela como arma de sedução. De "bem inato", ela passa a "bem adquirido":

"Mais pour avoir ce pouvoir, il faut travailler dur. Jour et nuit, la génération "fitness" passe sa vie dans les gymnases - la seule ville qui en compte plus que Rio est Los Angeles. C'est une névrose nationale. Les femmes s'entraînent jusqu'à avoir des insomnies. On en a vu certaines devenir accros à leur propre production d'endorphine, ce qui les a ensuite obligées à suivre une thérapie! Tant pis, ce qui compte est de pouvoir exhiber des fesses fermes, hautes, rebondies, des seins exubérants et des jambes bien roulées. Génération sportive, oui. Et exhibitionniste. Le "tanga " brésilien n'a rien d'un vêtement de sport, son rôle est purement fétichiste, fétichic. »

A religião do corpo, o culto da beleza, a ode à sensualidade são caracterizadas aqui como uma "névrose nationale". Mais uma vez o enunciador 
expande as atribuições de propriedades da classe-objeto "Rio de Janeiro", "cariocas" a todo o território nacional. $O$ dêitico temporal jour et nuit caracteriza uma atividade incessante da geração "fitness" em busca da perfeição corporal. A névrose nationale é assim explicitada no comportamento das mulheres que "treinam até terem insônias", que "tornaram-se fanáticas, dependentes químicas de sua própria produção de endorfina" ao ponto de recorrerem à terapias. A indignação do enunciador está marcada graficamente no ponto de exclamação no final da frase. Ao mesmo tempo, ele corrobora o que acabou de narrar com o emprego da locução adverbial Tant pis (apreciação do enunciador). Deste modo, ele reafirma que todo o esforço realizado para se atingir esse padrão de beleza corporal (ter insônias, tornarse fanático, necessitar de uma terapia) é justificado na possibilidade de se "exibir bumbuns firmes, altos, arrendondados, seios exuberantes e pernas roliças". Nesta sequência de adjetivos qualificativos, encontram-se outras propriedades do protótipo do corpo feminino perfeito. Entretanto, o enunciador não exclui da geração "fitness" o gosto da prática de esporte pela prática de esporte em si ao declarar "Génération sportive, oui", mas adiciona que não se trata somente disso, pois esta geração se caracteriza pelo esporte e pelo exibicionismo que vem justificar a religião do corpo, o culto da matéria:

"Le culte du muscle, c'est plutôt celui de la fermeté. La Brésilienne a depuis longtemps remplacé le corset par la musculature. Ou le silicone ? Ici, tout le monde le sait, il est facile de changer de seins, de fesses, de tout. Le pays est sûrement champion du monde de la chirurgie esthétique, avec un million d'intervention par an, derrière les Etats-Unis quand même! On a en horreur l'idée de vieillir dans une vieille peau. Madame s'occupe constamment de son capital corps. Travailler ne fait pas partie de son programme. »

O marcador temporal que expressa duração "depuis longtemps" indica que esse comportamento feminino do culto da firmeza, da rigidez do músculo existe há muito tempo. Ao mesmo tempo, a substituição do corset pela musculatura evidencia 
que a preocupação em se mostrar bela data igualmente de muito tempo, pois esta peça do vestuário feminino respondia a uma exigência modística da época em que as mulheres ditas "belas" apresentavam cinturas finas e abdômens retos, muitas vezes graças a esse artefato ou "artifício".

Ao introduzir a questão "Ou le silicone?" o enunciador procede à mudança dos meios que caracterizamos no início desta análise como naturais para os meios artificiais, cirúrgicos, anunciados no lead do artigo: "Ici, à la force des muscles ou à la pointe du bistouri, on forge son physique".

Do mesmo modo que o enunciador atribui a todo o povo brasileiro a prática de exercícios físicos visando atingir um ideal de corpo e beleza a ser exibido, ele atribuirá a todos os brasileiros a recorrência à cirurgia plástica para se atingir tal objetivo. Além disso, ao declarar que "Ici, tout le monde le sait, il est facile de changer de seins, de fesses, de tout", ele partilha o seu julgamento sobre a facilidade de se trocar os seios, etc, com toda a nação brasileira. Este conteúdo de julgamento é, portanto, de domínio comum.

A neutralidade do pronome "on" na frase "On a en horreur l'idée de vieillir dans une vieille peau" não esclarece se o enunciador se inclui ou não nesta categoria. No entanto, visto que se trata de uma jornalista brasileira, é possível que o leitor-destinatário compreenda o emprego do pronome "on" como sendo "nous".

No enunciado seguinte onde o sentido de "horror em se envelhecer numa pele velha" vem justificar mais uma vez o esforço em se manter "bela", o enunciador emprega o pronome de tratamento "Madame" - que em francês é correntemene utilizado para todas as mulheres em idade de se casar, para as casadas, ou para as que já foram casadas - de uma forma que o leitor brasileiro interpretaria como sendo aquela mulher de boa condição social, que não trabalha, e que de uma certa maneira, é fútil. Esta interpretação de ordem socio-cultural dentro da língua portuguesa não nos parece tão evidente na língua francesa, onde "Madame", além do emprego citado acima, compreendia antigamente um título atribuído às mulheres da nobreza e da burguesia. Dentro deste enunciado, este pronome de tratamento que podemos identificar como um pré-construido cultural (Grize:1997) nos parece muito mais impregnado dos sentidos atribuídos pela sociedade brasileira do que do sentido corrente no contexto francês. Dizemos isso, pois o enunciador além de declarar que Madame s'occupe constamment de son capital corps, ele acrescenta 
que Travailler ne fait pas partie de son programme, o que nos remete aos dados extra-lingüísticos citados acima.

"Il est normal de se faire opérer comme on va chez le coiffeur. Des filles de 15 ou 16 ans y passent. Elles se rendent chez le chirurgien le lundi pour être plus belle à la fête du samedi prochain... »

O efeito de sentido que o autor-enunciador quer suscitar no leitor através da comparação entre a frequência com que as mulheres "se fazem operar" e a frequência com que em geral os brasileiros vão ao cabeleireiro reside na reconstrução de um sentido dependente do seu conhecimento de mundo, pois ele atribui a normalidade do ato "ir ao cabeleireiro" ao ato de "se submeter a uma cirurgia plástica". Esta comparação banaliza a frequência com que as brasileiras recorrem às cirurgias plásticas, caracterizando este ato, através da analogia feita, como uma prática corrente, semanal:

"Et nos hommes? "Au cours du Ille millénaire, dit le créateur japonais Yohji Yamamoto, le monde masculin va être de plus en plus vaniteux. » Et voilà, on $y$ est déjà. Body-building is the question. II faut donc passer une bonne partie de son temps (les gymnases sont ouverts 24 heures sur 24) à se forger des abdominaux, des pectoraux ou des biceps. Avec l'énergie du désespoir on s'emploie à modifier ce qui est sous la peau. Le triathlon (natation, course à pied et cyclisme) est un sport national. Courir en groupe est absolument sacré, et les rendez-vous sont gérés par e.mail d'une semaine à l'autre. Des agences organisent même des voyages de groupes à New York, à Chicago, pour que les obsédés puissent participer aux marathons internationaux - et $y$ exhiber leur physique fabuleux. La plupart de ces jeunes gens et de ces messieurs (tous les âges 
partagent le même trip) se font désormais épiler au prétexte que c'est mieux pour certains sports, la natation par exemple. Cecilia, manucure du salon Jacques et Janine à São Paulo, raconte qu'ils arrivent pour l'épilation toujours le plus tard possible. Après 19 heures, il y a moins de danger de rencontrer madame... »

Ao sair do domínio feminino e entrar no universo masculino através da frase interrogativa "Et nos hommes?", o autor-enunciador inicia a caracterização dos brasileiros e o seu culto ao corpo da mesma maneira. Para isso, serve-se de dois outros argumentos de autoridade, citando o criador japonês Yohji Yamamoto e a manicure Cecilia - na verdade três, pois ao dizer ao leitor que a manicure em questão é funcionária do salão Jacques e Janine, em São Paulo, o autor-enunciador joga com as representações do leitor diante de um dado que the é familiar, os salões Jacques et Janine franceses.

Em oposição às mulheres brasileiras que se preocupam em «forjar » 0 bumbum, os seios, as pernas, os homens brasileiros se aplicam em «forjar » 0 abdômen, o peitoral e os bíceps na mesma intensidade que elas: "avec l'énergie du désespoir".

Uma rede do culto à forma física é estabelecida no enunciado embreado "Courir en groupe est absolument sacré, et les rendez-vous sont gérés par e.mail d'une semaine à l'autre", onde a apreciação do enunciador expressa na palavra "sacré" nos remete ao domínio da religião, do culto semanal. A caracterização das mulheres como accros é feita aos homens através do adjetivo apreciativo obsédés. Do mesmo modo que para as mulheres, o enunciador estabelece a relação entre a prática do esporte visando o exibir um corpo perfeito:

Mulheres: «Génération sportive, oui. Et exhibitionniste. »

Homens: "[...] pour que les obsédés puissent participer aux marathons internationaux - et y exhiber leur physique fabuleux ”

Sem excluir nenhuma categoria (homens e mulheres fanáticos pela forma física), o autor-enunciador através de mais uma frase interrogativa, introduz a classe dos "preguiçosos", ativando o pré-construído daqueles que "evitam e recusam o 
esforço", neste caso, físico como meio de se atingir a forma desejada ou "imposta" como afirma o texto introdutório do presente artigo: "Venu de la plage, partout s'impose le culte de la beauté, une ode à la sensualité devenu obsession nationale.":

"Et les paresseux? Ne vous inquiétez pas, cher Monsieur, il y a mille et une solutions. Une bonne liposuccion pectorale, par exemple. Ou l'application d'une poitrine artificielle, pour donner l'impression de pectoraux "malhado, trincado»: bien travaillés. Dernier cri, apothéose de la sophistication masculine: l'implantation de petites bananes de silicone au niveau de l'abdomen pour sculpter une "tablette de chocolat "... à croquer. Il paraît que cette ondulation, bien dure, est incroyablement excitante. Mais les malheureux qui s'occupent beaucoup de leurs bras négligent souvent leurs jambes. ”

A recorrência à cirurgia plástica para atingir o padrão de beleza não se relaciona, deste modo, somente ao universo feminino. A diferença repousa, desta vez, nas partes do corpo a serem forjadas de acordo com a anatomia masculina, ou seja, onde o tempo exerce mais a sua influência:

\section{«[...] liposuccion pectorale, l'application d'une poitrine artificielle, l'implantation de petites bananes de silicone au niveau de l'abdomen pour sculpter une " tablette de chocolat [...]"}

As marcas do autor-enunciador neste parágrafo são numerosas: na frase injuntiva "Ne vous inquiétez pas, cher Monsieur [...]", onde implicitamente ele reproduz o discurso do médico frente ao seu paciente (interdiscurso); ao determinar a função da implantação de tabletes de chocolate "... à croquer"; no conteúdo de julgamento expresso na frase "ll paraît que cette ondulation..."; e ao designar os preguiçosos como malheureux onde ele opera sobre a identificação desta categoria. 
Ao empregar dois adjetivos qualificativos em português "malhado, trincado", o autorenunciador representa o discurso dos praticantes de musculação e reformula dizendo bien travaillés.

O autor-enunciador procura, a partir da escolha das categorias citadas (a das mulheres, a dos homens, a dos jovens, a dos mais idosos, a dos preguiçosos, e agora a dos homosexuais ) e de suas respectivas caracterizações, argumentar o seu discurso que propõe como objeto o corpo na sociedade brasileira, ou melhor, o culto ao corpo, a religião do corpo:

"En revanche, les homos ne commettent pas cette erreur. "Je suis totalement corps, dit Lili Ferraz, un fantastique make-up artist à la mode. L'amour, c'est fini. Alors le plus bel objet de consommation et de plaisir, c'est le corps! On ne vit que pour ça. Entre nous, les homos, on ne se demande pas comment ça va, mais "comment vont tes fesses? Toujours belles? "Nous ne pouvons pas vieillir, nos fesses ne peuvent pas flétrir. " Lili porte le slip dit "fil dentaire " depuis l'âge de 13 ans. Coquet/coquette, il/elle a l'intention de mourir très "vieux/vieille ", son microscopique slip pour linceul. Dans les boîtes de nuit, les homos bodybuildés par les exercices, les anabolisants et les prothèses aiment danser torse nu, montrer leurs bras sculptés, leur thorax glabre, leur ventre plat. On les appelle les "Poupées Barbie ". Ils ont un succès fou! Pourtant Lili Ferraz, très "femme-femme", préfère les "hommeshommes ». Question de goût. »

O ápice do culto ao corpo é atingido tanto através do depoimento de Lili Ferraz onde suas declarações podem ser interpretadas como a decadência moral e social desta sociedade que se aplica somente a cultivar o corpo, o seu único capital: / L'amour, c'est fini/ le plus bel objet de consommation et de plaisir, c'est le corps ! On ne vit que pour ça/ on ne se demande pas comment ça va, mais «comment vont 
tes fesses? Toujours belles? Nous ne pouvons pas vieillir, nos fesses ne peuvent pas flétrir/ les homos bodybuildés par les exercices, les anabolisants et les prothèses aiment danser torse nu, montrer leurs bras sculptés, leur thorax glabre, leur ventre plat/, quanto no primeiro enunciado do parágrafo seguinte onde o autor-enunciador finaliza a representação da "religião do corpo" na sociedade brasileira atual:

«Finalement, le corps, en l'absence de toute conscience existentielle, est «tout» Le manque vient de loin. »

Toda esta decadência é argumentada nas palavras de duas outras autoridades citadas pelo autor-enunciador: as da socióloga Silvia Lobo:

"[...] Vingt ans de dictature ont tué notre idéalisme, dit la sociologue Silvia Lobo. C'était une époque triste: des professeurs exilés, des étudiants en prison... Tout le monde avait peur. La répression a étouffé le désir de changer le monde, le rêve de revaloriser l'homme, les émotions, l'imagination de la jeunesse. 》

A valorização do corpo como único capital do brasileiro é justificada, nas palavras da socióloga, como resultante de vinte anos de ditadura. Pode-se inferir que esse período aniquilou os valores da sociedade brasileira ao privá-la de sua classe intelectual (des professeurs exilés, des étudiants en prison...), ausência da "gente pensante" cujos valores repousam sobre o conhecimento e o cultivo do espírito pelo saber. $\mathrm{O}$ que restou a essa massa foi o retorno e o cultivo de suas heranças indígenas restringidas e transformadas em uma nudez consciente e poderosa, de suas heranças africanas estampadas nos quadris das brasileiras, na sua malemolência, nos seus gostos, nas suas superstições, no espírito competitivo dos homens, no seu capital físico em detrimento do seu capital intelectual:

"Loin de la politique, de l'action, de l'amour de littérature, notre héritage tropical en est venu à 
occuper tout l'espace. Et voilà, le plaisir primaire passe avant tout. Notre unique motivation est la sexualité, la beauté, la santé, la forme et, pendant qu'on y est, la jeunesse éternelle. Voilà les impératifs absolus, le blason incarné de la réussite sociale. Vieillir, grossir ou simplement se laisser aller, laisser tomber, c'est du suicide. Toutes les portes se ferment, celles du travail comme celles de l'amour. ”

E as do psicanalista Reinaldo Lobo:

“[...] Le Dr Reinaldo Lobo en est convaincu: "Devant l'avalanche d'images que déversent les médias, la société a sombré dans le narcissisme, dans le besoin de se montrer à n'importe quel prix. Avec les relations sexuelles fugaces, les familles éclatées, les identités usurpées, les fausses célébrités, on est dans l'ère du traumatisme psychique. L'être a été anéanti par le paraître. ”

O autor-enunciador insere e caracteriza tanto o modo de vida quanto os valores da sociedade brasileira dentro de um todo fútil, oco e efêmero onde, para se sobreviver, é necessário saber navegar ao ritmo do samba:

"Tout est un clin d'œil, futilité, presque rien. Mais au milieu de ces turbulences, il faut bien savoir naviguer. Le rythme idéal reste celui de la samba, aucune tempête n'y résiste. ”

A partir da análise feita, pudemos observar que a construção do objeto de discurso "religião do corpo" pelo enunciador é realizada a partir dos seguintes pontos: 
- Pela atitude e pelo comportamento dos brasileiros(as): o tempo dedicado ao culto do corpo, à forma física, os meios naturais e artificiais buscados para se atingir um ideal de beleza física;

- Pela influência da própria geografia do Brasil : $8000 \mathrm{~km}$ de plages, climat tropical;

- Pela referência à dados históricos ( herança indígena / herança africana);

- Pela referência à dados estatísticos (analogia feita com os Estados Unidos);

- Pela referência ao número de academias existentes e os horários de funcionamento (dia e noite);

- Pelos argumentos de autoridade: Luiz Tripolli - fotógrafo; Dr Reinaldo Lobo - psicanalista; Regina Lobo - socióloga; Lili Ferraz - make-up artist; Cecilia - manicure do salão Jacques e Janine em São Paulo;

- Pelas designações feitas deste objeto do discurso no texto a partir da retomada dos semas do culto, da obsessão, da ode, da nevrose:

- culte de la beauté

- ode à la sensualité

- obsession nationale

- névrose nationale

- le corps est devenu une obsession

- le culte des fesses

- le culte du muscle

- Pela caracterização do corpo ideal que constrói o protótipo do corpo belo, estabelecendo, deste modo, os padrões de beleza :

- ferme

- bronzé

- sain

- aux courbes harmonieuses

- jeune

- fesses fermes

- fesses hautes

- fesses rebondies

- seins exubérants

- jambes bien roulées

- malhado

- trincado

- muscles bien travaillés 
As representações do Brasil são construídas e reconstruídas pelo discurso:

Pelas designações e caracterizações do Brasil no texto:

\begin{tabular}{|c|c|}
\hline $\begin{array}{c}\text { Paradigma designacional (designações } \\
\text { do Brasil no texto) }\end{array}$ & Caracterização do Brasil \\
\hline $\begin{array}{l}\text { - la patrie de la chirurgie plastique } \\
\text { - le pays (qui invite à la quasi- } \\
\text { nudité) } \\
\text { - un pays-paradis } \\
\text { - cette société exubérante, } \\
\text { extravertie, désinhibée } \\
\text { - un "pays métis" } \\
\text { - un pays ni blanc, ni noir, ni } \\
\text { indigène, ni jaune, ni rouge }\end{array}$ & $\begin{array}{l}\text { - } \text { paradis } \\
\text { - libre } \\
\text { - glorieux } \\
\text { - plein de sève } \\
\text { - plein de sensualité } \\
\text { - plein de force } \\
\text { - plein de vie } \\
\text { - exubérant } \\
\text { - extraverti } \\
\text { - désinhibé } \\
\text { - } \text { métis } \\
\text { - jaune, nianc, ni noir, ni indigène, ni } \\
\text { - champion du monde de la } \\
\text { - chirurgie esthétique } \\
\text { - avec } 8000 \mathrm{~km} \text { de côtes } \\
\text { - chec } 8000 \mathrm{~km} \text { de plages } \\
\text { - davantage (30 C, } 40^{\circ} \text { même } \\
\text { - tropical }\end{array}$ \\
\hline
\end{tabular}

Pela caracterização dos brasileiros:

- sexy

- pur sexe

- quasi-nu(e)s

- hanches larges

- démarche chaloupée - "malemolência"

- aphrodisiaques

- qui aiment les couleurs vives

- qui aiment les bijoux bizarres

- qui aiment les épices aphrodisiaques

- qui sont superstitieuses

- qui ne travaillent pas

- qui passent leur temps à cultiver le "corps"

- accros de sports

- compétitifs

- extravertis

- musclé(e)s 
- exhibitionnistes

- sensuels

- assemblage complexe d'un multiculturalisme indigène, européen, africain, arabe, japonais...

Pela metonímia: o enunciador aplica ao Brasil e a todo o povo brasileiro as características comportamentais e físicas dos cariocas. A cidade do Rio de Janeiro passa a ser a metonímia do Brasil :

- O protótipo da mulher brasileira: a carioca; a sambista; a Madame

Pela caracterização da identidade e da cultura brasileiras:

\begin{tabular}{|l|l|}
\hline \multicolumn{1}{|c|}{ Identidade brasileira } & Cultura brasileira \\
\hline - Ensoleillée & Na época dos índios: \\
- Volutptueuse & éperdument exotique \\
naïve \\
primitive \\
- lascive & Atualmente: \\
& infantile \\
\hline
\end{tabular}

- Enfim, pela construção do próprio objeto do discurso "religião do corpo" .

Antes de passarmos para a próxima análise, destacamos, abaixo, as marcas da enunciação no texto chamando a atenção, sobretudo, para os conteúdos de julgamento (enunciados embreados que apresentam outros traços da presença do enunciador: apreciações, interjeições, exclamações, ordem, interpelação do coenunciador):

Marcas do enunciador no texto - embreantes de pessoa:

- A partir de cette carence essentielle, ils ont dû créer leur identité. Notre identité. 
- On n'en a vu certaines devenir accros $[. .$.$] ce qui les a ensuite obligées$ à suivre une thérapie!

- On a en horreur l'idée de vieillir dans une vieille peau.

- Et nos hommes?

- Et voilà, on y est déjà.

- On les appelle « Poupéé Barbie » [...]

- ...notre héritage tropical en est venu à occuper...

- Notre unique motivation est la sexualité...

- ... et, pendant qu'on y est, la jeunesse éternelle.

Marcas de modalidade apreciativa do enunciador (conteúdos de julgamento) :

- Oh, my God, toutes les têtes tournent...

- [...] il n'est donc pas surprenant que la femme de Rio, de Salvador de Bahia ne s'habille pas mais se déshabille.

- Evidemment, il y a encore mille autres raisons....

- Dans les veines du peuple brésilien, le sang bout fort, très fort...

- Eperdument exotique, naïve et primitive ...

- Au secours ! la libido de l'enfant commençait dès le berceau...

- ... épices (ouh la la !) aphrodisiaques mais aussi des superstitions le plus souvent absurdes

- On n'en a vu certaines devenir accros ... ce qui les a ensuite obligées à suivre une thérapie!

- Tant pis, ce qui compte est de pouvoir exhiber des fesses fermes, hautes, rebondies, des seins exubérants et des jambes bien roulées ...

- Génération sportive, oui. Et exhibitionniste.

- Le «tanga » brésilien n'a rien d'un vêtement de sport, son rôle est purement fétichiste, fétichic.

- Le culte du muscle, c'est plutôt celui de la fermeté.

- Ici, tout le monde le sait, il est facile de changer de seins...

- Le pays est sûrement champion du monde ..., derrière les Etats-Unis quand même!

- On a en horreur l'idée de vieillir dans une vieille peau.

- Madame s'occupe constamment de son capital corps.

- Il est normal de se faire opérer comme on va chez le coiffeur.

- Et voilà, on y est déjà. Bodybuilding is the question.

- Il faut donc passer une bonne partie de son temps...

- Avec l'énergie du désespoir ...

- Courir en groupe est absolument sacré...

- Des agences organisent même des voyages de groupes...pour que les obsédés puissent participer aux marathons internationaux et y exhiber leur physique fabuleux

- Dernier cri, apothéose de la sophistication masculine...

- Il paraît que cette ondulation, bien dure, est incroyablement excitante...

- Mais les malheureux qui s'occupent beaucoup de leurs bras négligent souvent leurs jambes.

- En revanche, les homos ne commettent pas cette erreur.

- Ils ont un succès fou! 
- Finalement, le corps, en l'absence de toute... est « tout ».

- Et voilà, le désir primaire passe avant tout.

- ... et, pendant qu'on y est, la jeunesse éternelle.

- Voilà les impératifs absolus...le blason incarné de la réussite sociale.

- Tout est un clin d'œil, futilité, presque rien.

- [...] il faut bien savoir naviguer. Le rythme idéal reste celui...

Embreantes temporal e espacial:

- Venu de la plage, partout s'impose [...]

- Ici, à la force des muscles ou à la pointe du bistouri...

- ... aujourd'hui encore la culture brésilienne demeure infantile...

- Le culte des fesses dans la société brésilienne d'aujourd'hui ...

- La nudité 2005 est différente.

- La Brésilienne a depuis longtemps remplacé le corset par la musculature.

- Ici, tout le monde le sait, il est facile de changer de seins...

Após termos identificado os clichés recorrentes sobre o Brasil no nosso corpus exploratório, partimos para a análise do artigo sobre o Rio de Janeiro (pois nos pareceu evidente a concentração desses clichés nesta cidade), e em seguida, dentre os clichés evocados, optamos por analisar a questão da beleza física tão atribuída aos brasileiros (sobretudo "brasileiras"). Esta penúltima análise retoma a questão dos clichés sob uma forma crítica, procurando denunciar de maneira bem particular (o tom é de sátira) a sua difusão na França. 


\section{iii. Brasil e França: outras Vibrations}

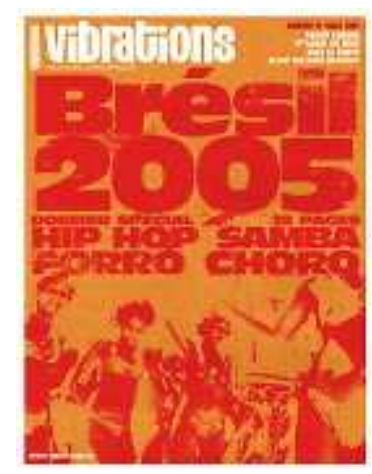

\section{Revista: Vibrations}

Capa: Brésil 2005

Data de publicação: Março de 2005

Autor do texto analisado: Gilles Tordjman

A revista Vibrations é uma revista mensal de música, destinada ao público francófano de todas as idades e que publica artigos sobre variados gêneros musicais. O texto que nos propomos analisar foi publicado no mês de março de 2005 e dedica um dossier sobre os ritmos brasileiros, como hip hop, o carnaval da Bahia e os novos interprétes da música deste país, como Maria Rita, Renata Rosa, Beatriz Azevedo entre outros.

A escolha do artigo que vamos analisar se deve a dois critérios que julgamos pertinentes para atingirmos o objetivo que nos propusemos neste trabalho: a apresentação da produção musical brasileira que vai além do samba e a forma encontrada pelo enunciador para tratar do seu objeto de discurso.

Ao se servir da lenda de difusão da beleza sobre o mundo dos homens cujas responsáveis eram as nove musas que presidiam as artes liberais, filhas de Zeus e Mnémosyné - Clio (História) ; Calliope (eloqüência e poesia heróica) ; Melpomène (tragédia); Thalie (comédia); Euterpe (música); Terpsichore (dança); Erato (elegia); Polymnie (lirismo); Uranie (astronomia) - o enunciador busca explicar, numa primeira leitura, as origens da beleza e da riqueza artística brasileira oriunda do acúmulo de pacotes que, por negligência, se fez sobre o espaço brasileiro representando, deste modo, o acúmulo da inspiração e do gosto da beleza expresso nas artes deste país. 
A narrativa, que em geral se caracteriza através de enunciados não embreados apresenta-se aqui permeada de apreciações do enunciador que intervém, por vezes, em seu próprio discurso e Ihe imputa um tom sarcástico. Tais marcas podem ser observadas no emprego de locuções familiares como pour des prunes, crêpages de chignon; de palavras que fazem parte do léxico corrente na língua francesa, como comme ça, embêtées, moquerie; de enunciados apreciativos como [...] et lui aussi (c'est fatigant d'avoir neuf belles filles à nourrir), "les muses firent tomber - volontairement ou pas - on en débat encore, [...] dans l'une de ces opérations marketing qui lui tiennent lieu de cerveau reptilien; pela heterogeneidade mostrada: si l'on en croit les meilleurs exégètes antiques [...], [...] comme disait l'autre; pelos adjetivos: leur glorieuse descendance, le redoutable honneur; pelos advérbios : assister silencieusement, bien embêtées ; c'est un peu ... l'hommage [...] ; la France décida [...] que 2005 serait très officiellement [...].

Este texto se compõe deste modo, de enunciados embreados e não embreados. Seu objeto de discurso consiste na riqueza da cultura brasileira, sobretudo a produção artística do Brasil, que ultrapassa os clichés veiculados na França. A lenda, gênero de discurso escolhido para explicar as origens dessa riqueza apresenta todas as características do texto narrativo, emprego do passé simple (que marca um distanciamento entre o momento da enunciação e o momento do discurso), personagens da mitologia grega, acontecimentos fantásticos, a expressão un jour que, em geral, inicia a narrativa e coloca em cena os personagens principais dentro de um contexto imaginário. A marca de um interdiscurso pode ser identificada no gênero discursivo escolhido e nos personagens colocados em cena. Em relação aos fatos narrados, eles não compõem nenhum mito pré-existente, eles foram criados pelo enunciador com vistas a explicitar a diversidade da cultura artística brasileira (do Brasil plural, terra de ritmos e de melancolia, onde o horizonte musical é infinito) em detrimento dos clichés veiculados na França: "plages paradisiaques", "filles canon", "foot aérien", "carnavals olé-olé", "sens du rythme" "et bons sauvages à tous les étages". Ao recuperarmos o texto da capa Brésil anthropophage, Brésil pluriel, Brésil terre de rythmes et de mélancolie: l'horizon musical y est infini, podemos observar, desta maneira, que a palavra "ritmo" encontra-se no plural e é seguida pela explicação de que, no Brasil, o horizonte musical é infinito. 
A construção dos sentidos de riqueza e diversidade além dos clichés é feita não somente através da reconstituição dos elementos eufóricos atribuídos ao Brasil, mas, sobretudo, a partir da negação das mesmas propriedades à França:

\begin{tabular}{|c|c|}
\hline Brasil & França \\
\hline $\begin{array}{l}\text { "[...] les muses firent tomber }[\ldots] \\
\text { leurs dernières munitions sur le côté } \\
\text { est du sous-continent américain; une } \\
\text { terre que les hommes nommeraient } \\
\text { plus tard Brésil » }\end{array}$ & $\begin{array}{l}\text { "[...] leur stock de beauté désormais } \\
\text { vide, elles s'avisèrent que certaines } \\
\text { zones n'avaient pas du tout été } \\
\text { arrosées par leur manne, et notamment } \\
\text { une minuscule province à l'ouest } \\
\text { d'Europe qui ne s'appelaient pas } \\
\text { encore France" }\end{array}$ \\
\hline $\begin{array}{l}\text { "[...] au Brésil, la terre sur laquelle le } \\
\text { fond de bonnes choses s'était } \\
\text { répandu dans toute la mesure de } \\
\text { l'excès" }\end{array}$ & $\begin{array}{l}\text { "ll suggéra alors que la France ne soit } \\
\text { pas détruite, mais qu'on la conserve } \\
\text { comme un parc d'attractions, destinée } \\
\text { à l'amusement des dieux. Le spectacle } \\
\text { d'une si grande pauvreté humaine, } \\
\text { intellectuelle et artistique [...]" }\end{array}$ \\
\hline «la vertu» & "le vice » \\
\hline $\begin{array}{l}\text { "une région du cœur [...] où tout } \\
\text { semble sonner au diapason d'une } \\
\text { vibration plus forte et surtout, plus } \\
\text { juste" }\end{array}$ & " un pays de culs-de-plomb» \\
\hline $\begin{array}{l}\text { "un des rares pays à cultiver encore } \\
\text { des avant-gardes sans rien renier de } \\
\text { son passé " }\end{array}$ & - \\
\hline "phare du monde sensible" & - \\
\hline
\end{tabular}


A difusão de clichés sobre o Brasil na França é assim atribuída à consciência, por parte deste último, da ausência das mesmas propriedades qualitativas atribuídas ao primeiro, podendo ser observada nos seguintes enunciados:

“[...] le Brésil n'est pas une nation; c'est une région du coeur. Où tout semble sonner au diapason d'une vibration plus forte et surtout, plus juste. Si forte et si juste, à vrai dire que les représentations triviales du Brésil se devaient d'être salement folklorisées : on espérait ainsi en amoindrir la portée, et racheter la honte ancestrale d'être né dans un pays de "culsde-plomb $»[\ldots] »$ "La France a donc jusqu'ici colporté du Brésil les clichés qui arrangeaient son indignité : plages "paradisiaques », filles "canon », foot " aérien », carnavals "olé-olé »; "sens du rythme » et bons sauvages à tous les étages ${ }^{40}$. 》

Uma outra propriedade qualificativa atribuída ao Brasil pelo enunciador e que se vê negada à França diz respeito ao comportamento, à reação dos artistas brasileiros face a esses clichés, demonstrando, ao mesmo tempo, que preocupações de ordem superior the ocupam o pensamento:
"De tout cela, les artistes brésiliens rient bien volontiers, du rire bienveillant et supérieur des anciens dieux. Ils ont d'autres problèmes: digérer l'amère victoire de Lula, extirper le poison raciste qui

\footnotetext{
${ }^{40} \mathrm{Na}$ revista mensal Paris Capitale (15 de fevereiro à 15 de março de 2005), Jean-Marie Dubois descreve da seguinte maneira os clichés do Brasil na França e as relações que estes dois países mantém entre si: "Le Brésil? Un pays continent de tous les extrêmes que l'on a tous l'impression de connaître : la mer et ses plages sans fin, la samba, la forêt amazonienne dévastée, le carnaval de Rio, les filles (et les garçons) de rêve aux corps ultra-sophistiqués, le football, le Pain de Sucre, les favelas et leur violence inouïe, un ensemble de clichés, pas toujours faux, mais souvent réducteurs pour un pays encore en développement (et pourtant huitième puissance mondiale) [...]. La relation entre la France et le Brésil est faite de fascination mutuelle, sans doute le résultat de deux identités culturelles très fortes. D'un côté, une vision un peu tiers-mondiste de ce paradis tropical, de l'autre une image survalorisée $d u$ "rationalisme " à la française. C'est cet amour-répulsion qui va être particulièrement mis en valeur durant cette année qui s'annonce d'une richesse exceptionnelle. "
} 
infuse dans toutes les sociétés créoles, accepter l'idée qu'une ex-figure du tropicalisme s'accommode d'être devenu un politicard comme autre et pourquoi pas? - œuvrer à dissoudre chez eux comme ailleurs toutes les conditions du monde présent. ”

Entretanto, o enunciador não assume a responsabilidade de algumas afirmações feitas no texto, servindo-se, por vezes, de um "tiers parlant", ou seja, de um enunciador outro não identificado no discurso, mas a quem é atribuída a responsabilidade do que está sendo dito, consistindo, assim, em uma heterogeneidade mostrada e marcada por glosas onde não há coincidência entre o discurso e o enunciador:

"Si l'on en croit les meilleurs exégètes antiques, les muses firent ainsi tomber - volontairement ou pas; on en débat encore - leurs dernières munitions sur le côté est du sous-continent américain [...] 》

"Le spectacle d'une si grande pauvreté humaine, intellectuelle et artistique, ne pouvait selon lui (Zeus) que provoquer une salutaire moquerie [...] »

"C'est un peu, comme disait l'autre, l'hommage du vice à la vertu»

«[...] on espérait ainsi en amoindrir la portée, et racheter la honte ancestrale d'être né dans un pays de "culs-de-plomb" selon la juste formule nietzschéenne "

É interessante notar que o distanciamento entre o momento da enunciação e o momento do discurso marcado em quase todo o texto pelo emprego do passé simple associado ao pretérito imperfeito insere a tomada de decisão por parte da 
França em homenagear o Brasil dentro da lenda, mostrando-se tanto como uma consequência prevista por Zeus quanto como uma forma de reparação dos clichés difundidos:

«Le spectacle d'une si grande pauvreté humaine, intellectuelle et artistique, ne pouvait selon lui (Zeus) que [...] réévaluer, par contraste, tout ce que l'humanité future allait devoir au Brésil [...] »

“Très longtemps après cette histoire, la France décida, dans l'une de ces opérations marketing qui lui tiennent lieu de cerveau reptilien, que 2005 serait

très officiellement célébrée comme «l'Année du Brésil ».

No entanto, a presença do verbo tenir lieu empregado no presente do indicativo e a referência às operações de marketing escapam ao universo lendário e inserem esse acontecimento no ano de 2005, remetendo o leitor-destinatário ao momento da enunciação. Além disso, este enunciado apreciativo constitui uma crítica ao que, na verdade, se apresenta muito mais como uma forma de promoção ${ }^{41}$ da imagem da França do que uma homenagem visando a promoção do país homenageado. Subliminarmente, o enunciador sugere que a verdadeira intenção francesa é a de se promover através do Outro, tendo em vista que os "amantes de música" não necessitam de um ano de homenagem ao Brasil para apreciar algo que faz parte do seu quotidiano:

\footnotetext{
${ }^{41}$ No editorial da revista bimensal Le Journal des Arts (04 de janeiro à 17 de fevereiro de 2005) intitulado Culture et Diplomatie, Philippe Régnier declara abertamente que as intenções da França ao organizar essas saisons culturelles desde 1985 não se restringem às trocas artísticas e culturais entre os países homenageados e o Hexagone, mas implicam interesses políticos, diplomáticos ou econômicos: "[...] Autant ces échanges sont riches d'un point de vue culturel, autant leur initiative est rarement, pour ne pas dire jamais, liée à ces seuls enjeux. La France a en effet, sans le cacher, des intérêts politiques, diplomatiques ou économiques à dérouler le tapis rouge culturel pour nos nouveaux partenaires de l'Union Européenne, ou encore pour une puissance qui va devenir le premier marché du monde. La mise à l'honneur du Brésil cette année n'est pas non plus sans arrière-pensées puisque ce grand pays d'Amérique du Sud est un allié de choix pour les grandes causes que la France entend défendre devant les organisations internationales [...]. 》
} 
«En vérité, cela fait longtemps que l'amateur de

musique vit tous les jours son année brésilienne »

A criação de uma lenda como forma de representar o seu objeto de discurso possibilita ao enunciador jogar com uma dialética similar à do bem e do mal. O que nos parece importante ressaltar é que juntamente ao seu objeto principal de discurso, ele insere um sub-objeto que consiste na crítica ao seu próprio país. A forma encontrada para representar discursivamente os dois países em questão Ihe permite, deste modo, jogar com as suas próprias representações dentro do texto sem assumí-las por completo. Ao mesmo tempo, o tom de sátira que permeia o seu discurso colocando em permanente desvantagem a França em detrimento das qualidades atribuídas ao Brasil pode ser compreendido como uma brincadeira saudável visando uma reavaliação, por parte da França, dos seus julgamentos. Este elemento atenuante que pode ser visto como um procedimento reparatório nos parece estar implicitamente inserido em um dos "discursos representados" de Zeus a respeito do espetáculo da pobreza humana, intelectual e artística francesa:

"Le spectacle d'une si grande pauvreté humaine, intellectuelle et artistique, ne pouvait selon lui (Zeus) que provoquer une salutaire moquerie et réévaluer, par contraste, tout ce qui l'humanité future allait devoir au Brésil [...] » 
Ao tecer o seu discurso, o enunciador joga com a face ${ }^{42}$ positiva dos brasileiros e franceses, valorizando a primeira em detrimento da segunda. Deste modo, a imagem que a França procura veicular de si mesma se vê ameaçada pelo discurso do enunciador, ao mesmo tempo em que ele pode ameaçar a face positiva dos franceses em geral, como num efeito de irradiação do qual nem mesmo o enunciador estará isento enquanto responsável do artigo que assina. Sendo assim, a maneira de preservar a sua face positiva consiste em atenuar os efeitos do seu discurso através da introdução do elemento reparador contido no modalisador "salutaire moquerie".

O Brasil representado na sua produção musical é assim designado e caracterizado pelo enunciador como sendo:

- Um país antropófago; um país plural; terra de ritmos e de melancolia; terra onde o horizonte musical é infinito: "Brésil 2005 - Brésil anthropophage, Brésil pluriel. Brésil terre de rythmes et de mélancolie : I'horizon musical y est infini »

- O qual tem a honra de fazer frutificar a abundância nas artes e no gosto "fauve " de viver : "[...] à qui échut le redoutable honneur de faire fructifier cette abondance dans les arts et le goût fauve de vivre "

- A terra sobre a qual o fundo de boas coisas se espalhou em excesso : " $L a$ terre sur laquelle le fond de bonnes choses s'était répandu dans toute la mesure de l'excès "

- Um país que não é uma nação: "Le Brésil n'est pas une nation”

\footnotetext{
${ }^{42}$ A noção de « face » foi desenvolvida por Erving Goffman (1974) em seus estudos sobre os ritos de interação. O termo é definido por ele como la valeur sociale positive qu'une personne revendique effectivement à travers la ligne d'action que les autres supposent qu'elle a adoptée au cours d'un contact premier. La face est une image du moi délinéée selon certains attributs sociaux approuvés, et néanmoins partageable, puisque, par exemple, on peut donner une bonne image de sa profession ou de sa confession en donnant une bonne image de soi (Goffman, $1974: 9$ ). De acordo com Maingueneau (2000), esta noção foi ampliada por Brown e Levinson (1978) que distinguiram duas faces indissociáveis do indivíduo: a face negativa que corresponde ao território de cada um, do ser singular; e a face positiva, ou seja, a "fachada", nossa imagem positiva que nos esforçamos para exibir. Tais faces podem ser ameaçadas na interação, consistindo no que Brown e Levinson denominaram como Face Threatening Acts (FTA), ou seja, atos ameaçadores tanto para as faces positiva e negativa do locutor quanto do interlocutor (Maingueneau, 2000:65,66). C. KerbratOrecchionni (1996) sublinha que a interação pode tanto ameaçar as faces dos interactantes quanto valorizá-las. Neste caso, ela propõe que se leve em consideração os Face Flattering Acts (FFAs), ou seja, les actes valorisant ou gratifiants pour les faces (Dictionnaire d'Analyse de Discours, 2002:260). Embora essa noção tenha sido desenvolvida e venha sendo aplicada nos estudos discursivos das interações verbais "face à face", nos serviremos brevemente desta noção para explicar como a face positiva dos brasileiros e franceses pode ser ou não ameaçada neste artigo.
} 
- Um país que é uma região do coração: "Une région du cœur"

- Um país onde tudo parece soar em conformidade com uma vibração mais forte e mais justa: "Où tout semble sonner au diapason d'une vibration plus forte et surtout, plus juste "

- Um país que não está mal posicionado no mercado: "[...] le Brésil n'est pas mal positionné"

- Um dos raros países que ainda cultivam as avant-gardes sem negar nada do seu passado: "Un des rares pays à cultiver encore les avant-gardes sans rien renier de son passé »

- Um país onde a palavra dos antigos é difundida: "[...] il y fut toujours question de porter plus loin la parole des anciens plutôt que de la nier ”,

- Um país onde a memória sempre foi reconhecida como a principal condição do futuro: "[...] la mémoire y fut toujours reconnue comme la principale condition du futur »

- Um país que pode continuar exercendo a sua função de farol do mundo sensível: «[...] le Brésil d'aujourd'hui peut sereinement continuer à faire fonction de phare du monde sensible "

- Um país orgulhoso de "canibalizar" o mundo que o cerca para inventar, pela mistura, novos sabores: "Le Brésil, c'est certain, a toujours tiré fierté de " cannibaliser »le monde alentour. Mais c'était seulement pour inventer de nouvelles saveurs mêlées [...].

\section{Língua, cultura e representações na Didática do Francês Língua Estrangeira}

A necessidade de se traçar primeiramente o percurso evolutivo das concepções de cultura, de sua origem latina até à primeira concepção científica, e como a língua passou a ser considerada um de seus elementos constitutivos foi 
decorrente do interesse e da importância que damos ao estudo da construção das representações culturais dentro do processo de ensino-aprendizagem de línguas estrangeiras.

Partimos do pressuposto de que, na didática das LE, a construção de tais representações culturais está estreitamente ligada a três fatores:

- à concepção de cultura dos manuais de língua refletida na escolha dos elementos culturais a serem abordados;

- à concepção de cultura dos professores de língua estrangeira (assim como das instituições onde trabalham) e as suas representações acerca da cultura ensinada;

- à abordagem metodológica dos professores no tratamento dos documentos destinados à apresentação de uma outra cultura.

Centramos, desta forma, o nosso trabalho de pesquisa, na abordagem dos documentos destinados à apresentação de uma outra cultura, documentos esses que contribuem, ao nosso ver, na construção de representações culturais dentro do processo de ensino-aprendizagem de LE. O papel do professor nos parece, deste modo, de grande importância por acreditarmos que o referido processo de construção sofre a influência da sua concepção de cultura refletida na escolha ou seleção dos documentos a serem trabalhados em sala de aula, assim como de suas representações acerca da comunidade cultural estudada.

A língua, por sua vez, como um dos elementos constitutivos da cultura e parte integrante do processo de abordagem de uma cultura estrangeira, representa seu papel na elaboração do discurso construtor de representações culturais cuja análise pode auxiliar o educador a melhor intervir junto aos aprendizes enquanto mediador entre duas culturas.

Tal intervenção se caracterizaria, sobretudo, pela conscientização, no aprendiz, de que o discurso está permeado de representações que podem influir no caráter formativo do processo de ensino-aprendizagem de línguas no que diz respeito tanto à construção e/ou consolidação de representações estereotipadas - 
que tendem a supervalorizar ou a denegrir certos aspectos de determinada comunidade cultural (por vezes em detrimento da própria cultura do aprendiz) quanto à inobservância das diferenças culturais que nos parecem importantes de serem tratadas não do ponto de vista do exótico ou do excêntrico, mas do ponto de vista de realidades históricas e culturais distintas, contextualizadas no tempo e no espaço. Dentro desta perspectiva, o professor consciente de seu papel de mediador e de formador estará munido de elementos concretos calcados na análise atenta e crítica do discurso e na variedade de documentos provenientes de fontes diferentes, não se baseando somente em suas experiências pessoais de contato com a outra cultura.

Essa descrição da realidade cultural estrangeira com bases somente empíricas é denunciada por Zarate (1986:29) como um erro metodológico que consiste em transformar uma experiência individual em verdade generalizada:

« [...] Faute d'être reconnue et analysée (la perception des faits culturels français de la part des enseignants) comme un point de vue spécifique, l'opinion se transforme en jugement absolu: «les Français sont... ». Ces jugements à l'emporte-pièce, si fréquents dans la conversation

quotidienne, sont autant de lampes rouges qui signalent l'erreur de méthode. L'abus consiste à transformer une expérience individuelle en vérité générale [...] » (Zarate, 1986:29)

Além disso, para uma descrição objetiva da cultura estrangeira, o professor não nativo deveria considerar, em sua análise descritiva, vários outros elementos que, segundo Zarate (1986:29) são de extrema importância para que experiências individuais não se transformem em verdades generalizadas:

«Tout discours contient le point de vue de celui qui l'énonce [...] Cela s'applique dans toute sa rigueur à 
l'enseignant non français qui, après un contact de courte, moyenne ou longue durée, rend compte en classe de la réalité française (ou francophone). Dans la relation qu'il en fera à ses élèves, en quoi sa description reste-t-elle dépendante de son expérience singulière et partiale? Un séjour de boursier ou de touriste, une expérience d'homme ou de femme, des origines provinciales ou parisiennes, un contact en milieu rural ou urbain, des amis étudiants ou aux prises avec la vie professionnelle sont pour l'enseignant de français langue étrangère autant de variables qui peuvent intervenir dans sa perception des faits culturels [...] » (Zarate, 1986:29)

De acordo com essas afirmações, a intervenção do professor deve ser considerada muito mais como um testemunho particular de uma experiência específica vivida do que como uma intervenção de mediador cultural entre a sua realidade e a de seus alunos com a dos estrangeiros, visto que o próprio professor carrega consigo as suas próprias representações.

A escolha de analisar textos da imprensa francesa sobre o Brasil nos pareceu a melhor maneira de demonstrar objetivamente o mesmo processo passível de ser realizado ao abordarmos uma cultura estrangeira, pois estamos sob o olhar do Outro, este Outro que nos esboça, que nos descreve, que nos caracteriza e que nos coloca diante de uma realidade que conhecemos e, ao mesmo tempo, desconhecemos, da qual fazemos parte ou não, pois estigmatizada e imobilizada em representações estereotipadas. A construção dos sentidos mobiliza, desta maneira, a cada momento, as representações que temos sobre nós mesmos brasileiros. Isto deve nos servir a refletir sobre o processo inverso, ou seja, como estamos habituados a representar o Outro.

A cultura estrangeira apreendida de várias formas suscita, deste modo, no aprendiz, a relatividade de pontos de vista e de experiências. Este estudo e esta conscientização são, ao nosso ver, uma via de mão dupla que auxilia tanto na compreensão do Outro como na redescoberta de si mesmo, pois o olhar externo sobre uma realidade cultural estrangeira propicia ao observador desperto à 
diversidade cultural um retorno a si mesmo e as suas "verdades absolutas", favorecendo uma objetivação sobre a sua própria cultura, suas referências e práticas culturais. Ao mesmo tempo, esse retorno a si mesmo pode lhe servir a respeitar tais diferenças tanto no macro quanto no micro universo de suas relações.

A declaração de Trotot (1998) feita na apresentação do livro de Jean de Léry Histoire d'un voyage fait en la terre du Brésil (1578), ilustra de forma pertinente o que acabamos de mencionar:

\section{Or, s'interroger sur l'autre c'est s'interroger sur ce qui me sépare de l'autre, mais aussi sur ce qui m'en rapproche. Ce qui revient à ajouter à la question «qui est cet autre homme que je rencontre ? " qui suis-je, moi qui le rencontre ? »(Trotot,1998:10-11).}

Entretanto, a tentativa de se ensinar uma cultura estrangeira não é assunto recente dentro da didática de língua estrangeira. Desde o século XIX busca-se, a partir do ensino de línguas, abordá-la e penetrá-la através da literatura e das artes em geral, visando ao enriquecimento do espírito. Esta concepção do ensino da cultura teve vida longa e chegou até quase o final do século $X X$ tendo sofrido poucas alterações, e por vezes limitando-se à aquisição de conhecimentos informativos e factuais que pouco contribuem à construção da consciência e competência culturais apregoadas pela abordagem interacionista. Vemo-nos, deste modo, confrontados à questão do como desenvolver, tanto na formação de professores quanto na dos aprendizes, uma competência cultural.

Através do estudo das principais metodologias de ensino de LE, podemos verificar as diversas formas de se conceber a língua e a cultura ao longo do tempo dentro da didática de LE.

No período em que predominou o método tradicional ou clássico (assim chamado por ensinar as línguas clássicas latim e grego), a língua era concebida como "un ensemble de règles et d'exceptions observables dans des phrases ou des textes" (Germain, 2001:103), e o seu ensino, calcado no estudo de textos literários, privilegiava a gramática e a tradução, com ênfase na leitura para a compreensão dos mesmos, e na escrita para a redação de composições ligadas ao tema estudado. $O$ objetivo principal era o de "rendre l'apprenant capable de lire les ouvrages littéraires 
écrits dans la langue cible [...] et de développer ses capacités intellectuelles" (Germain, $2001: 102$ ). Assim sendo, acreditava-se que 0 acesso à cultura estrangeira dava-se através do conhecimento da literatura e das artes. Dentro deste contexto, vislumbramos a concepção da cultura como sinônimo de enriquecimento de espírito através da aquisição de conhecimentos depreendidos da produção literária e artística de um povo. Entretanto, vale lembrar que não se ensinava qualquer língua, ensinava(m)-se a(s) língua(s) considerada(s) veiculadora(s) de valores culturais superiores, afinal de contas só assim poderia-se ter o enriquecimento do espírito e o desenvolvimento intelectual desejados.

A hegemonia da língua francesa durante os séculos XVIII e XIX na Europa confirma esta convicção da época de que aprender uma língua, e por conseqüência, a sua cultura (entendida como literatura e arte), nos eleva a um patamar social superior, nos diferenciando dos outros. Falado por todos os soberanos europeus, o francês era a língua da elite, veiculador de uma civilização superior e dotado do poder de esclarecimento das idéias e pensamentos e de emancipação da espécie humana. Esta concepção da língua francesa como sendo a língua de uma elite se perpetua no tempo e chega à primeira metade do século $X X$ se não com a mesma força, pelo menos propagando a mesma idéia. Segundo Antônio Cândido (1977:12), a França sempre representou um papel de mediadora cultural, pois foi "graças (a ela) que pudemos ver o mundo, que adquirimos o senso da Historia, que lemos os clássicos de todos os paises, inclusive gregos e romanos". Ainda segundo Cândido (1977:10), enquanto mediadora, ela nos ofereceu "a possibilidade de nos pormos em contato com outras culturas" (Id. Ibid, p.10).

Já no final do século XIX e início do século XX (após a pequena evolução do método tradicional gramática-tradução para versão-gramática), vemos renascer ${ }^{43} 0$ método direto cujo objetivo era o de se ensinar a língua para se comunicar. Suas características principais, e opostas ao método tradicional, eram as de priorizar a língua oral cotidiana, sendo as aulas ministradas na língua-alvo. Desta forma, esperava-se levar o aluno a pensar na língua estrangeira através da associação de idéias, servindo-se de imagens, objetos, gestos e mímicas. A língua é vista como instrumento de comunicação oral, e a cultura não é mais sinônimo somente de literatura e artes. Começa-se, então, a perceber que o ensino da cultura (mesmo que

\footnotetext{
${ }^{43}$ Dizemos "renascer", pois a sua origem remonta ao ensino do latim no início do século XVI, portanto quase tão antigo quanto o método gramática-tradução.
} 
de forma indireta), passa pelo "l'étude des valeurs culturelles (par exemple, le mode de vie du quoitidien des natifs de L2) aussi bien que la géographie et l'histoire" (Germain, 2001:128). Apesar da artificialidade dos diálogos esvaziados de implícitos, pela primeira vez eles se encontram inseridos num contexto ou situação (correio, banco, restaurante), e pela primeira vez há a integração das quatro habilidades lingüísticas - ouvir, falar, ler e escrever.

Os crescentes avanços tecnológicos e científicos e o desenvolvimento das ciências da linguagem na primeira metado do século $X X$ contribuiram muito para a evolução do ensino das línguas estrangeiras. A Segunda Guerra Mundial vem forçar os Estados Unidos a desenvolverem uma metodologia de língua capaz de formar seus soldados em tempo recorde a fim de se expressarem com fluência na língua dos locutores nativos. Precursor da metodologia áudio-oral que atingiu o seu apogeu na década de 50, o Método do Exército ou The Army Method contou com o embasamento teórico de importantes lingüistas, como Bloomfield e Sapir, que haviam desenvolvido uma outra metodologia (se assim podemos dizer) para o ensino das línguas indígenas. Besse (1985:35) descreve a concepção de um curso sob os princípios do Método do Exército da seguinte forma:

Les leçons étaient centrées sur des dialogues de langue courante, élaborés par lês concepteurs, mais différents du dialogue interactif à visée strictement pédagogique de la méthode directe, dialogues qu'il fallait mémoriser parfaitement, "sur-apprendre", avant de s'efforcer de comprendre le fonctionnement grammatical des phrases les composant, en s'aidant d'ouvrages de grammaire portant sur la L2 (mais aussi sur la L1) et d'explications magistrales. Ayant ainsi appris quelques répliques et ayant "compris" leur construction interne, l'étudiant-recrue était alors invité à les réutiliser, si possible en les recombinant entre elles et en recombinant leurs éléments lexicaux et grammaticaux selon les règles de la description grammaticale enseignée. Chaque classe 
disposait d'un professeur linguiste, apte à donner des explications grammaticales ou autres en L1 sur L2 (et évidemment sur L1), et un moniteur natif de L2 qui servait de modèle pour présenter les dialogues, et de répétiteur pour les faire apprendre par coeur. Le cours comprenait deux à trois sessions de cinq à six semaines chacune, à raison de quinze heures par semaine d'explications (grammaticales ou autres) sur la L2 et sur le pays où elle est pratiquée, 15 heures de répétition et de réemplois avec le moniteur, et une vingtaine d'heures de travail individuel (lectures en L1 sur le monde de $L 2$, révisions, exercices,...), soit en tout une cinquantaine d'heures hebdomadaires. (Besse, 1985 :35).

O sucesso deste método, segundo Besse, se deve muito menos aos procedimentos pedagógicos adotados do que ao contexto em que foi desenvolvido. O caráter extremamente intensivo deste ensino-aprendizagem, a motivação em aprender a língua do país de destino, o estímulo suscitado pelas sessões fechadas, a competência dos dois professores e o desejo de participar da vitória foram, segundo Besse (1985:36), os grandes responsáveis pelo seu êxito. Com uma vida útil de apenas dois anos, este método despertou o interesse nos meios escolares e no público em geral, pois demonstrou qu'il était possible d'apprendre à comprendre et à parler une $L 2$ dans un temps relativement court et sans exiger une grande capacité intellectuelle (Besse, 1985:36).

Empolgados com as descobertas da psicologia behaviorista e da lingüística estrutural, e estimulados pelos resultados obtidos pelo método do Exército, nasce, na metade dos anos 50, o método Áudio-Oral. De origem também americana, concebia a língua como um conjunto de hábitos e o seu aprendizado como a criação de automatismos lingüísticos. Tinha por objetivo o de levar o aluno a se comunicar na língua estrangeira seguindo a ordem de aquisição da língua materna, ou seja, compreensão oral (CO), expressão oral (EO), compreensão escrita (CE) e 
expressão escrita (EE). Pela primeira vez, alia-se a tecnologia à educação com aulas ministradas com o auxílio de gravações usadas, igualmente, no laboratório de línguas. A proibição expressa do uso da língua materna em sala de aula não impedia a análise comparada de ambas (LM e LE), nem tampouco dos elementos culturais tratados pelos manuais de língua, como por exemplo, o modo de vida dos membros dessas sociedades.

Brooks (apud Germain, $2001: 111$ ) define a concepção de cultura vigente como l'ensemble des croyances et des modes de comportement d'un groupe social, tels que reflétés dans les arts et les métiers artisanaux, dans les contes et les mythes, dans le travail et dans le jeu, dans la religion et dans la vie quotidienne [...]. A partir desta definição, nota-se um alargamento na concepção do que vem a ser cultura. Apesar de ainda se manifestar nas artes, na literatura, nos contos e nos mitos, vemos acrescentada a esta concepção o conjunto das crenças e dos modos de comportamento de um grupo social. Este acréscimo ou esta complementação feita por Brooks à concepção de cultura demonstra a evolução da noção expressa pelo termo aplicada no ensino das línguas estrangeiras. Isto nos deixa entrever uma abertura e um encaminhamento ao seu sentido sociológico e não meramente literário e artístico, como declara o próprio autor:

II ressort clairement de notre analyse [...] que le professeur doit rattacher la langue à la culture [...] Telle est la conclusion de Robert Politzer, qui écrit [...]: "En tant que professeurs de langue nous devons nous intéresser à l'étude de la culture (dans le sens sociologique du terme), non pas parce que nous voulons enseigner nécessairement la culture de l'autre pays mais parce que nous devons l'enseigner. Si nous enseignons une langue sans enseigner en même temps la culture dans laquelle elle s'insère, nous enseignons des signes dépourvus de sens ou des signes auxquels l'étudiant attribue une signification 
erronée. Car, à moins qu'il ne soit prévenu ou qu'il n'étudie la culture en question, il risque d'attribuer un sens américain aux objets ou aux concepts auxquels correspondent les signes de l'autre langue [...] (Brooks apud Germain, 2001 :149).

Mesmo que concebidos de forma estática, a associação do ensino da língua ao ensino da cultura representa um avanço metodológico na didática de língua estrangeira.

Com o relativo fracasso do método áudio-oral decorrente, entre outros fatores, da incapacidade dos alunos de se expressarem na língua estrangeira ao final de um número considerável de horas de estudo, e com o crescente aumento da importância do inglês após a Segunda Grande Guerra, o Ministério da Educação Nacional na França decidiu implantar uma Comissão encarregada de elaborar um glossário (denominado Français Fondamental) das palavras mais correntes do francês falado. Mediante esta necessidade de resgatar a importância do francês como língua estrangeira, sentiu-se a necessidade de elaboração de um método eficaz que levasse em consideração a língua cotidiana. Assim sendo, privilegiou-se o léxico, o francês cotidiano falado, e pela primeira vez o fator afetivo (com a introdução de expressões de sentimento e de emoções, assim como a consideração do aspecto não-verbal da comunicação - gestos, mímicas, etc.). Está criado o método SGAV44 ( Structuro-Global Audio Visuel ), método predominantemente oral, com ênfase na compreensão de diálogos centrados num tema da vida cotidiana, e que apresenta os elementos culturais de forma explícita ou implícita, elementos estes que poderiam se referir tanto ao modo de vida dos franceses quanto à sua literatura. Segundo Renard (apud Germain, 2001) uma excelente maneira de ter

\footnotetext{
${ }^{44}$ Sob a responsabilidade de Peter Guberina, da Universidade do Zagreb (ex-lugoslávia) e de Paul Rivenc, da Ecole Normale Supérieure de Saint-Cloud, nasce o V.I.F. (Voix et Images de France), manual didático destinado ao ensino do francês para crianças de 8 a 11 anos, baseado na noção de "structuro-global" (a palavra em situação) e na teoria verbo-tonal de Guberina (teoria da percepção auditiva e visual).
} 
acesso a uma civilização estrangeira - inclusive à literatura - é falar e compreender a língua que serve precisamente de veículo para esta civilização ${ }^{45}$.

As três gerações que compuseram a evolução do método SGAV foram marcadas e delimitadas pela elaboração de três manuais de língua, Voix et Images de France - VIF 1 e 2 (CREDIF, Paris, 1970), De Vive Voix - DVV (Ecole Normale Supérieure de Saint-Cloud e CREDIF, Paris,1975), e Archipel (CREDIF/Didier, Paris, 1982), representando este último um grande avanço em direção à abordagem comunicativa.

O surgimento do manual C'est le printemps (Montredon J. et al., Clé International, Paris, 1976), que intermediou a passagem do SGAV para a abordagem comunicativa, suscitou inúmeras críticas em virtude das inovações de ordem cultural apresentadas, por exemplo, a introdução de temas polêmicos como o do racismo. Com vida curta, pois não veiculava a imagem idílica da França, este manual, no entanto, representou um marco na evolução das metodologias ao propor uma abordagem crítica e mais realista da cultura francesa:

\begin{abstract}
Aussi (C'est le Printemps) n'est-il pas l'histoire d'une famille petite bourgeoise sans problèmes ou une idylle entre jeunes gens timides, mais une suite de situations mettant en scène des personnages divers, des gens de tous âges, des Français et même des étrangers vivant en France. Par eux, à travers eux, une certaine réalité française apparaît.....] C'est le Printemps est également né d'une critique d'ordre linguistique.[...] La progression linguistique des six premières unités vise à l'autonomie d'apprentissage de l'étudiant, ainsi que d'acquisitions de moyens linguistiques directement utilisables en situation de communication ${ }^{46}$.
\end{abstract}

No final da década de 60 e início da década de 70, a didática de línguas estrangeiras se defronta com uma nova realidade mundial, marcada pela grande

\footnotetext{
45 Tradução da autora.

${ }^{46}$ C'est le Printemps, livre du professeur, p.5 apud Maddalena de Carlo, L'interculturel, Clé International, 1998 : 32.
} 
abertura dos mercados, pelo desenvolvimento dos meios de transporte assim como pela maior divulgação dos avanços tecnológicos do primeiro mundo. Estes fatores, responsáveis por uma maior mobilidade e comunicação entre as culturas, alavancaram o ensino das línguas estrangeiras baseado nas necessidades lingüísticas profissionais e de formação acadêmica. O acesso à literatura específica e às publicações científicas se faz cada vez mais necessário, e impõe a necessidade de renovação e adequação da concepção do ensino das línguas estrangeiras tanto no plano lingüístico quanto no plano pedagógico a fim de se responder a esta nova demanda do mercado. Não se trata mais de ensinar o francês "geral", mas o francês centrado nas especificidades locais e de público, o francês veiculador de informações, o resgate do francês escrito, o nascimento do Francês Instrumental. A grande mudança acarretada foi a centração do ensino de línguas estrangeiras às necessidades do aluno "adulto", levando-se em consideração alguns fatores externos até então desprezados, como a sua disponibilidade de tempo, seus objetivos, suas expectativas e suas características próprias:

Esta prática corresponde a escolhas precisas de objetivos, de conteúdos e de métodos, motivadas pela situação dos países em questão e pelas necessidades presentes e futuras dos seus estudantes [...] $O$ francês instrumental [...] visa 0 ensino massivo aos estudantes que se iniciaram numa disciplina universitária [...] Trata-se de fornecer uma ferramenta de trabalho ao estudante de qualquer área [...] com o objetivo de tornar o estudante capaz de compreender o conteúdo de um texto, de extrair a informação e eventualmente, de transmiti-la a outras pessoas na sua língua materna [...] Supõe-se que já exista o nível elementar (de língua dos alunos), seja através de um curso de francês tradicional, ou de um curso VIF, ou outro (ALVAREZ, 1976:7) $^{47}$

\footnotetext{
${ }^{47}$ Tradução da autora.
} 
O ensino da língua e, por conseguinte, da cultura estava associado, deste modo, à divulgação dos avanços tecnológicos e científicos do país da língua-alvo com vistas a buscar novos mercados nos países em desenvolvimento.

Concomitantemente, os avanços das pesquisas nas várias áreas das ciências da linguagem vêm contribuir à evolução das concepções de língua e de cultura dentro da didática de línguas estrangeiras. A consideração dos aspectos sociais da linguagem reivindicados por Hymes, as reflexões acerca da linguagem como instrumento de comunicação, de Austin e Searle, o interesse de vários outros autores nos aspectos semânticos da linguagem, juntamente com o diagnóstico das novas e diferentes necessidades lingüísticas de um falante dentro do contexto expandido das relações européias encontram-se na base da abordagem comunicativa nascente, como declara Germain (2001:202):

C'est la convergence de ces quelques courants de recherche ainsi que l'avènement de différents besoins linguistiques dans le cadre d'une Europe élargie (marché commun, Conseil de l'Europe, etc) qui a en définitive donné naissance à l'approche communicative [...] L'événement marquant qui allait donner l'occasion à quelques chercheurs de fondre en un tout l'ensemble des courants théoriques convergents [...] est d'ordre politique [...] et en 1972, le Conseil de l'Europe réunissait un groupe d'experts chargés de mettre sur pied des cours de langues pour adultes (Germain, 2001 :202).

Nasce, deste modo, a noção de competência de comunicação que engloba, além da competência gramatical, a competência sociolingüística e a competência estratégica (estratégias verbais e não-verbais). A língua é vista tanto como instrumento de comunicação quanto de interação social. O objetivo principal é o de fazer o aluno se comunicar de forma eficaz na língua estrangeira, sendo capaz de adequar os vários registros de língua à situação de comunicação segundo a sua intenção, tendo em vista que o domínio das regras gramaticais não basta para que ele adquira esta competência de comunicação. $O$ que se pretende é o 
desenvolvimento da sua capacidade de recriar a língua, de descobrir novas regras de formação de enunciados, participando assim da sua própria aprendizagem, segundo a psicologia cognitiva.

Le but général est d'en arriver à ce que les apprenants communiquent de façon efficace [...] les tenants de l'approche communicative considèrent qu'une communication efficace implique une adaptation des formes linguistiques à la situation de communication (statut de l'interlocuteur, âge, rang social, lieu physique, etc) et à l'intention de communication (ou fonction langagière : demander d'identifier un objet, demander une permission, donner des ordres, etc) (Germain, 2001 :203)

A cultura, por sua vez, é concebida de forma mais dinâmica considerando os fatos da vida cotidiana, o comportamento e os elementos não-verbais presentes em toda comunicação lingüística:

Par culture, l'approche communcative fait surtout référence à la vie quotidienne, en tenant compte du comportement non-verbal qui accompagne toute communication linguistique. (Germain, 2001:204)

A pedagogia deixa de ser a pedagogia do ensino para se tornar a pedagogia da aprendizagem, onde o aluno é o fator mais importante deste processo. É preciso, desde então, considerar as suas características e as suas necessidades de aprendizagem que interferirão na sua motivação em aprender uma língua:

II existe donc des stratégies d'apprentissage

différentes selon la situation, et sans doute selon 
d'autres facteurs tels que le milieu socioculturel, l'âge, la formation antérieure, etc. de l'apprenant" (ROULET, E.L.A, no. $21: 64$ )

A abordagem comunicativa não oferece receitas e fórmulas a serem seguidas para que se obtenha o sucesso e se atinjam os objetivos, mas se baseia em princípios fundamentais que devem ser levados em consideração pelo professor diante de seu grupo-classe. Com a introdução da noção de intenção de comunicação associada a uma situação, o aluno é exposto mais cedo a um conjunto de possibilidades variadas para um mesmo ato de fala ou "fonction langagière". A sensibilização a esses elementos desestatiza a concepção de língua, inserindo-a num movimento mais dinâmico do que o que vinha sendo feito até o método SGAV. O leque de possibilidades apresentado faz com que o aluno comece, por si só, a recriar a língua e a adequar essas variantes a contextos específicos.

Dentro de uma perspectiva similar e acompanhando toda a evolução política, econômica e social mundial dos últimos tempos, entramos, a partir da metade dos anos 90, na era "actionnelle". Centrada primeiramente nas necessidades de uma Europa unificada, esta mais recente perspectiva das didáticas das línguas estrangeiras visa à preparação dos europeus a um convívio social e de integração profissional. A formação de aprendizes não somente capazes de falar e compreender uma língua estrangeira, mas também de agir e reagir se servindo desta língua dentro de uma outra sociedade, levando-se em consideração a diversidade cultural são as bases da perspectiva actionnelle. A concepção de língua passa a ser a de um outil d'action commune et non plus seulement de communication réciproque (Puren, 2001:9-10).

O resultado de todas estas indagações, considerações e constatações para o ensino de línguas é a publicação do Cadre Européen Commun de Référence pour les langues (elaborado pelo Comité de l'Education do Conseil de l'Europe, em 1996) que considera antes de tudo l'usager et l'apprenant d'une langue comme des acteurs sociaux ayant à accomplir des tâches (qui ne sont pas seulement langagières) dans des circonstances et un environnement donné, à l'intérieur d'un domaine d'action particulier $^{48}$.

\footnotetext{
${ }^{48}$ Cadre Européen Commun de Référence pour l'apprentissage et l'enseignement des langues, cap.2, p.15.
} 
Este importante documento de referência para o ensino e a aprendizagem das línguas vivas concebe o uso da língua e o seu aprendizado como des actions accomplies par des gens qui, comme individus et acteurs sociaux, dévéloppent un ensemble de compétences générales et, notamment une compétence à communiquer langagièrement. Ils mettent en oeuvre les compétences dont ils disposent dans des contextes et des conditions variés et en se pliant à différentes contraintes afin de réaliser des activités langagières permettant de traiter (en réception et en production) des textes portant sur des thèmes à l'intérieur de domaines particuliers, en mobilisant les stratégies qui paraissent le mieux convenir à l'accomplissement des tâches à effectuer. Le contrôle de ces activités par les interlocuteurs conduit au renforcement ou à la modification des compétences (id.ibid.).

Parte-se do princípio de que o aprendiz de língua passa a ser, de acordo com as bases "acionais", um usuário da língua e que, como tal, agirá e reagirá conforme os variados contextos ao qual um nativo está exposto. A concepção de língua não é mais a de une expression neutre de la pensée, mas le besoin et le désir de communiquer naissant d'une situation donnée dont la forme et le contenu de la communication doivent répondre à cette situation (id, cap.4 :41).

A expansão do conceito de cultura na perspectiva actionnelle engloba tanto 0 conhecimento de mundo do aprendiz (conhecimento este que pode ter sido adquirido pela experiência, pela educação, pela informação ou por outros meios) quanto o seu saber sóciocultural, a sua consciência intercultural, os seus traços pessoais ligados a sua personalidade, e o seu saber-aprender. Desta forma, o conhecimento da sociedade e da cultura da língua que se está aprendendo compreende um dos aspectos das competências gerais visadas:

La connaissance, la conscience et la compréhension des relations (ressemblances et différences distinctives) entre "le monde d'où l'on vient » et "le monde de la communauté cible » sont à l'origine d'une prise de conscience interculturelle [...] Elle s'enrichit également de la conscience qu'il existe un plus grand éventail de cultures que celles véhiculées par les $L 1$ et $L 2$ de l'apprenant [...] et 
englobe la conscience de la manière dont chaque communauté apparaît dans l'optique de l'autre, souvent sous la forme de stéréotypes nationaux. (id. cap.5: 83)

Chegamos, assim, à necessidade de integração efetiva do desenvolvimento da competência cultural do aprendiz como parte integrante do processo de ensinoaprendizagem de língua estrangeira, o que nos remete à questão levantada no início deste capítulo sobre o "como" desenvolver no aprendiz esta competência, ou como "ensinar a cultura".

Segundo Marie-Bernadette Le Berre (1998:40), o ensino da cultura nos dias de hoje compreende a construção de referências que nos orientem e que definam nossas práticas pedagógicas ${ }^{49}$. Para tanto, três postulados constituiriam a base de uma didática das culturas :

- Une culture se construit, c'est-à-dire se définit comme modes de production plutôt que comme catalogue de produits ;

- Une compétence culturelle, comme maîtrise personnelle de ces procédés de construction, est l'objectif spécifique de l'enseignement des cultures ;

- La méthodologie d'accès à cette compétence est donc fondée sur l'apprenant/producteur de sens culturel et sur une pédagogie active d'apprentissage.

Estes três postulados nos remetem à construção de representações a partir da experiência e da percepção do mundo. Fundamentar o ensino da cultura numa metodologia centrada no aprendiz/produtor de sentido cultural equivale dizer tomar como ponto de partida todo o seu conhecimento de mundo, todas as suas

\footnotetext{
${ }^{49}$ Le Berre, M.B. Concepts et outils utilisés en maîtrise FLE pour une éducation à la perception interculturelle au CUEF/Université Stendhal in L'apport des centres de français langue étrangère à la didactique des langues, Grenoble, 1998, p. 40
} 
experiências, percepções e representações para que ele desenvolva a sua competência cultural. O objetivo é o de se adquirir não mais conhecimentos informativos sobre a cultura estrangeira, mas um saber que lhe permita compreender o funcionamento de uma dada sociedade, e que lhe permita ler e relativizar o mundo que se expandiu através de um processo de redescoberta de si mesmo e de descoberta do Outro, a fim de que ele possa interagir neste novo contexto.

Vemo-nos, desta maneira, confrontados à importância das representações neste processo construtivo do savoir-faire e do savoir-être que preconiza um processo de relativização baseado na diversidade cultural, favorecendo 0 reconhecimento da inexistência de verdades absolutas ou realidades indiscutíveis. Como declara Le Berre (1998:42):

«Regarder les cultures des autres oblige à regarder la sienne »

Desta maneira, o próprio educador deve ter em mente, e conseqüentemente ter posto em prática estes postulados no seu próprio processo de formação. Daí a necessidade de se desenvolver, também nos futuros educadores, esta consciência da diversidade e da pluralidade das culturas a fim de que eles possam repensar, construir e finalmente conduzir e fornecer elementos aos seus aprendizes para a formação de sua competência cultural.

Le Berre (1998) propõe aos estudantes do seu curso de Maîtrise FLE três linhas diretrizes que funcionam como desencadeadores deste processo de formação e de despertar às outras culturas. A primeira é o reconhecimento da importância da antropologia cultural e das ciências sociais neste processo de formação da pessoa que exige, por sua vez, um processo de descentração. Isto equivale dizer que o indivíduo terá que sair do centro do universo que o rege e olhar o mundo em sua volta. Olhar o mundo equivale a se ver através dele como num espelho cuja função não é a de refletir a sua própria imagem tal qual os seus olhos lhe mostram, mas a de servir de instrumento para que ele se olhe e se veja a partir dele. 
A segunda linha diretriz corresponde à objetivação através de técnicas que auxiliariam o futuro educador a descobrir o efeito que ele realmente produz e não o que ele pretende ou imagina produzir, visto que a sua função de educar o coloca em posição de influência sobre os seus aprendizes. Deste modo, objetivar a sua própria ação se constituiria, segundo Le Berre (1998:43) em um:

"Processus méthodique, pratiquable par tout le monde, selon lequel on construit un phénomène à étudier [...]. Pour cela, on met le phénomène à distance, on le considère "comme de l'extérieur" [...] Les techniques d'objectivation conduisent à la construction d'un terrain commun, donc de ce qui rend possible le travail collectif et la coopération" (Le Berre, 1998:43).

Porcher (apud Le Berre, 1998:43) afirma que objetivar a sua própria ação compreende igualmente a construção de um saber provisório a partir das diferenças, e muitas vezes, a partir da oposição e da ruptura com saberes antigos. Deste modo, tomamos consciência da necessidade de se adquirir instrumentos que nos possibilite remediar um trabalho que freqüentemente é realizado às cegas.

Compondo esta tríade preconizada pela antropologia cultural, viria a grande importância da contextualização no processo de ensino-aprendizagem de uma língua e de sua cultura.

A contextualização dos fatos e das culturas permite ao aprendiz de língua estrangeira e a qualquer indivíduo desejoso de aprender e conhecer outras culturas de refletir sobre o novo e de compreendê-lo dentro do quadro que lhes deu origem. Assim como é necessária a inserção de determinado acontecimento dentro do seu contexto histórico, é necessário que enxerguemos as outras culturas dentro do contexto que as atualiza incessantemente a fim de nos mantermos coerentes e de evitarmos um processo de folclorização.

A contextualização se define, segundo Le Berre (1998:44), da seguinte maneira : 
Inscription des divers phénomènes culturels dans le canevas d'ensemble qui leur donne cadre et rend possible leur compréhension, permet de construire une véritable systématique de la civilisation étudiée. (Le Berre, 1998:44)

A importância da contextualização dos fenômenos culturais para se compreender uma cultura nos remete à importância indiscutível da contextualização das interações sociais, lugar onde a língua, a cultura e as representações interagem, comunicam e produzem sentidos.

Segundo Cuche (2001:50), a pluralidade dos contextos de interação explicam o caráter plural e instável de toda cultura, e também os comportamentos aparentemente contraditórios de um mesmo indivíduo. Assim como a língua é o produto da interação entre os falantes, a cultura, segundo Cuche (2001:49), só existe pelo jogo interativo dos indivíduos. Como declara Pretceille ${ }^{50}$ (2005):

A cultura é uma ferramenta da qual nos servimos para ser e viver no mundo. Ela é um meio de comunicação que se atualiza no comportamento, nas ações, no discurso, na interação social. É um processo dinâmico, suscetível de várias leituras interpretativas e expressões plurais e, sobretudo, a cultura é a expressão de um ponto de vista suscetível de ser confirmado ou refutado por outras versões. (Pretceille:2005).

Deste modo, língua e cultura atualizam-se, constroem sentidos e apresentam a sua dinamicidade na diversidade de contextos, das relações e das interações

\footnotetext{
${ }^{50}$ Seminário "La Communication Interculturelle" ministrado por Martine Abdallah-Pretceille, na universidade Paris III, Sorbonne Nouvelle, no primeiro semestre do ano letivo 2005-2006, o qual seguimos.
} 
sociais. Neste sentido, a língua nos dá acesso à cultura em seu sentido sociológico, pois necessitamos dela para interagir. E são nas interações que entram em jogo as representações das quais nos servimos para agir e reagir junto aos nossos interlocutores.

Partindo da premissa de que as relações são dependentes das representações (Abdallah-Pretceille, 1996:32), nosso objetivo, com esse estudo, foi o de colaborar para a formação de professores e, por conseguinte, de aprendizes mais conscientes e respeitosos das diferenças culturais em suas relações sociais.

5. Conclusão 
Os debates mais fervorosos acerca da cultura ocorridos nas últimas décadas dentro da didática de línguas estrangeiras são decorrentes, como dito anteriormente neste trabalho, da necessidade de formarmos hoje, enquanto educadores, indivíduos conscientes e respeitosos da diversidade cultural e melhor preparados a interagir socialmente. Esta diversidade não se refere somente à pluralidade de países, mas, sobretudo, à diversidade da espécie humana. Assim sendo, a expressão e a interpretação da cultura devem ser vistas como expressões e interpretações múltiplas, pois dependentes da diversidade de contextos, de situações, de experiências, de relações e de intenções à qual cada um de nós, enquanto indivíduos, estamos expostos diariamente.

A complexidade da questão exige, ao nosso ver, a necessidade imperativa de identificarmos como os professores de língua estrangeira concebem a cultura e a língua, hoje não mais restritas, como vimos, à aquisição de conhecimentos e ao domínio de estruturas lingüísticas, mas reconhecidas como um fato social, produto da interação entre os indivíduos. Esta identificação permitirá avaliar a abordagem de ambas nas práticas pedagógicas desses profissionais do ensino, e elaborar programas de formação de professores que abordem e reflitam sobre esta questão.

A sensibilização à diversidade de pontos de vista e interpretações sobre uma mesma comunidade cultural representa, para nós, o ponto de partida para a compreensão de que a cultura se manifesta através dos indivíduos, de acordo com a sua história pessoal, seu grupo social, sua profissão, sua idade, sua região de origem, sua vivência de mundo. Somos desta forma, transmissores de cultura, pois, como afirma Pretceille (1996:45), nunca são as culturas que estão em contato, mas os indivíduos ${ }^{51}$. Portanto, a tentativa de formalizar uma cultura, generalizando a toda uma sociedade traços e comportamentos, fragmenta a realidade e faz com que neguemos a sua complexidade e heterogeneidade.

O conteúdo dos artigos sobre o Brasil selecionados neste trabalho ilustra de forma pertinente o que acabamos de afirmar: quantos brasileiros e brasileiras se identificam com as caracterizações feitas sobre a cultura deste país e o seu povo? Seria possível expandir a 180 milhões de brasileiros o culto do corpo, a religiosidade,

\footnotetext{
${ }^{51}$ Tradução da autora.
} 
entre outras características que Ihes são atribuídas? Evidentemente não, pois como afirma Linton ${ }^{52}$ :

Aucun n'individu n'est familier avec le tout de la culture à laquelle il participe; encore moins en exprime-t-il tous les modèles dans son propre comportement [...] En raison de cette différenciation dans la participation culturelle, c'est une erreur fondamentale de considérer une culture comme le commun dénominateur des activités, idées et attitudes des membres composant la société. (Linton apud Filloux, 1999 : XXXVI)

Reafirmamos, com isso, a importância de despertar professores e aprendizes à teoria do diverso. Esperamos, deste modo, que a pesquisa realizada neste trabalho favoreça a reflexão sobre o papel da língua, da cultura e das representações dentro do processo de ensino-aprendizagem de línguas estrangeiras, pois é necessário compreender cada noção para que efetivamente possamos abordá-las de uma outra forma.

\section{Bibliografia}

ABDALLAH-PRETCEILLE, M. Vers une pédagogie interculturelle. Paris : Anthropos, 1996.

\footnotetext{
${ }^{52}$ Citação de Linton feita por J.-C Filloux no prefácio do livro de Linton, Le Fondement culturel de la personnalité, Paris: Dunod, 1999:XXXVI.
} 
ABDALLAH-PRETCEILLE, M. PORCHER, L. Éducation et Communication interculturelle. Paris: PUF, col. Education et Formation, primeira edição, 1996, segunda edição, 2001.

ALBERT, P. La presse française. Paris: La Documentation Française, col. Les études de la documentation française, 2004.

ALVAREZ, G. La Notion de Français Instrumental in Langues et Linguistique, no. 2, p.1-9, 1976.

BAKTHINE, M. Marxisme et Philosophie du Langage. Paris : Les Éditions de Minuit, 1977.

BASTIDE, R. Brasil, Terra de Contrastes. São Paulo : Difel, 1976.

BEACCO, J.-C. Les dimensions culturelles des enseignements de langue. Paris : Hachette, col. F références, 2000.

BERLIN, I. Vico e Herder - Pensamento Político. Brasília: Editora Universidade de Brasília, 1976.

BESSE, H. "La méthode audio orale - la méthode audio visuelle (SGAV)" in Méthodes et Pratiques des Manuels des Langues. ENS Saint Cloud, Crédif. Paris: Didier, 1985.

BOAS, F. Race, langage and culture in The Mind of Primitive Man. New York: The MacMillan Company, pp. 145-158, 1940

. Early cultural traits in The Mind of Primitive Man. New York: The MacMillan Company, pp. 159-174, 1940.

. The Interpretations of culture in The Mind of Primitive Man. New York: The MacMillan Company, 1940:175-196.

. The Race Problems in modern Society in The Mind of Primitive Man. New York: The MacMillan Company, pp. 253-273, 1940.

. Race and Language in Handbook of American Indian Languages. Bulletin 40, Bureau of American Ethnology. Washington: Georgetown University Press, pp. 583, 1911.

. Language in General Anthropology. Boston: D.C. Heath and Company, pp. 124-145, 1938.

. On alternating sounds in A Franz Boas Reader - The Shaping of American Anthropology, 1883-1911. Edited by George W. Stocking Jr. Chicago: The University of Chicago Press, pp. 72-77, 1883. 
BRAIT, B. Bakhtin, Dialogismo e Construção do sentido. Campinas: Editora da Unicamp, 1997, reimpressão, 2001.

. Bakhtin, conceitos chaves. São Paulo: Editora Contexto, 2005.

BRANDÃO, H.H.N. Introdução à Análise do Discurso. Campinas: Editora da Unicamp, 8‥ edição, 2002.

BRONCKART, J.-P. "Interactions, Discours, Significations" in Langue Française, no. 74, pp.29-50, Paris: Larousse, 1987.

BROUAT, T. On n'appelle pas toujours un chat un chat in Langues Modernes, no. 2, pp. 41-47, 1986.

BRUNER, J. Culture et modes de pensée - L'esprit humain dans ses œuvres. Paris : Éditions Retz, 2000.

BYRAM, M. Culture et Éducation en langue étrangère. Paris: Hatier/Didier, col. École Normale Supérieure de Fontenay - Saint-Cloud, CREDIF, 1992.

CANDIDO, A ; CARONI, I ; LAUNAY, M . O Francês Instrumental - A experiência da Universidade de São Paulo. São Paulo: ed. Hemus, 1977.

CARRELL, Patrícia L. "Culture et contexte dans la lecture en langue étrangère:Rôle des Schémas de Contenu et des Schémas Formels" in Acquisition et utilisation d'une langue étrangère, Paris: Hachette, pp. 8-21, 1990.

CELADA, M.T. O espanhol para brasileiros - uma língua singularmente estrangeira. Tese de doutorado apresentada ao Curso de Lingüística, Unicamp:2002.

CHARAUDEAU, P. MAINGUENEAU, D. Dictionnaire d'Analyse du Discours. Paris : Éditions du Seuil, 2002.

CONSEIL DE LA COOPERATION CULTURELLE, Comité de l'Education, "Apprentissage des langues et citoyenneté européenne", Division des Langues Vivantes, Conseil de l'Europe. Un Cadre Européen Commun de Référence pour les Langues. Paris: Didier, 2001.

CUCHE, D. La notion de culture dans les sciences sociales. Paris : Éditions La Découverte, 2001.

CULIOLI, A. La Communication Verbale in L'Homme et les Autres, Encyclopédie des Sciences de l'Homme "L'Aventure Humaine », tome I. Paris: Ed. GrangeBatelière, 1967.

DAHLET, P. Les représentations sociales. Fonctionnement Discursif (2a. Parte) in Revista Rencontres, no. 2, pp. 7-34, São Paulo: Departamento de Francês da PUCSP,1992. 
DE CARLO, M. L'Interculturel. Paris: Clé International, Col. Didactique des Langues Étrangères, 1998.

ERLICH, S. Les représentations sémantiques in Psychologie Française, tome 30, pp. 285-296, 1985.

FALL, K. FORGET, D. VIGNAUX, G. Construire le sens, Dire l'identité - catégories, frontières, ajustements. Québec: Les Presses de I'Université Laval. Paris: Les Editions de la Maison des Sciences de l'Homme, 2005.

FAUSTO, B. História do Brasil. São Paulo: Edusp/FDE, 1996.

GARABAtO, M.-C. A. AUGER, N. GARDIES, P. KOTUL, E. Les Représentations Interculturelles en Didactique des Langues-Cultures - Enquêtes et analyses. Paris: L'Harmattan, col. Langue \& Parole, 2003.

GAUTHEY, F. XARDEL, D. Le management interculturel. Paris : PUF, col. Que SaisJe?, 1990.

GEERTZ, C. A Interpretação das Culturas. Rio de Janeiro: Zahar Editores, 1978.

GERMAIN, C. Evolution de l'enseignement des langues:5000 ans d'histoire. Paris : Clé International, col.Didactique des Langues Etrangères, 2001.

GOFFMAN, E. Les rites d'interaction. Paris: Les Éditions de Minuit, col. Le Sens Commun, 1998.

GRIZE, J. B. Logique et Langage. Paris : Ophrys, col. L'Homme dans la langue, 1997.

JAKOBSON, R. La notion de signification grammaticale selon Boas in Essais de Linguistique Générale. Paris : Édition de Minuit, 1963.

JODELET D. Les représentations sociales. Paris : PUF, col. Sociologie d'Aujourd'hui. 1a. edição 1989 ; sétima edição, 2003.

LADMIRAL, J-R. LIPIANSKY, E.M. La communication interculturelle. Paris: Armand Colin, 1989.

LE BERRE, M.B. Concepts et outils utilisés en maîtrise FLE pour une éducation à la perception interculturelle au CUEF/Université Stendhal in L'apport des Centres de français langue étrangère à la didactique des langues. Grenoble: LIDILEM Université Stendhal-Grenoble, pp. 39-52, 1998.

LE GUIDE DU ROUTARD : BRESIL. Paris : Hachette, 1999/2000.

LE NY, J-F. Comment (se) représenter les représentations in Psychologie Française, tome 30 , pp. 231-237,1985. 
LÉRY, J. Histoire d'un voyage fait en la terre du Brésil in Récits de voyage I, Le nouveau monde. Paris : Flammarion, col. Etonnants Classiques, 1998.

LINTON, R. Le fondement culturel de la personnalité. Paris : Dunod, 1999.

MAINGUENEAU, D. L'énonciation en linguistique française. Paris: Hachette Supérieur, col. Les Fondamentaux, nova edição 1999.

- Analyser les textes de communication. Paris : Dunod, 1998.

. Termos chaves da Análise do discurso. Belo Horizonte: Editora

UFMG, 2000.

MARCUSCHI, L.A. Leitura como processo inferencial num universo cultural-cognitivo in Estado de Leitura. Campinas: Mercado de Letras, pp. 95-124, 1999.

MAZIERE, F. L'analyse du discours. Paris : PUF, col. Que sais-je ?, 2005.

MOIRAND, S. Situations d'Ecrit, Clé International, Paris, col. Didactique des Langues Etrangères, 1979.

. Une grammaire des textes et des dialogues. Paris: Hachette

F.L.E., col. F, 1990.

MOORE, D. Les représentations des langues et de leur apprentissage - références, modèles, données et méthodes. França : Didier, col. CREDIF Essais, 2005.

MOSCOVICl, S. Des représentations collectives aux représentations sociales: éléments pour une histoire in Les Représentations Sociales, Paris: PUF, col. Sociologie d'Aujourd'hui, pp. 79-103, 2003.

MOURA, M.M. Celebração de Boas - O nascimento da Antropologia Cultural na obra de Franz Boas. Tese de Livre Docência apresentada ao Departamento de Antropologia da FFLCH - USP. São Paulo : 2000

PARÂMETROS CURRICULARES NACIONAIS DE LÍNGUA ESTRANGEIRA TERCEIRO E QUARTO CICLOS DO ENSINO FUNDAMENTAL. Ministério da Educação e do Desporto/Secretaria de Educação Fundamental: Brasília, 1998.

PAVEAU, M.-A. SARFATI, G-E. Les grandes théories de la linguistique. Paris: Armand Colin, 2003.

PIETRARÓIA, Cristina Casadei. Questões de leitura - aspectos práticos e teóricos da leitura em Francês Língua Estrangeira. São Paulo: Annablume, col. Parcours, 2001.

PUREN, C. Quelques considérations sur la politique européenne des langues in Les Langues Modernes, no. 3, pp. 4-12, 2001. 
REVUZ, C. "A língua estrangeira entre o desejo de um outro lugar e o risco do exílio" in Lingua(gem) e identidade. Campinas: Mercado de Letras, 2002.

ROBERT, A.D. BOUILLAGUET, A. L'analyse de contenu. Paris : PUF, Col. Que saisje ?, 2002.

ROULET, E. L'apport des sciences du langage à la diversification des méthodes d'enseignement des langues secondes en fonction des caractéristiques des publics visés in E.L.A., no. 21, pp. 43-77.

TROTOT, C. Récits de voyage I, Le nouveau monde. Paris: Flammarion, col. Etonnants Classiques, 1998.

TYLOR, E.B. La civilisation primitive. Paris: Ancienne Librairie Schleicher, Alfred Costes (éditeur), 1920. Traduit de l'anglais sur la deuxième édition par Mme. Pauline Brunet.

VYGOTSKY, L.S. Pensamento e linguagem. São Paulo: Martins Fontes, col. Psicologia e Pedagogia, 1991.

ZARATE, G. Enseigner une culture étrangère. Paris: Hachette, col. Recherches/Applications, 1986.

- Représentations de l'étranger et didactique des langues. Paris:

Didier, col. CREDIF Essais, 1995. Edição consultada, 2004.

ZWEIG, S. Le Brésil, terre d'avenir. France : Éditions de l'Aube, traduzido do alemão por Jean Longeville, 2005. 